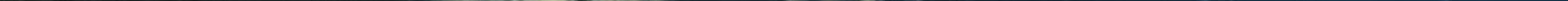




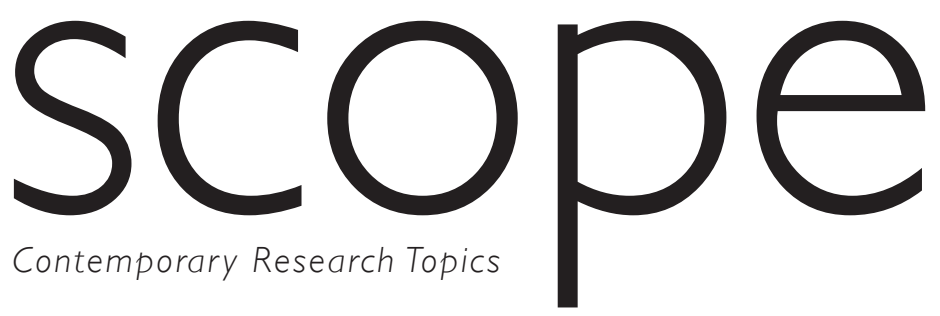

Work-based Learning 2

November 202I 


\section{Scope: Contemporary Research Topics, Otago Polytechnic Press.}

Otago Polytechnic Ltd is a subsidiary of Te Pūkenga - New Zealand Institute of Skills and Technology

Scope Contemporary Research Topics (Work-based Learning) focuses on contemporary research in assessment of prior learning, learning in, for, and about work, and professional practice. It is concerned with critical debate about practice, theory, and history, and their relationships as manifested in the experiences of learners, practitioners, and researchers in work-based learning and professional practice. ISSN 2703-6227 (Print); ISSN 2703-6235 (Online)

Scope Contemporary Research Topics series are open access journals and can be accessed at www.thescopes.org; ISSN (for hardcopy version) 2703-6227; ISSN (for online version) 2703-6235; (C) 2021 the authors; @ illustrations, the artists or other copyright owners.

Submissions for Scope (Issue No. 3) are invited under the theme 'working around'. Our professional practice-based theme is open and ambiguous since it allows us to address the numerous 'work arounds' that the age of Covid-19 have hoisted around researchers and practitioners alike in professional practice. It talks to innovations or pivots in research and workplaces alike. It also implies that work is all around us in the world of professional practice, and enables us to explore round about our work and practice to find the spaces where it meets enquiry, research or scholarship.

Formats include: editorials, articles, perspectives, essays, research notes, and work in progress. Other formats will also be considered.

Copyediting: Ingrid Sage

Design \& Typesetting: Suzanne Thornton

Printing: Dunedin Print Ltd

Cover Credit: Pieter du Plessis, 'Kaikorai Lagoon'

Series Editor: Professor Leoni Schmidt [il https://orcid.org/0000-000 I-7/85-7800

Editorial Team: Dr Martin Benedict Andrew (Editor), Dr Jan Hendrik Roodt (Editor), Su Bolland (Editorial Assistant)

\section{Editorial Board:}

Dr Nell Buissink, Auckland University of Technology

Prof Carol Costley, Middlesex University London

Dr Stanley Frielick, Auckland University of Technology

Dr Phil Ker, Tertiary Education Consultant 


\section{scope}

\section{CONTENTS}

6 Martin Andrew and Jan Hendrik Roodt

$8 \quad$ Glenys Ker and Martin Andrew

10 Martin Andrew

19 Claire Goode and Martin Andrew

30 Bonnie Robinson

$40 \quad$ Alexa Forbes and Steve Henry

49 Sandy Geyer and Jan Hendrik Roodt

57 Lesley Brook

66 Mandy Pentecost and Karlin Austin
Editorial: Our Choir of Work-based Research

Malcolm Macpherson: "I Cannot Teach Anybody Anything; I Can Only Make Them Think"

Interventions to Assure Rigour in a Professional Practice

Doctorate

"You Don't Have to Be Who You're Not": Reflections on the Learner-Mentor Journey in a Professional Doctorate

Plovers In Lockdown: An Autoethnographic Study about Values in Leadership Decision-Making

Designed to Inspire, Disrupt and Transform: Reflections on 10 Years of the Graduate Diploma in Sustainable Practice

Empowering Voices of Entrepreneurial/Enterprise Leadership from Within: A Learning Journey

Extending the Professional Toolkit: A Case Study of Work-Based Learning in Research Management

"A Really Important Role": Using a Participant-Voiced Poem to Explore Students' Expression of Social Work's Professional Identity 


\section{Work-based Learning 2}

November 202I

72 Kathryn Wright

74 Robert Nelson

$82 \quad J$ Jana Alexandra Nino

Rodriguez and

Marianne Cherrington

9l Campbell Macgregor,

Alison Stewart, Mary Cooper, and Pavitra Dhamija

103 Marcia Johnson

III Vicki Rangitautehanga Murray, Ashley Winiata Simpson,

Te Poono Te Poono,

Charlie Houia, and

Patricia Denny

I20 Kevin Hollingsworth,

Vicki Rangitautehanga Murray,

Goldie Mihinui, Billy Mihinui,

Tuihi Carre, Tiwana Taiatini,

Pauline Tai, and Edith Te Papa
My Mahi Toi

Ode to an Educator, Work Based Learner and Change Agent

Communicating Trusts

A National Snapshot of Sterilisation Technology: Preparing

Students for Professional Practice

Professional Development through the Harmony of Different Voices within Constructive Critical Conversations

Haumi E, Hui E - A Gathering of Reflections

Ka Tiritiria - Sharing the Seeds of 'Hope' (Hold On Pain Ends) 


\section{EDITORIAL: OUR CHOIR OF WORK-BASED RESEARCH}

\section{Martin Andrew and Jan Hendrik Roodt}

Welcome to the second edition of Scope - Work-based Learning, with its broad theme of multiplicity of voices and its central musical metaphors of the chorus and the orchestra. In such contexts, voices work in complex ways beyond mere harmony singing from one hymn book. Voices can sing in four-part harmony or counterpoint, articulate in different techniques, generate sound effects, and engage in word painting. Choral voices can also merge, blur, and overlap in much that same way that voices in drama create a real-world of human chatter. Within the choral artefact, there can also be soloists. As editors, we have curated, or even orchestrated, a collection of various articles in the range of professional practice where voices are celebrated and given expression.

Scope - Work-based Learning 2 presents for you a veritable euphony/cacophony of the voices of members of communities of practice aligned to and with Otago Polytechnic's College of Work-based Learning and Capable NZ. Even the single-authored pieces, such as Martin Andrew's commissioned article, give voice to voices from the worlds of scholarship and practice, and reflect and sometimes refract the voices of the author's lived experiences and, by extension, the voices of those who are fellow-travellers on his own journey. Scope Work-based Learning 2, then, celebrates the multivocal nature of professional practice research, and recognises that such research cannot by its very nature happen in a vacuum, but is situated in a world of activity, one of workplaces, a world of pragmatic practitioners.

The musical metaphor reminds us that during 2021, Aotearoa New Zealand was one of few countries where orchestras or choirs were able to interact with audiences in physical and architectural spaces. Similarly, other groups that regularly meet to debate in such contexts as conferences, colloquia, symposia or summits, experienced grateful moments of 'actual' togetherness before migration to the 'virtual' spaces, where voices and the communications they convey presented different challenges and offered alternative dynamics. The ways in which COVID-19 has changed or impacted on the voices of professional practice research is an underlying theme of many articles. For Bonnie Robinson, the concatenation of the voices of the plover and the family feline offers a catalyst for an exploration of values-driven decision-making in leadership. We count among our voices not only the human, but also the calls of the whenua, the sounds of the world around us.

An observant reader may have groaned through several puns in the above paragraph, but the playfulness of voices in professional practice is also represented in items in this volume. There are epistolary collaborative duets between Claire Goode and Martin Andrew, and Alexa Forbes and Steve Henry, and even wider vocal ensembles in the study by Sandy Geyer and Henk Roodt. The latter ask the leading question, "How can we better prepare our future entrepreneurial/enterprise leaders earlier in their education?" and use multivocal methods to generate a response. Such studies draw on research methodologies that have come to the fore in times of pandemic, methodologies that can join voices across geographical and time zone barriers. One such methodology, community autoethnography, has proven to be a relationship-making activity among researchers who participate in, co-negotiate and co-construct each other's existence. Community autoethnography can be a disciplinary, transdisciplinary or multi-disciplinary approach and it helps its participants create a 'safer' environment for gaining in-depth and intimate understandings of any topic investigated.

The voices sing apart but together, aligned by the methodical processes of research and writing. Lesley Brook's multiplicity comes from investigating flux in her practice and emerging professional identity as an educational 
manager; it contributes to our understanding of the multiplicity of this role and, by extension, to how we view professional identities within vocational education. Mandy Pentecost creates a participant-voiced poem as a method of exploring professional identities - this time, those of the social worker with her dual, or more than dual, focus. The eloquent articulateness of participants underscores her vivid portrait of the profession in a work that "makes the shaping hand of the researcher apparent." Kathryn Wright contributes a slice of practice drawing on her multiple selves: "I am creative. I am patient. I teach. I am a writer. I am a counsellor. Some days, all of these things collide." Robert Nelson creates a rhyming poem, an ode to the multiple identities of his career, which engages the reader in rhetorical dialogue as its means of praxis. It is through such acts of collaboration that the kinds of changes both Nelson, Robinson, and Geyer and Roodt believe that agentive change is possible in the domain of leadership. There is an intimacy about this collection of studies, the kind of intimacy engendered by being impacted by the same phenomenon, in this case, COVID-19, the elephant in every room.

In some studies, the participatory nature of the methodologies for stakeholder engagement and research partnerships (Rodriguez and Cherrington, Macgregor et al.) evidence the multiplicity of voices involved in the generation of the study. The nature of the constructive critical conversation, as a method for supporting communication in leadership, education and coaching contexts, powers Marcia Johnson's choric, multi-voiced contribution, as she consults participants from multiple walks of voice as a necessary pivot of the COVID-19 era. The same is true of Glenys Ker and Martin Andrew's tribute to Capable NZ stalwart, Malcolm Macpherson, who is certainly more than the sum of what multiple voices say about him, but the voice-centred method indicates how identities are co-constructed discursively in professional practice.

The research in this volume is participatory, and it documents authors' interactions with their professional practice communities. We include articles of community-based ethnography, which has the key feature of being academically rigorous, socially responsive and multivocal. These are collaborative, often insider accounts, as in the studies led by Vicki Murray and Kevin Hollingsworth and their colleagues/whānau, where we hear the authentic songs and reflections of members of whānau, iwi, hapu. We hear Ka tiritiria: Our voices, and we encounter ways of unveiling research that are mana-enhancing, authentic and involving, in relation to two important topics: drug addiction and suicide prevention. The kete harakeke becomes symbolic of the collective artefacts of the community of practice in Murray's piece; it contains the power of group storytelling. Such studies involve a community-building or team-building activity as an approach to the production of professional practice knowledge and enact the principle that our work is stronger when we stand, and join, together. There is power here, and most importantly, there is hope.

Martin Andrew operates as a creative mentor in postgraduate programmes, including Master and Doctorate degrees in Professional Practice. Prior to his four to five years supporting the College of Work-based Learning in Otago, New Zealand, he had sojourned away from his hometown of Otepoti/Dunedin with two honorary posts at Melbourne universities in Creative Industries and Trans-national Education (TNE). His work and research have become increasingly focussed on doctorate education and supporting learners to reach their own personal best through critically reflective practice and writing. A transdisciplinarian, he emphasises that his past disciplines have included Education, Drama, Linguistics and Writing, Creative and otherwise. He holds honorary positions in Australia, Vietnam and Indonesia.

(C) https://orcid.org/0000-0002-0108-5195

Jan Hendrik Roodt is a transdisciplinary systems design engineer with business interests in New Zealand and Finland. He acts as postgraduate supervisor and assessor of masters and doctoral students in professional practice and applied innovation at the Otago Polytechnic and Waikato Institute of Technology in New Zealand. Based in Dunedin, he is a member of the Institute of Electrical and Electronics Engineers (Systems Council), the International Council on Systems Engineering, and Information Technology Professionals New Zealand.

(b) https://orcid.org/0000-0001-5250-8066 


\title{
MALCOLM MACPHERSON: "I CANNOT TEACH ANYBODY ANYTHING; I CAN ONLY MAKE THEM THINK”
}

\author{
Glenys Ker and Martin Andrew
}

In 202I, the retirement of Dr Malcolm Macpherson from Capable NZ's Central Otago branch and from the Scope journal whānau left a considerable hole in the expertise of both entities. Seen as a pioneer in business excellence qualifications, Malcolm left quite a mark on his areas of endeavour and continues to be an inspiration to his colleagues.

Recalling twelve or more years ago, Phil Ker relates, "those early days at the forefront of this work was inspirational." This article recognises some of the contributions that Malcolm has made, and brings together some reminiscences and recollections of close colleagues in order to paint a picture of the colleague whose retirement brings to a close a much feted engagement.

The quote from Socrates in the title was submitted by a colleague as a fitting whakataukT for Malcolm. When the authors asked those in Malcolm's communities of interest for words to summarise Malcolm, the concept of the philosopher was dominant. Margy-Jean Malcolm pays tribute, to Malcolm directly as one who "valued the depth and breadth of your experience - and the wisdom shared from that."

In addition to his collected wisdom and ability to philosophise on any topic, Malcolm is also viewed as one with breadth of vision. As Glenys and Phil Ker put it, "Malcolm always saw the big picture - an excellent strategic mind and an effective advocate for Central Otago." Malcolm's advocacy for the local saw him engaged closely in areas of regional governance, an area where Alexa Forbes comments of his advanced and foresightful thinking.

Alexa was also fortunate enough to have been mentored by Malcolm on her Masters of Professional Practice (MPP) journey. Alexa comments on his eye-opening mentoring: "your insights on thinking about the future and the likely disruptions to planned and expected paths were invaluable to me as you mentored me through my MPP." Another Capable NZ staff member who was also Malcolm's learner, Michael Simmons, concurs: "I learned a lot from you during my MPP and our time working together with Real Journeys and Corrections. I always enjoyed working with you. Thank you for your support and wise counsel."

Wise counsel may be one theme in the story of Malcolm Macpherson, but just as notable is his generosity. One colleague writes, "He was a generous colleague and particularly generous with his learners." Listing a long list of Malcolm's impacts, including his passion and editorial prowess, Glenys Forsyth concludes, "Thank you for being so generous in sharing your time, knowledge, and expertise for Capable NZ's cause." Jo Kirkwood also shares an anecdote on the theme of generosity:

Malcom was hugely generous with his time and expertise with learners and new staff. When I first started I had a few learners with Malcolm, and I often called on him for advice - and his significant experience with Capable NZ made me feel very supported in my work. His range of professional experience is significant, and our learners have benefitted from this wealth of knowledge, as well as Malcolm's patience and complete respect of our learners. 
Malcolm's impact on both colleagues and learners has been long-lasting and impactful. Cushla Donnelly, reflecting on her own engagement with learners, recalls having learned much in conversation with Malcolm, enabling her to continue to grow. Steve Henry recalls, with fondness, "his ability to capture with razor sharp precision the issue at hand is my abiding memory of working with him." There is special mention of "his positive contribution to the culture of enquiry", something common in the words of all who passed their tributes and thanks to Malcolm. As another colleague summarises, "His ability to work with a range of learners in other disciplines also demonstrated his wide-ranging skill and knowledge, and always his passion for learning." In addition to his wisdom and passion, Malcolm was noted for the versatility of his contribution to Capable NZ's culture.

A lifelong learner, Malcolm even undertook an MPP of his own in 2016 in order to walk in learners' shoes. His assessment presentation contains a poetic meditation that sums up Malcolm well in his own words:

I'm a constructivist by nature

I make sense of my world by writing about it

I scribble during phone conversations, make bulleted lists ...

... capture design ideas for my workshop on the backs of envelopes and table napkins

Journal, in an informal, free-range way

Moleskine notebooks on my desk date back a decade

I write. A lot.

A man of mixed methods, Malcolm resolutely refused to be a story. The words of James Harrison serve as a fitting retirement wish from the Capable NZ team: "I have always valued your considered and gentle advice and hope you will still have energy to contribute to those matters near and dear to you. My very best wishes for as long a retirement as possible." Ngā mihi mahana ki a koe.

Glenys Ker works as a facilitator of learning, an academic mentor, and assessor at Capable NZ in Otago Polytechnic's College of Work-based Learning. A lifetime career practitioner, she examined adult learning and independent learning pathways and professional practice qualifications in her doctoral journey. Her passion for supporting learners to articulate their skills, knowledge and attitudes gained from their work-based learning experiences is matched by her love of helping elite athletes think about "life during and after sport."

Email: Glenys.Ker@op.ac.nz

(D) https://orcid.org/0000-0001-9665-8752

Martin Andrew operates as a creative mentor in postgraduate programmes, including Master and Doctorate degrees in Professional Practice. Prior to his four to five years supporting the College of Work-based Learning in Otago, New Zealand, he had sojourned away from his hometown of Otepoti/Dunedin with two honorary posts at Melbourne universities in Creative Industries and Trans-national Education (TNE). His work and research have become increasingly focussed on doctorate education and supporting learners to reach their own personal best through critically reflective practice and writing. A transdisciplinarian, he emphasises that his past disciplines have included Education, Drama, Linguistics and Writing, Creative and otherwise. He holds honorary positions in Australia, Vietnam and Indonesia.

(b) https://orcid.org/0000-0002-0108-5195 


\section{INTERVENTIONS TO ASSURE RIGOUR IN A PROFESSIONAL PRACTICE DOCTORATE

\author{
Martin Andrew
}

\section{PREFACE}

Now in its fourth year, the Doctorate in Professional Practice (DProfPrac) within Otago Polytechnic's Capable NZ (College of Work-based Learning) faces a challenge to demonstrate its rigour to a range of internal and external stakeholders. Having celebrated its first completion in $202 \mathrm{I}$ and with others in the offing, now is an appropriate time to celebrate the intensity and authenticity of the organisation's distinct species of DProfPrac. In broad terms, the programme requires candidates to create new practice-led knowledge through a process strong in developing reflective and self-managing practitioners. The doctorate aims to implement and develop the Middlesex model of professional doctorates (Costley \& Lester, 2010); indeed, representatives of this organisation serve as annual external reviewers of the developing programme. The programme is also open to scrutiny from within, such as research quality gate-keepers and the broad doctoral mentoring team. Further, it is closely watched by other tertiary providers of similar qualifications, and those wishing to enter the doctorate space. Universities watch to see if the professional doctorate offers legitimate threat to traditional and thetic models of representing coming to know. Is it a threat? There is clear pressure on demonstrating the robustness of the programme and, in turn, each candidature's rigour.

Having a clear understanding of 'rigour' is crucial to the sustainability and quality assurance of programmes positioned at levels 9 and 10 on the New Zealand Qualifications Authority (NZQA) framework, particularly during times of 'super-complex' change. If, as Barnett (2000, 2004, 2017) might suggest, super-complexity is characterised by the constellation of critical moments comprising threats both inside the system (restructuring, amalgamation) and outside it (COVID-19, the world in turmoil, residual neoliberalist ideology), such educational providers must look to their sustainability to endure, and loss of survival would lead to rigor mortis.

\section{WHAT IS THIS ARTICLE?}

This article takes the form of a non-Cartesian subjective academic narrative, telling a research narrative emerging through ethnography and autoethnography (Arnold, 20I5). It is a story of multiple stakeholders and their voices - learners, mentors, research quality gatekeepers, governmental representatives - and their remembered utterances become part of this multi-vocal autoethnography. The following background paragraphs exemplify this pastiche or mosaic as I assemble and reorganise a description of the programme chorally, and the words of many echo throughout (Arnold, 2011; Sparkes, 2018). As the writer of a subjective academic analysis, I draw consciously from the corpus represented by professional practice scholars such as Costley, Elliot, and Gibbs (20I0) and Costley and Lester (2010); and unconsciously from everything I have heard or read about professional practice in the manner of all autoethnographers (Sparkes, 2018).

The narrative traces a journey through the concept of 'rigour', eventually examining strategies to ensure it developed via practice from the DProfPrac's mentoring team, before heading towards another concept - one likely to replace 'rigour' as a descriptor as the decade wears on - 'doctorateness'. 


\section{TOWARDS UNDERSTANDING 'RIGOUR'}

In principle, the work-based practitioner research enquiry or design project generates rigour by contributing to new understanding of theory as it relates to the learner's professional practice or realm of endeavour. The doctoral work contributes to the solving of authentic dilemmas by taking an evidence-based and hence robust approach to problem-solving with as clear an understanding of potential outcomes as possible, although open to the vicissitudes of the unforeseen such as COVID-19. It also situates itself as much in the spaces of the learning process as in the product of enquiry, linking these two elements through sound acts of critical reflection, turning experience into learning.

Learners' work will also emerge from identifying a practical need in a specific context or environment and construct an appropriate line of enquiry to tackle that perceived opportunity; the line of enquiry, traditionally starting with a problem and a question, is less likely to emerge in practice models by finding a niche or gap in existing scholarship. Like the article I present here, the Capable NZ DProfPrac opens the door for nonCartesian and post-enlightenment representations of research (Arnold, 2015). Holistic in scope and futurefocussed in orientation, the professional doctorate is an instrument of and for ethical education and sustainability, affording social, environmental, and organisational impacts that can develop individual capability and create transformative change for immediate communities, ecologies and workplaces.

The legitimacy of any professional or creative doctorate model has benefitted from the opening up of alternative modes of knowing (Stock, 201I). The model has become safer in the 2020s and is more sustainable than the traditional, thetic research doctorate. The 'learner to educational organisation to workplace/industry partnership' speaks more to impact and sustainability than conventional modes of doctoral thesis. As late as 2009, Butt had observed that "there continues to be an undercurrent of snobbery in some parts of the academy, which claims that practice-based doctorates are somehow less intrinsically valuable than purely research-based doctorates, that 'thinking about' is more original than 'doing'" (p. 53). The greatest of risks is if such voices resound in the host organisation itself. Despite 'doubting Thomases', it is true that a large part of the legitimacy comes from the doctorate's potential for capacity-building by creating leaders in professional contexts (Boud et al., 202I). This potential for self-transformation and organisational empowerment in itself speaks to the theme of impacting sustainability.

\section{KEY DEFINITIONS}

Before we consider key interventions implemented by this species of DProfPrac to shore up the sustainability of the professional doctorate, we must first, a little playfully, enter the minefield of educational semantics. What is 'rigour' and how does it relate to 'quality assurance'? And what is 'super-complexity'? Are we tossing word salad if we speak of 'doctorateness'? This is a question I return to as the article closes as it anticipates the evolution of 'rigour' in doctoral contexts.

\section{Rigour}

There are key words that reverberate in the discourse of 'rigour' and its oak-like synonym 'robustness'. Grappling with and indeed embracing 'complexity' comes first, with demonstrating a clear and holistic intellectual and methodological 'grasp' being a key outcome (Winter et al, 2000). We also read in both the literature, policy and in-house curricular documents much about 'clarity' (helping others understand) and 'depth' (which I gloss as engagement with complexity). These relate to the communicative transmission of discovery and the application of analytical thinking and critical synthesis to acts of interpretation and presentation. The practical (applied), practice-based (fresh work, including scholarly, extending from a leading professional space of experiential knowing) or practice-led (creative, generative, iterative) work may accord with any of these adjectives: original, unique, innovative, inventive, distinctive, publishable, impactful, transformative, and inspiring of change. All these adjectives beg the critical questions 'to or for whom?' and 'in whose interests?' 
In contrast, traditional modes of qualitative research in higher education, as opposed to work-based professional practice, align with even more abstract concepts such as credibility, transparency, analysability, generalisability, validity, and usefulness, (Roller \& Lavrakas, 2015) - to whom I also ask, 'to and for whom?' The abstract nature of such nouns obscures the fact that such concepts are hard to measure objectively. Thus, a feature of the professional doctorate, like creative ones, is to accept, absorb and celebrate the inevitability of the subjective and the generative and critically locate it as an essential aspect of the work's uniqueness. It allows the "muddled, idiosyncratic fluid eccentricities that make us unique" (Muncey, 20I0, p. xi.) rather than bracketing them off as facets that muddy rather than clarify the waters. A method broadly known as 'the self as data' (Arnold, 20II) manifests itself often as one of the many species of autoethnography that reflect and refract a worldview through acts of showing and telling, such as narrative and vignette writing. The rigour in this model of doctorate comes in part from the interplay of 'reflectivity' and 'criticality', and in part from a convincing argument for 'doctorateness.' These are three concepts to which we return.

Roller and Lavrakas (2015) offer what is arguably the most definitively quality-focused model of qualitative research. In their work, the methods for ensuring research throughout the lifespan of the research include: thorough rationales for the necessity for the research via context mapping or needs analysis; 360-degree grounding in recent scholarship; quality project and 'instrument' design, including controls for variables and critiques for participant selection and sampling methods. There will be an emphasis on the 'density' or 'thickness' of the 'data' and the explicability of the logic behind the finding of connections or patterns in the sense-making process and the saturation thereof. Interviewers and observers need to be skilled with consistent instruments. We will expect consistency in data collection, analysis and presentation and an enrichment of transparency in any ethnographic elements.

Before your head explodes and you wonder how long a piece of string is, we need to remind you that our scale is that of a doctorate, not a Nobel prize (Mullins \& Kiley, 2002). Further, we can take stock from the observation that the principles behind the Roller and Lavrakas model of quality research align with some central concepts underpinning professional doctorate work. These facets include an eschewing of the possibility of 'truth' and an emphasis on context-environment, meaning-generation, and the participant-researcher relationship, all of which are to be examined closely (read: reflectively and critically). It affords, too, a measure of design flexibility though the professional doctorate offers more. Potentially, as Mann (2020) indicates, in its imagined fourth generation iteration, the heutagogical-based professional doctorate can accommodate the crazy messiness of professional life and indeed its super-complexity by aligning the practice journey with an advanced frame of professional practice.

Alongside the features of old and new versions of the professional doctorate, work will speak to the originality agenda by incorporating what Dolan (2015) called "a succinct, focused, critical appraisal of the specific contribution to knowledge" (p.I I), possibly in the form of an extended critical reflection. Like modern creative doctorates, the professional doctorate allows the messy, the unfolding and the emergent. It can also align with the tenets of transdisciplinarity, focussed on thorough stakeholder involvement in collaborative project work responding to a particularly wicked problem. It is a space of huge potential.

\section{Quality assurance}

Quality assurance belongs to the discourse of institutional and national policy, and conveys compliance and surveillance. In NZQA's outline of the qualities of Level 10, the level of 'doctorateness', we find the usual buzzwords: "Critical reflection on existing knowledge or practice and the creation of new knowledge" (NZQA, 2020, p. 30). We also read about the 'culmination' of research and the conclusion of the researcher journey being characterised by increased 'independence' in scholarship. We read of the substantiality and originality of the work and its quality assurance by 'recognised experts' who both guide and assess the work. Importantly, quality in process is assured by mentors, advisors, or supervisors while a quality product is figured by the readings of examiners. Both mentors and assessors will be members of the kind of community of practice to which the learner may aspire. 
There is a temporal measure - at least two years' fulltime enrolment to show 'sustained commitment'; and one using the quantitative logic of the system - 360 credits. In describing the application of knowing and skills, the wording is measured: you must show "sustained commitment to the professional integrity and to the development of new ideas or practices at the forefront of discipline or professional practice" (NZQA, 2020, p. 30). The concept of professional integrity is as close we get to ethical rigour in the discourse of compliance. With 'forefront' connoting vanguards and spearheads, not even NZQA can escape from metaphor: 'doctorateness' consists in the contribution of "knowledge at the most advanced frontier of a field of study or professional practice." Cowboys, Indians, and Captain Kirk vie for space in my brain, and I muse on how 'culmination', like zenith, is a stellar and astronomical term. Clearly NZQA think doctoral learning is like Star Trek (prior to William Shatner's real flight to space).

The modes of quality assurance at national level, as at institutional level, are underpinned by self-assessment and include accredited entry processes as well as ongoing risk management alongside occasional (usually annual) consistency reviews, external moderation, independent monitoring and external evaluation and review (NZQA, 2020).

\section{Super-complexity}

Doctoral professional practice learners are afforded an opportunity to create what Barnett had in 2004 called "authentic being" (p. 259) in his germinal 'real world' study of learning for an unknown future. Such moments as 'the COVID moment', any organisational restructure, or the mergser of Te Pükenga remind us that engaged real-world responsiveness in education has the capacity to create in the practitioner-researcher "a self that is adequate to such an uncertain world" (p. 254).

This 'adequacy' is achieved through "encountering strangeness ... wrestling with it and ... forming one's own responses to it" (Barnett, 2004, p. 257). The strategy for achieving this is, of course, reflectivity, "a meaningmaking process that moves a learner from one experience into the next with deeper understanding of its relationships with and connections to other experiences and ideas" Rodgers (2002, p. 845). Making sense of mayhem, Barnett maintained in 2000, remains a constant function of higher education, even in the supercomplex age where knowledge lacks status and legitimacy in an era hijacked by rampant neoliberalism.

Critiquing the neoliberalised place of learning, Bengtson (2017) demonstrated how prescient Barnett's notions (from 2000, 2004, and others) has been, and 2020's COVID moment demanded methodological and ideological flexibility not the linear Cartesian rigidity of traditional knowing. What higher-vocational learning needs is to be, in Barnett's terms, open, bold, engaging, accessible, and, above all, conscious of its own insecurity. This necessity requires the application of strategies and pedagogies that emphasise our mutual project of 'being and becoming' through practice and move beyond the worries of measurement and surveillance to embrace the hope and community impact that professional practice doctorates afford. One of the strategies that enables moving beyond what Foucault (1980) calls 'forms of thought', or 'regimes of truth' is criticality, an instrument for disrupting master narratives like 'neoliberalism is the only way forward' and breaking down both dominant and taken-for-granted notions. Barnett's vision represents a mature educational philosophy where learning stems from bravely encountering dilemmas and disequilibrium and ideally results in grounded learners and community well-being. These are also results we would also hope to see from a professional doctorate.

Learning for a super-complex world requires the application of two core features of rigour: criticality and reflectivity. Critical reflectivity, Murray and Kujundzic (2005, p. 4) tell us, "can increase our intellectual independence, increase our tolerance for different points of view, and free us from the snares of dogmatism ... Critical thinking invites us to call the bluff of accepted dogmas." Criticality involves being aware of our own theories of knowing and how we see the world, hence the ocular metaphors in research methodology of lenses, prisms, mirrors, and lights. It affords an action of moving beyond generalisation and description into creating 
linkages between the previously known and the recently discovered to generate new meanings. It involves both analytical unpacking and unravelling to move beyond assumption into fresh possibilities and synthesising so that the fresh and the emergent can make new meanings in the light of knowledge already embedded in existing scholarship and professional documentation.

Such a description of criticality brings us to its borders with reflectivity, which, Rodgers (2002, p. 845) tells us, also consists in "the thread that makes continuity of learning possible, and ensures the progress of the individual and, ultimately, society" and "a systematic, rigorous, disciplined way of thinking, with its roots in systematic inquiry." Reflectivity grounds our enquiry in real world contexts, ethical systems, and communities where we co-construct learning with others. It offers, Clutterbuck and Hirst (2003) famously argue, "an opportunity for discovery through dialogue", affording insights that teach us "new tactics, greater self-awareness and greater ability to manage oneself and others, and the establishment of clearer priorities" (p. 104). What the professional world of the 2020s needs most, I contend, is the critical, reflective practitioner. It comes with the territory with the rigour of professional doctorates.

In the light of the above discussions of rigour (bottom-up) versus quality assurance (top-down) and the necessity for professional doctorates to afford criticality and reflectivity as registers of robustness, I want to turn, now, to six features or 'interventions' of the Capable NZ Doctorate in Professional Practice that contribute to the generation of rigour.

\section{SIX INTERVENTIONS}

The six interventions I introduce here come under the following headings: alignment with bicultural frameworks; sustainability in the programme structure; levels of mentor support; the criticality gambit; leveraging the politics of evidence and lastly, without a proctological thought in mind, tightening the back end.

I will start by addressing the first two interventions of bicultural alignment and sustainability. The programme's three stages create a trajectory of being and becoming for the learner that also embeds sustainability, a facet of rigour, at the programme, institutional and national levels. This process also articulates with the quality assurance descriptors implemented by NZQA. The first third of the programme structure both audits a candidate's professional learning through a critically reflective work known as a review of learning, and proposes a plan for action and enquiry, also critically reflective, known as a learning agreement, a placeholder term for the proposal of traditional models. In these two courses within the programme, learners select and justify sustainable approaches to tasks, problems, or dilemmas, considering how their work might impact others' capacity as well as their own. Thus, sustainability is considered not only in relation to the emerging professional self, but also to communities which might benefit. A critically reflective process of considering how the study might involve or benefit Māori ensures a rigorous interrogation of alignment with biculturality, and upholds the programme's commitment to Te Tiriti o Waitangi. The bicultural requirement, while common throughout professional doctorates in Aotearoa New Zealand, validates indigenous ways of knowing and representing knowledge in a rigorous and sustainable way.

Learners must pass these courses to progress to the final two thirds, the practitioner enquiry or 'thesis' equivalent, which can manifest itself in manifold forms. This process enables learners to play a unique role in implementing change, developing innovative approaches and creating sustainable solutions to complex issues (Costley \& Lester, 2010).

Thirdly, the programme draws on a range of professional doctoral mentors, many of whom are 'doctored' professional practice staff or members of the broader organisation from the disciplines. Those mentors with a record of doctorate completions, 'specialisms' in work-based learning, and practitioners in the realms of mentoring and coaching, work collaboratively with less experienced mentors, enacting the capacity building that 
I argued above was essential to sustainability. In addition to the peer support inherent in mentoring dyads or teams, the organisation runs programmes of doctoral education training in addition to a particular intervention: the professional doctorate mentor community of practice, where experienced and core members share mentoring discourse and knowledge repertoire with the broader group. Although there are major challenges with organising time, this community functions effectively to build capability and discuss dilemmas as well as addressing formal, methodological and procedural issues. Since NZQA emphasises the role of the 'guide' in assuring the quality or rigour of the doctoral journey, it is crucial to offer a site where practice is discussed and critical reflectivity modelled. Further, those mentoring learners have an open-diary invitation to consult with an experienced mentor for critical friendship.

Fourthly, the criticality gambit ensures that not only do mentors reflect critically in their pedagogical being in the context of this doctorate, they also become conscious of areas needing practice and experience and they implement a conscious programme of ongoing professional development. The criticality gambit relates to learners as well, since criticality is the subject of additional material available to learners via the learning management system and is also the focus of mentor-led learner development seminars. Since many learners on the programme are practitioners from workplaces, we can anticipate that criticality might be a weakness in their thinking and production. Building criticality in the first year of the programme is a conscious pedagogical imperative in the programme, affording learners who begin the practitioner enquiry to be possessed already of a strong ability to apply critical thinking to their research project. The ethics and indigenous knowledge application processes that accompany the first year are further opportunities for applied criticality. In the final stages of the programme, when learners in theory become autonomous experts, the mentor's role becomes identifying further opportunities to leverage criticality in the writing or other thetic outputs.

Fifthly, the accountability function of a doctorate journey requires evidence of emerging practice and advancing thought. The tripartite structure of the programme as outlined above affords the continuous production of evidence of enquiry so that the final submission is a portfolio of outputs generated during the period of candidature. In later stages of the candidature, meetings with mentors are earned on the basis of paying forward with work - evidence of practice and becoming. In meetings, work can be workshopped or the site of onthe-spot critical commentary. This process maximises the value of the limited mentor-to-learner sessions and ensures a continuous record of evidence is maintained to chart the journey of progress. Other evidence this process generates might take the form of maintaining a reflective learning journal or participation in professional communities which can be evidenced with outputs.

Finally, at the back end of the programme, when learners might be on their penultimate draft, an external expert reader processes the penultimate draft and offers feedback on lifting the work to mentors. This process ensures a more objective pair of eyes evaluate the work, seeing weaknesses mentors might be blind to owing to their closeness to the work. This process can enable the negotiation of a final draft which is more likely to meet the approval of examiners. As NZQA's quality assurance guides indicate, the selection of appropriate assessors is a further way of ensuring quality or rigour to the individual output and hence to the programme. A range of internal quality assurance panels vet the nominated examiners and assess their suitability to examine a particular work using such criteria as methodological alignment and examination experience. Placing the output in the context of national and international external experts ensures its acceptability and doctorateness at the highest level - the level of the peer to the community of practice of professional practitioners. The above process, tightening the back end, enables the individual to know that their work is acceptably and rigorous in terms of its doctorateness in the eyes of qualified experts.

As I head towards a conclusion where the concept of 'doctorateness' is developed to indicate the future directions of rigour, I move on from a key section where six local practices for ensuring rigour have been addressed. In concluding this way, I eschew the Cartesian notion that conclusions are for recapitulations. Why would you want to read again what I said above? This conclusion serves to look to the future. 


\section{CONCLUSION: TOWARD 'DOCTORATENESS’}

As the journey to define 'rigour' intensifies into the 2020s, it is increasingly expected to align with the idea of 'doctorateness.' This notion belongs to the discourse of debating what creative and professional forms and media constitute and represent doctoral knowing. The term 'doctorateness' is increasingly used as a determiner of rigour in all species of doctorates, thus enabling comparisons of all species of doctorates from the traditional to the professional to the creative or performative. 'Doctorateness' is an abstract noun that captures the concept of rigour, complete with high levels of criticality and reflectivity. Trafford and Leshem (2009) see it as a threshold concept where key components like conceptual framework, contribution to knowledge, appropriate methodology and clear presentation converge, making it theoretically more than the sum of the doctoral examination criteria. I believe that 'doctorateness' is a term that works synergetically with Barnett's (2004) idea of learning for an unknown future, allowing critically reflective expression of encounters with the unexpected in the context of the learner journey. Doctorateness is an expression of response to complexity; indeed supercomplexity. How practitioners wicked-problem-solve and reorient themselves in the face of dilemmas becomes a fundamental part of their experiential and transformative learning.

Evaluating the potential for doctorateness occurs when learners present their research to a pseudo-examination panel when they are assessed for their learning agreement in both textual (or other evidential output) and performative or presentational media. Those judged as lacking evidence of doctorateness or rigour are given feedback or feed-forward to enable them to reconfigure their proposals for requisite depth and breadth.

Studies of doctorateness continue to grapple with the concept despite a changing tide in its favour (Stock, 20II), and research into what it looks and feels like in practice continues. Yazdani and Shokooh (20I8) see 'doctorateness' as

A personal quality, that following a developmental and transformative apprenticeship process, results in the formation of an independent scholar with a certain identity and level of competence and creation of an original contribution, which extend knowledge through scholarship and receipt of the highest academic degree and culminates stewardship of the discipline (italics mine).

This definition addresses the aspects of rigour that align with quality assurance, but does not address the issues of emergence and complexity, the ability of candidates to pivot in their methodological approach and ability to communicate findings in light of external dilemmas such as Covid-19. It is not yet a model of doctorateness for a super-complex world. This thinking on one's feet - Barnett's (2004) encountering the 'strange' and Dewey's (1938) learning via disequilibrium, involving Schönian reflecting in as well as on and for action (Schön, |99|) - is surely a key attribute of doctorateness in a professional practice doctorate in professional practice.

There is clearly more to do in outlining the parameters of doctorateness in emerging forms and there are many more voices to heed and represent, but in the meantime it is wise for institutions offering such programmes to ensure and position their programmes as duly rigorous before further storms of super-complexity rage and return the rigour to rigor mortis. 
Martin Andrew operates as a creative mentor in postgraduate programmes, including Master and Doctorate degrees in Professional Practice. Prior to his four to five years supporting the College of Work-based Learning in Otago, New Zealand, he had sojourned away from his hometown of Otepoti/Dunedin with two honorary posts at Melbourne universities in Creative Industries and Trans-national Education (TNE). His work and research have become increasingly focussed on doctorate education and supporting learners to reach their own personal best through critically reflective practice and writing. A transdisciplinarian, he emphasises that his past disciplines have included Education, Drama, Linguistics and Writing, Creative and otherwise. He holds honorary positions in Australia, Vietnam and Indonesia.

(D) https://orcid.org/0000-0002-0108-5195

\section{REFERENCES}

Arnold, J. (20II). The self as data: A qualitative methodology, Journal of Educational and Developmental Psychology, II(I), 65-73.

Arnold, J. (2015). Research as stories: an academic subjective analysis. Advances in Research, 4(I), 59-66. http://doil 0.9734/ AIR/20I5/13050

Barnett, R. (2000). University knowledge in an age of supercomplexity. Higher Education, 40, 409-422.

Barnett, R. (2004). Learning for an unknown future. Higher Education Research \& Development, 23(3), $247-260$.

Barnett, R. (2017). Researching supercomplexity: Planes, possibilities, poetry. In L. Ling \& P. Ling (Eds.), Methods and paradigms in education research (pp. 29I-308). IGI Global.

Bengtson, S. E. (2017). Supercomplexity and the university: Ronald Barnett and the social philosophy of Higher Education. Higher Education Quarterly, 72(I), 65-74.

Boud, D., Costley, C., Marshall, S., \& Sutton, B. (2021). Impacts of a professional practice doctorate: a collaborative enquiry, Higher Education Research \& Development, 40(3), 43I-445. http://doi: I0.1080/07294360.2020.1765744

Butt, M. (2009). Creative writing research degrees: range and rigour. International Journal for the Theory and Practice of Creative Writing, 6(I), 53-56.

Costley, C., Elliot, G., \& Gibbs, P. (2010). Doing work-based research: approaches to enquiry for insider-researchers. Sage.

Costley, C. \& Lester, S. (2010). Work-based learning at higher education level: value, practice and critique. Studies in Higher Education, 35(5), 56I-575.

Clutterbuck, D., \& Hirst, S. (2003). Talking business: Making communication work. Butterworth-Heinemann.

Dewey, J. (1938/1986). Logic: The Theory of Inquiry. In J. A. Boydston (Ed.), The Later Works of John Dewey 1925-1952, volume 12 (pp. I-539). Southern Illinois University Press.

Dolan, G. P. (20I5). Originality and the PhD: what is it and how can it be demonstrated? Nurse Researcher, 22(6), II-15.

Foucault, M. (1980). Power/Knowledge: selected interviews and other writings 1972-1977 (ed. C. Gordon). Pantheon.

Mann, S. (2020). Shape of professional practice research. Scope contemporary research topics: work based learning, I, 22-31.

Mullins, G. \& Kiley M. (2002) 'It's a PhD, not a Nobel Prize': how experienced examiners assess research theses. Studies in Higher Education, 27(4), 369-386.

Muncey, T. (2010). Creating autoethnographies. Sage.

Murray, M. \& Kujundzic, N. (2005). Critical reflection: a textbook for critical thinking. McGill-Queen's University Press.

New Zealand Qualifications Authority (NZQA, 2020). The New Zealand qualifications framework. The New Zealand Government.

Rodgers, C. (2002). Defining Reflection: Another look at John Dewey and reflective thinking, Teachers College Record, I04, 4, 842-866.

Roller, M. R., \& Lavrakas, P. J. (2015). Applied qualitative research: A total quality framework approach. Guildford Press.

Schön, D. (|99|). The Reflective Practitioner. Ashgate.

Sparkes, A. C. (2018). Autoethnography comes of age: consequences, comforts, and concerns, In D. Beach, C. Bagley \& S. Marques da Silva (Eds.), The Wiley Handbook of Ethnography of Education (pp. 479-499). John Wiley \& Sons. 
Stock, C. F. (20II). Approaches to acquiring 'doctorateness' in the creative industries: An Australian perspective. In L. Justice \& K. Friedman (Eds.), Pre-Conference Proceedings: Doctoral Education in Design Conference 2011 (pp. I-II). Hong Kong Polytechnic University.

Trafford, V., \& Leshem, S. (2009). Doctorateness as a threshold concept. Innovations in Education and Teaching International, 46(3), 305-15.

Winter, R., Griffiths, M., \& Green, K. (2000). The 'academic' qualities of practice: what are the criteria for a practice-based PhD? Studies in Higher Education, 25(I), 25-37.

Yazdani, S., \& Shokooh, F. (2018). Defining doctorateness: a concept analysis. International Journal of Doctoral Studies, I3, 31 -48. https://doi.org//0.28945/3939 


\section{"YOU DON'T HAVE TO BE WHO YOU'RE NOT": REFLECTIONS ON THE LEARNER-MENTOR JOURNEY IN A PROFESSIONAL DOCTORATE}

\section{Claire Goode and Martin Andrew}

By the end of 202I, it is estimated that as many as five Capable New Zealand learners will have completed their professional doctoral journeys in the Doctorate of Professional Practice, which was launched in 2018 and grounded philosophically in the University of Middlesex's well-established research and development doctoral model. The Capable New Zealand re-versioning of the Middlesex University model revolves around experiential and transformative learning, is grounded in the reflective unpacking of critical incidents, and affords strategies for research messiness and the non-linearity of the process, particularly in the light of COVID-19. The Middlesex model is also for "advanced practitioners to develop their professional knowledge at doctoral level, benefiting both individuals and their organisations or professional fields" (Middlesex University London, online, 202I).

The programme also enables the embedding of self-narrative in the reflective spaces of learner-mentor communications, as is appropriate for the autoethnographic nature of the professional doctorate. This, in turn, allows a practice-based ontological and epistemological background to the generation of emergent knowing, through which the learner can be clearly understood as being socially constructed and in a constant flux regarding their professional/ academic/ personal image (Hayes \& Fulton, 2014). Narrative and theorised accounts of doctoral candidatures are increasingly plentiful in traditional and creative doctoral models, and some are beginning to emerge within professional doctorates, starting with the ten case studies of Stephenson, Malloch, and Cairns (2006).

Less common, however, are dualistic, praxically-oriented accounts of the doctoral trajectory from the perspectives of both learners and mentors or supervisors. By 'praxis' we refer to a connection between theory and practice that moves beyond the linear and uses pragmatic and reflective processes to enact and respond to real world challenges (Arnold \& Mundy, 2020). A praxical orientation reflects a Freirean worldview that values two-way (or multivocal) dialogue in teaching and learning (Freire, 1989), enabling a close exploration of pedagogical experiences and theory to critique the practices of both learning and mentoring. The mentor/ supervisor - learner relationship has been viewed through many metaphors, usually geographic (Gravett, 202I) or journey/odyssey-related (Batchelor \& Di Napoli, 2006), or occasionally through physical metaphors such as dancing the tango with shifting dynamics (Banagan et al., 2012). This paper recounts critical moments in the learning journey - perhaps more like a labyrinth - of one of the first learner-mentor relationships in the early history of the Capable New Zealand Doctorate in Professional Practice. It recounts, on a very small scale, a sense of the collaborative effort and mutual participation that Costley and Pizzolato (2018) see as key to the transdisciplinary professional doctorate.

We contend that this study is valuable because it offers a mirror for both learners and mentors at different stages along this journey, enabling empathetic engagement and offering a context wherein fellow travellers might recognise themselves, and see how relative pioneers encountered and overcame disorienting dilemmas through constructive critical conversations, trial and error, and oftentimes sheer faith in the process and hence in each other. 
Our purpose here is less to describe the shape of the journeying, often seen as generative, rhizomatic and non-linear (Gravett, 202I), than to use a form of dialogic narrative to chart this process of 'coming to belong' by drawing on data from the collective memory of those on the journey, and to provide a single-case study of a three-year teaching and learning engagement. Such a study exemplifies the "irregular, fluid and messy" experiences characterising doctoral journeys (Gravett, 202I, p. 293) and further disturbs the myth of linearity.

Rather, such acts of storying as research suggest that learnings central to a process of becoming a professionalas-researcher have the power to elucidate the notion that entering into quagmires or indecision and quicksands of dilemma afford the crucial learning at the heart of the professional doctorate. In other words, active reflection both in- and for-action operationalises the kinds of work-based cognitive demands characteristic of the professional in the 2020s. This is less of an individual journey of coming to belong to a desired imagined academic community of scholars than an enactment of the aspiration to research leadership within a professional community which is the key driver of professional doctorates; in Claire's case, that of an educational developer.

This study charters what Manathunga (2019) calls the "unexpected events or issues [that] may impede a candidate's progress" (p. 1230) by drawing on the entire time-scape of the trajectory: past, present and future. We re-enact this time-scape by presenting the process as a praxical dialogue imagined as retold over time. Although pressure to be timely appears throughout the dialogues, the story that plays out here is beyond the performative measures of the neoliberalist agenda. It is not our aim to create either a happy-ever-after or a doctorate as sausage-machine retelling; rather, we wish to highlight how genuinely gruelling moments become a sequence of opportunities for learning transformation by means of collaborative dialogue.

Such voice-centred methods enable the "authentic personal power or agency of the individual," bringing to the fore the forces driving, or impeding the learning (Milburn et al., 2019, p. 90). In the case of Milburn at al. (2019), who recomposed vignettes from a panel discussion with professional doctorate candidates, the key drivers were a sense of responsibility, supporting others, and 'gratitude' for the emerging identity. These same elements are reflected in our own mentor-learner story.

\section{METHODOLOGY}

The qualitative method involves the re-presentation of narrative data (Riessman, 2008) and draws from both collaborative email data (Drake, 2015) and dialogue (Clandinin \& Connelly, 1990), including meetings recorded with open consent. Sorting multiple emails over time, Drake (2015) argues, enables access to chains and patterns of developing attitudes and thinking in a way that affords chronological narrative construction. This study also draws on authentic artefacts co-constructed in the 'journey' to reimagine a sequence of dialogues integrated towards confronting and working through dilemmas.

This study draws on the voices of the principal mentor and the learner, following the praxical dialogue-oriented studies of the mentoring-learning trajectory of Batchelor and Di Napoli (2006), who co-construct an odyssey in which dilemmas are harpies or sirens. In another voice-oriented study, Perry and Brophy (200I) draw on Japanese renga (collaborative poetry with alternating lines) to construct a sequence of chained thoughts drawing on thoughts, images, and phrases in each other's exchanges, with each utterance grounded in inquiry and the sharing of identities. The phenomenon they grapple with in their sequenced narrative is the material overlap of creative work and exegesis within the newly emerging creative writing doctorate. Their study uses debate as a mode of encountering and allaying anxiety with the metaphors of the path, the sea, and ultimately doing what you're told ("eat your peas") as guiding images. 


\section{OUR NARRATIVE}

The authentic artefacts chosen are a small sample of the exchanges between mentor and learner. We use symbols here to indicate whether they occurred via email $\downarrow$, in conversation $\Omega$, or are extracts from the learner's research diary 圈园.

\section{$\triangle 18$ May 2018}

Kia ora Dr Andrew,

I don't know if you remember me, but we met back in October (with my 'Learning and Teaching' hat on). I have now begun my DProfPrac journey, and it has been suggested that you might be a good fit to be one of my mentors. Please find attached my proposal and an extra piece of writing I did for the panel, around my professional influences and values.

If you are interested in talking more about this, please let me know and we can set up a time to meet

I look forward to hearing from you.

Kind regards,

Claire

$\triangle 25$ June 2018

Kia ora,

My DPP 'Notebook', as discussed briefly on Thursday, is available here. I've added notes from last week, including a copy of the Mentor-Learner agreement (tbc) and the 'Role Perception Rating Scale' document we worked through. Please do let me know if you have any problems accessing anything.

Kind regards,

Claire

\section{$\triangle 25$ June 2018}

Thanks for today's communications.

This will work well for notes! A good share space.

Best wishes,

Dr Martin Andrew

\section{$\triangle 20$ August 2018}

\section{Hi Claire}

Thanks for your draft review of learning. Your writing is beautiful, and the work flows wonderfully. It's a perfect length, with room for additions from feedback. It's a joy to read and it is clearly a positive experience to write as well as read.

In offering feedback, according to the DProfPrac Learner Guide (2018), we need to consider:

- the level to which they are self-evaluating and are able to deploy strategies to explore new personal insights

- their critical understanding of how learning occurs in their workplace and how learning has occurred for them through their career 
- $\quad$ diverse strategies for engaging in Work-Based Learning

- $\quad$ an analysis of how learning at work has informed their professional identity

- $\quad$ approaches they use to evaluate knowledge gained from their practice

- $\quad$ approaches they use to engage with theory relevant for a range of contexts, and apply that theory to practice

- $\quad$ how their prior and current learning impacts their ability to design and conduct research project.

Terms such as 'self-evaluating', 'critical', diverse strategies', 'analysis' and 'approaches' jump out. Your writing is an autobiography, and it's wonderful. But does it engage with those terms as consciously as the descriptor suggests? Personally, I see the solution in a tighter analysis of how 'autobiography' differs from 'autoethnography'. The latter is more likely to accommodate the ideas embedded in the terms l've pulled out. On Wednesday, l'll bring Creating Autoethnographies, as it is an unpretentious, feminist and appropriate way for you to reflect on your work here.

I realise how much we have in common too - including the horror of colleagues committing suicide and working as an educator in a jail.

Til soon,

Dr Martin

\section{专 13 December 2018}

I met with Martin today. I told him I was concerned after the DProfPrac workshop earlier this week - most other learners were all talking about their ontology, their epistemology, and different paradigms. I don't think l'm ever going to talk like that - it just doesn't feel like me. Maybe a doctorate is not for me. Martin thinks I'm having "an ontological crisis" but reassured me that I don't have to change. It really helped when he said, "You don't have to be who you are not".

\section{圈 21 February 2019}

I was talking with Martin about 'excellence' today. He suggested thinking of 'excellence' perhaps as the hub of a wheel; so what are the spokes? As he was talking, I had a very clear image of light going through a prism and seeing 'teaching excellence' going through and breaking into its component parts. I asked if that could work. Martin very positive about this. Conveys the complexity of the notion of 'excellence', much more than if I were to just talk about a 'lens'; Refractive thinking?

\section{April 2019}

Never lose sight of the fact that this is a Professional Practice qualification; it's about my Professional Practice - it's OK (and expected) to write in the first person and include some more personal aspects that you wouldn't typically see in more 'traditional' academic writing.

\section{April 2019}

Kia ora, Claire,

I think you are almost there with your Learning Agreement. I've answered a few Qs and made a couple of comments.

I had the weird feeling reading your work that I had written it - a sensation I associate with 'saturation', or that sensation when you've read something so often that you feel there is little more that you can say.

DrM 


\section{May 2019}

I presented my research proposal/learning agreement to the panel today. Unanimous approval for me to proceed with the project, which is great, but panel gave feedback to Martin that I was obviously very nervous. Need to think about perhaps adding my work on this (nerves re: public speaking) as a suboutcome of my project. As far as the panel were concerned, I was "perfectly well-prepared and had a beautiful presentation" - "Why is she so nervous? She's so grounded in this!". It's a bit of a worry, as I was actually much less nervous than I expected to be!

\section{July 2019}

Claire: Now that I'm getting ready to start data collection, how often should we be meeting?

Martin: I'm not sure that you need meetings at the moment. Get on with your participant interviews and contact us if you need to. We [mentors] should become redundant over time

\section{July 2019}

Thanks for sending your draft interview questions through, Claire.

Your questions are great, and very open. It's clear that there will be a need for intonation and stress around the word 'excellent'/'excellence'. I can hear your voice intoning it differently in different uses of the term when I read through the questions. This may be worth monitoring yourself on in a reflective log, just as you'll be monitoring how to improve the interviews as you do, learning more with each interview and making tweaks. This is the nature of 'reflective' interviewing. And, yes, you will ask different questions depending on where the interview goes. You'll learn to be comfortable with going with the flow. There will be some key questions you want to ask consistently because that will affect the themes of your data. These 'anchor' questions will help to structure the interview, even though there will also be 'flow' questions. Anchor and flow.

Ngā mihi!

Martin

\section{December 2019}

Hi Martin,

I hope this finds you well, and that you had a good Christmas - I'm just trying to get back into 'work and study' mode.

I have a query I'm hoping you can help with... and forgive me for 'thinking out loud' as I type.

I bumped into a colleague on the last day on campus and she asked how everything was progressing with my project. I said that I was hoping to "start coding" over the break, but she said something along the lines of 'not coding, theming'. Isn't coding necessary before I can identify themes? I've been doing some reading on this over the past couple of days, and there seems to be conflicting advice. Some texts suggest using research question and sub-questions to guide coding (so, for example, I was envisioning a spreadsheet page for each sub-question, and looking for content that answers/relates to that particular question); others suggest not looking at the questions at all.

I've gone back to Braun and Clarke (2006) and this would seem to be the difference between deductive and inductive analysis (I think). Going with inductive, I look at the data without focusing on my research questions, so coding/theming (?) is data-driven. 
I have several other articles/chapters I can read but am concerned I'm not using this time to the best of my ability (I'm not suggesting that reading is not helpful, but feel that I am maybe delaying the start of data analysis because I am nervous about how to begin!).

Hope that makes sense. Any particular advice at the moment, please?

Ngā mihi maioha,

Claire

\section{国 3 February 2020}

Met with mentoring team today. I talked through why I'm doing my analysis manually, rather than using any software or technology, because it means that I become more familiar with the data, the more I work with it. Martin is also an advocate of this; likes letting things emerge using rational processing, and readerly techniques (constant comparison, metaphor analysis, seeking synonyms...), perhaps because of coming from a linguistic background, like me. People with this type of background usually find it much easier to understand synchronicities between words and concepts.

Some of the literature around data analysis is less helpful than others. Martin agrees, and advised me not to get bogged down in anything that mentions axial coding or any other complex types of coding.

Robustness of my work will come from the fact that I'm engaging in the two types of narrative analysis; both the re-writing/re-telling of the stories (so as to maintain as much as possible the authenticity of each participant's voice, preserve metaphors etc), and, at the same time, from a more scientific, social sciences' perspective, I'm picking apart the original narratives and presenting a thematic analysis. Interesting that Martin suggests it's not necessary, strictly speaking, to do both; for a PhD, you could do one or the other. To me, this feels almost like l'd be doing a disservice to the participants; that one or the other wouldn't do people's stories justice.

\section{March 2020}

I met with Martin today. We talked about us going into lockdown imminently. Lucky that l've done my data collection.

\section{March 2020}

Kia ora, Claire,

I'm writing to assure you of the plans to keep the momentum going on the DProfPrac at this time.

Let's harness the energy and channel it into the reading and creation of works rather than moping on the Coronavirus Channel.

We have a new Zoom and I'm hoping to be able to leverage this for us. We are aware that technology can be erratic sometimes and will keep open the following options for our 'DPP whānau': Facebook messenger, Teams, and I'm also open to text messages at any time to stay in touch and for those pesky nagging questions that lead to writers' block.

I see this time as an excellent opportunity to get the thinking and writing underway!

Ngā mihi!

Martin 
$\triangle 18$ May 2020

Kia ora,

My outlook calendar is telling me it's time for an e-mail update, so here goes...

- All draft stories completed; shared with individual participants on 24 April, asking for feedback by I5 May

- As of today, 8 (out of 13) participants have got back to me and are happy for me to proceed. I've sent out a reminder to those I haven't heard from yet.

- I've been working on my methodology recently, trying to decide how best to incorporate reflections.

- Was very distracted this past weekend, and did not achieve anything much; I made a start on my Introduction.

Could you please let me know when you'd like to start our face-to-face meetings again? We have one pencilled in for Thurs 4 June - does that suit? I'm adjusting to being back on campus today - lovely to see some real people!

Ngā mihi nui,

Claire

\section{May 2020}

Kia ora, Claire,

This progress sounds most satisfactory, and many thanks for reporting it so succinctly and conscientiously. I admire your use of calendar and reminder software.

I went through the campus area today and felt horrified that there were numerous cars where there had recently been peaceful empty spaces. There was a feeling of sadness - the golden age of lockdown coming to a close; for this time at least.

It is true that June 4 is in the diary for you, and l'll meditate over whether l'll turn up in person or virtually. At the moment, it feels so much more real to be virtual.

Ngā mihi!

Martin

\section{目 4 June 2020}

I had a catch-up with my mentoring team today, which was good. It feels like ages (given the lockdown). It was a good discussion, but uncomfortable for me in lots of ways. I'm not demonstrating enough reflexivity in my methodology at the moment, and I need to rethink how to do this. Martin said I looked annoyed at one point, but it was more that I was confused. I can actually feel it physically... the worry of not understanding what they're asking me to do. I said at one point "I'm not having any 'aha moments' here!" and laughed, but it's not funny. I feel like I should understand this. Is this like a 'zone of proximal development' thing - challenging me slightly beyond where I am currently sitting? Of course I need to be challenged; I wouldn't learn otherwise. I need to remember the uncomfortable elements though, when thinking about my own learners.

\section{$\triangle 15$ June 2020}

Kia ora, Claire,

I've looked at the vignettes and commented on the first one. It strikes me that they do become increasingly reflexive as it moves on. My epiphany here was that the missing part of your thinking might come, will 
come, with a tighter investigation of the 'epic'/'etic', the insider perspective. I've included a couple of references to focus this and there's a recommended reading (a handbook) too. I think that what puzzled us last meeting consists in the need for a bit more on this. It's the key to the type of reflexivity you wish to achieve.

Opening out your thoughts and the rationales behind your actions/choices/thinking has led to a more reflective sense in the vignettes. In my comments I've added a few thoughts about them too. In short, I think they could be micro-narratives, 'Smithereens' as poet Elizabeth Smither calls her very short but insightful little poems.

On track? Yes.

Ngā mihi!

Martin

\section{July 2020}

Claire: I'm struggling a bit... It feels like, at the moment, nothing is finished. Everything is in process.

Martin: That's perfectly OK... what you've just described is something l've heard described by just about every doctoral candidate ever! It just means that a whole lot of gems, which might be rough at the moment, all need to be polished... It shows me that you've gone about this project in a very Professional Practice-kind of way, where everything is left open, until such time as everything is saturated or crystallised, and it's time to put the finishing touches on.

\section{August 2020}

Listening back to recordings, I'm noticing how much more I'm speaking up and 'defending' my thinking.

\section{圈目 6 November 2020}

When I initially shared my model with mentors, I said that it all seemed a bit obvious. Would people look at this and say, "Yeah, we do all of that"?... Martin says that, with almost all the models he's seen (resulting from doctoral research in education), there is always an element of "Is that all I've got to show for all my work?!". I laughed and commented that I had thought "Is that it?"! Sometimes the apparent over-simplicity of a model is part of its beauty. It needs to be accessible.

Also talked about how, when I was doodling draft models, I wondered whether a pyramid model was a good fit (similar to Maslow's hierarchy). Yes, focusing on learners underpins everything, BUT it's not a pyramid because it's not a case of 'You do this first, then you do this, then this...'; you have to look at the whole. I also don't want it to be perceived as something that's unobtainable (the top of the mountain being 'excellence').

\section{$\triangle$ I December 2020}

Kia ora,

I think we are thrilled you are sharing your findings and that they are to be shared with Ako Aotearoa, who are, after all a true stakeholder. This is definitely in the spirit of professional practice and reflecting on this 'dissemination' part of the project will go nicely in the last section of your work.

It's quite thrilling when people are fascinated enough to photograph your slides. It's also common for conference organisations to ask you to perhaps share your presentation as part of the shared repertoire of that particular community of practice, but always check that such 'publications' don't preclude you from publishing in a refereed source. 
After the thesis is done and dusted, I'll ask you to submit to a journal I have in mind. Your work is a good fit for this and it's a good 'next stage' from local journals and with sufficient prestige factor.

See you soon.

Martin

\section{January 2021}

Kia ora, Claire, and welcome to a fresh year,

I enclose the two documents you've been working on and once again see any stalling as due to issues of confidence but would encourage you to trust your instinct, as instinct is grounded in experience, when that stuck feeling comes. Part of autonomy is being now able to dig yourself out of your own holes. And I do think that the epilogue testifies to the confidence growth and l'd like to reduce references to the nervous old Claire in the epilogue other than as part of the imposter narrative that we all continually tell ourselves.

Your strength is an ability to synthesise multiple voices from scholarship into a coherent narrative. In general, l'd still say that one thing to note going forward - and here l'm thinking of the place you left the epilogue - is to internalise the feedback that there is always more room, no matter how advanced we are as researchers, for more analysis and more criticality, both of which come from a different type of confidence and one still building in your 'becoming'.

I also appreciate the increased ability to think diagrammatically in a reader-centred way and wonder if this newfound sense might translate into a diagram for your frame of prof practice in the Introduction, setting the scene with the three domains of enquiry in the DPP, which may differ only slightly from those you use as focal points. I look forward to further iterations of both documents.

Nga mihi,

Martin

\section{January 2021}

And the findings are a fine blend of reportage and relation back to existing literature. Some may say the latter function belongs to discussions. I disagree. To me that is a very artificial and epistemologically ignorant thing to say (I get it from reviewers all the time). You've made the findings vivid and lively and relevant.

My comments are minor, and related to consistency in form and presentation, but it is a joy to read work that does not require continual corrective feedback.

Ngā mihi!

Martin

\section{The journey to the future ends with the work close to submission.}

\section{CONCLUSION}

This study has at its centre the trajectory of one learner's candidature, capturing a time-scape of critical moments and key turning points during the journey, to apply the most commonly used metaphor in doctoral literature to describe this process. In light of the metaphors describing the candidature (Gravett, 202I), one we feel is appropriate is Geertz's (1995) parade image, knowing that the reader sees part of the story but not what has come before, nor what will follow. Similarly, as mentors and learners, through our own day-to-day behaviour and interactions, we enter others' stories "in the midst" (Clandinin \& Connelly, 2000, p. 20) of those stories being lived and told. 
Our study serves both to show the evolution of the learner identity towards a confluence of the professional and the scholarly and to exemplify the kinds of eclectic critical conversations that might characterise the mentorlearner dyad. It is eclectic because, as Johnson (2021) writes (this issue) it involves "the unique combination of perceptions and conceptions the individual has, thus drawing upon both subconscious and conscious connectivity within the individual." Constructive critical conversations, she writes, "allow for individuals' voices to harmonise in a communal chorus toward a socially constructed overture."

This selection of eclectic artefacts from our mentor-learner journey show how the relationship evolves and how dynamics shift. As Erikson (1956) famously wrote, "a sense of identity is never gained nor maintained once and for all. Like any good conscience, it is constantly lost and regained" (p. 74). The narrative told through sequenced emails, reflections and conversations shows such moments of loss and gain, disequilibrium and re-equilibrium.

Eschewing monologic approaches to our phenomenon in the spirit of bricolage (Kincheloe \& Berry, 2004), we enact a dialogic and 'praxical' process where we approach practice so that it becomes research, recreating critical moments of problem-solving in action and practice-as-research. This way of seeing the candidature allows for the doctorate-ness of this journey to be seen as development and change. Workplace knowledge, Lester (20 I I) tells us, extends beyond any immediate context of research and opens the door to the possibility of existing in an authentically transdisciplinary space. Lester (201I) outlines the reasoning thus:

Complex change-oriented issues...approached with a researching and critically reflective orientation can be a powerful source, not only of contextual insights but of academically and professionally-valid knowledge, giving rise to new concepts, models, theories and critiques as well as different ways of doing things (p. 279).

Our tango through the fluid and messy topography of professional practice lands us here, with this paragraph as our ending. Our contribution to knowing in the doctoral space consists in how we hope readers might identify with the stages in this journey. Only you can tell us if it is, indeed, a mirror of encountering conundrums in the professional doctorate terrain.

Claire Goode is a member of the Learning and Teaching Development team at Otago Polytechnic. She works alongside academic staff across the Polytechnic to build their capabilities in multiple aspects of pedagogical practice. This role brings together skills, knowledge, and practice acquired throughout more than twenty-three years in education, in different contexts and countries. She has been enrolled in the Doctor of Professional Practice programme since mid-2018, and is on the verge of submitting her thesis for examination.

Email: Claire.Goode@op.ac.nz

(D) https://orcid.org/0000-0002-2255-6523

Martin Andrew operates as a creative mentor in postgraduate programmes, including Master and Doctorate degrees in Professional Practice. Prior to his four to five years supporting the College of Work-based Learning in Otago, New Zealand, he had sojourned away from his hometown of Otepoti/Dunedin with two honorary posts at Melbourne universities in Creative Industries and Trans-national Education (TNE). His work and research have become increasingly focussed on doctorate education and supporting learners to reach their own personal best through critically reflective practice and writing. A transdisciplinarian, he emphasises that his past disciplines have included Education, Drama, Linguistics and Writing, Creative and otherwise. He holds honorary positions in Australia, Vietnam and Indonesia.

(C) https://orcid.org/0000-0002-0108-5195 


\section{REFERENCES}

Arnold, J., \& Mundy, B. (2020). Praxis pedagogy in teacher education. Smart Learning Environments, 7, article 8. https://doi. org/l0.1186/s4056I-020-0116-z

Banagan, R., Hecq, D., \& Theiler, S. (2012). Dancing the tango within a triangle: Framing agendas in postgraduate pedagogies. New Writing, 9(I), 42-52. https://doi.org/l0.1080/14790726.2011.586705

Batchelor, D., \& Di Napoli, R. (2006). The doctoral journey: Perspectives. Educate, 6(I), I3-24. https://core.ac.uk/download/ pdf/74394073.pdf

Clandinin, D. J., \& Connelly, F. M. (1990). Stories of experience and narrative inquiry. Educational Researcher, 19(5), 2-14. http:// www.jstor.org/stable/I176100

Clandinin, D. J., \& Connelly, F. M. (2000). Narrative inquiry: Experience and story in qualitative research. Jossey-Bass.

Costley, C., \& Pizzolato, N. (2018). Transdisciplinary qualities in practice doctorates. Studies in Continuing Education, 40(I), 30-45. https://doi.org/I0.1080/0158037X.2017.1394287

Drake, P. (2015). Becoming known through email: A case of woman, leadership, and an awfully familiar strange land. Gender and Education, 27(2), I48-163. https://doi.org//0.1080/09540253.2014.993936

Erikson, E. H. (1956). The problem of ego identity. Journal of the American Psychoanalytic Association, 4(I): 56-121. https://doi. org/10.1177/000306515600400104

Freire, P. (1989). Education for the critical consciousness. Continuum.

Geertz, C. (1995). After the fact: Two countries, four decades, one anthropologist. Harvard University Press.

Gravett, K. (2021). Disrupting the doctoral journey: Re-imagining doctoral pedagogies and temporal practices in higher education. Teaching in Higher Education, 26(3), 293-305. https://doi.org/I0.1080/I35625I7.2020.1853694

Hayes, C., \& Fulton, J. (2014). Autoethnography as a method of facilitating critical reflexivity for professional doctorate students. Journal of Learning Development in Higher Education, 8. https://doi.org// 0.47408/jldhe.v0i8.237

Johnson, M. (202I). Professional development through the harmony of different voices within constructive critical conversations, Scope Work-based Learning, 2, 104-III.

Kincheloe, J. L., \& Berry, K. S. (2004) Rigour and complexity in educational research: Conceptualizing the bricolage. Oxford University Press/ McGraw Hill Education.

Lester, S. (2011). Creating original knowledge in and for the workplace: Evidence from a practitioner doctorate. Studies in Continuing Education, 34(3), 267-280. https://doi.org/10.1080/0158037X.2011.613595

Manathunga, C. (2019). 'Timescapes' in doctoral education: The politics of temporal equity in Higher Education. Higher Education Research \& Development, 38(6), 1227-1239. https://doi.org/10.1080/07294360.2019.1629880

Middlesex University London. (202I). The doctorate in professional studies. https://www.mdx.ac.uk/our-research/centres/workand-learning-research-centre/the-doctorate-in-professional-studies

Milburn, G., Dolfi, J., Parsons, R., \& Weller, G. (2019). Perspectives on Professional Doctorate research and learning: The lived experience of the learned professional. Work Based Learning e-Journal, 8(I), 89-104. https://wblearning-ejournal.com/ uploads/currentlssue/6\%20Milburn\%20et\%20al\%20amended\%20version\%20upload.pdf

Perry, I., \& Brophy, K. (200I). "Eat your peas": The creative Ph.D. thesis and the exegesis. In A. Bartlett \& G. Mercer (Eds.), Postgraduate research supervision, transforming (R)Elations (pp. 89-100). Peter Lang.

Stephenson, J., Malloch, M., \& Cairns, L. G. (2006). Managing their own programme: A case study of the first graduates of a new kind of doctorate in professional practice. Studies in Continuing Education, 28(I), 17-32. https://doi.org//0.1080/0158037050052568।

Riessman, C. (2008). Narrative methods for human sciences. Sage. 


\title{
PLOVERS IN LOCKDOWN: AN AUTOETHNOGRAPHIC STUDY ABOUT VALUES IN LEADERSHIP DECISION-MAKING
}

\author{
Bonnie Robinson
}

\section{DISCOVERING PLOVER-TOWN - WALKING INTO A CONFLICT BETWEEN MY VALUES AND MY ACTIONS}

Auckland was two days into Lockdown lite (Covid Level 3)' in August 2020 when my husband came back from supporting our local bakery, a little excitement in his voice as he gave me the news: "There are baby plovers on the wasteland."

My first thought was "Cool" and then "What exactly is a plover?"

I live in a newish subdivision and there are still undeveloped parts. Nature always takes on these unbuilt areas. Grass self-seeds, plants grow green mountains on the builder's rubble, ponds form in the hollows when it rains, and birds start gathering. Pũkekos rule of course, but from time-to-time other birds arrive and try to make this urban outpost home for a while.

The wasteland is our local bit of this green guerrilla resurgence (take back the land!). It is a large flat section next to our small shopping centre and has recently been fenced, which cuts off the shortcut to the bakery, but does not stop the birds, or the cats, since it is a wire fence with wide mesh.

Later that afternoon we go for our lockdown walk. Being good citizens, we keep to places that are local, and this means we know the square meterage of our small suburb incredibly well. The plovers are welcome added interest.

The plovers, it turns out, are a family of six - Mum, Dad and four fluffy chicks. Cute as. The first day I saw them they were at the venturing out from Mum stage. Although they can feed themselves almost from birth, plovers do not develop the ability to fly for three months after they hatch. Mum and Dad keep a careful watch, and Dad did a dive bomb reconnoitre of us as we stood watching. Something eventually spooked them. Mum called and Dad cried, and the chicks shimmied back to Mum and sat under her, completely unable to be seen.

I Covid Level 3 Lockdown in NZ means most workplaces and shops closed, but some takeaways available. 
We carried on with our walk, our Covid-suppressed spirits lifted a bit by the experience of plover watching, the simple wonder of nature, and how some things seem to be innate to all species such as the need to protect the vulnerable young.

And then we started counting cats. As we walked home suddenly it was like the suburb had literally rained cats. They were everywhere. So, we started to worry. Those silly plovers, nesting on open ground, they were surely doomed.

Back at home I looked at my beloved Burmese, $M$, and felt guilty. Moving into this house and getting a pet was a big deal. For years we had lived in housing supplied by my husband's employer. Buying this house meant I could keep a pet for the first time in II years. I have always loved animals, especially cats. I love their grace when they jump, their soft fur, and the fact that in their DNA they know they used to be worshipped as gods. When we moved into our own place, I got two Burmese kittens, Max and M.

I knew when I did this that it was, in fact, wrong. The world does not need more cats. New Zealand and its wild life do not need more cats. I knew about the destruction of our bird and lizard populations due to cats, but I still went and got two cats, because I wanted to feel at home, and I wanted something to nurture. In the end I put what I wanted above the needs of our native species. I went against my values.

To be fair, or maybe just self-justify, I have tried to be a very responsible cat owner. We keep the cats in from dusk to dawn - which is when they catch most of their prey. When Max died, I resisted the temptation to replace him. Cat population down by one. But still, M exists, and from time to time I come home to a murder scene. I just hoped she was too lazy to head to 'Plover-town.'

Each day during lockdown we walked past the plovers and counted chicks. My heart would skip a beat if we could not quickly see four. Once we had, we would head off on our walk, happy again. Then of course, the inevitable happened. One day we could not see four chicks, only two. We waited and waited but could not see them.

When I got home after that walk, I looked at M like she was an accessory to murder. "Stupid cats," I thought. "You are all urban cats here, well fed, no need to hunt." "That's nature," said my husband with annoying equitable logic. "If you have a cat it will hunt, and much, much more than you think. Most of their kill they don't bring home. You know that. You knew that when you got the cats. You made a choice."

I began to plot, or perhaps fantasize, about what I could do to save the plovers. Maybe I could distribute leaflets around the neighbourhood imploring cat owners to keep their cats in at night. "Justice for Plovers!" Maybe I could head down to Plover-town at dusk and dawn and try and scare away the cats. Yeah right. I had to face the grim reality that there was nothing I could do to save the plovers, and that by having a cat I had knowingly contributed to the possibility, perhaps the inevitability, of their demise. 


\section{VALUING PLOVERS OR VALUING CATS: THE PLOVER/CAT DILEMMA}

There is a grace, to be prayed before meals, attributed to the McLeod Clan in Scotland, that goes "And make us worthy of the esteem in which we hold ourselves." Typical Protestant self-depreciation, but also, a valid corrective for leaders who aim to be values-based.

\section{THE PLOVER CAT DILEMMA}

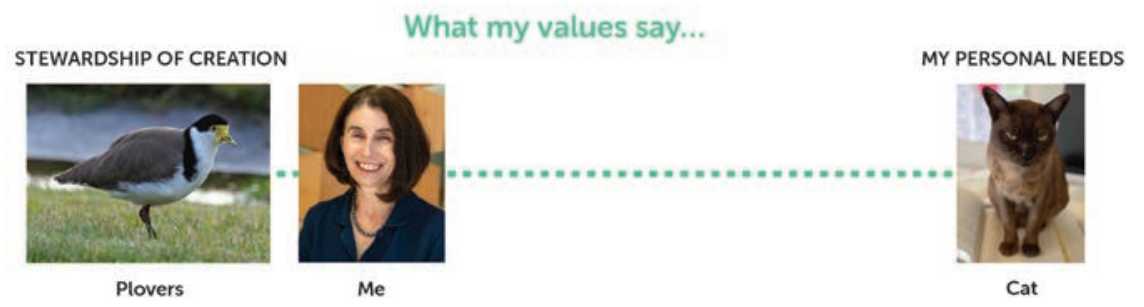

What I did...

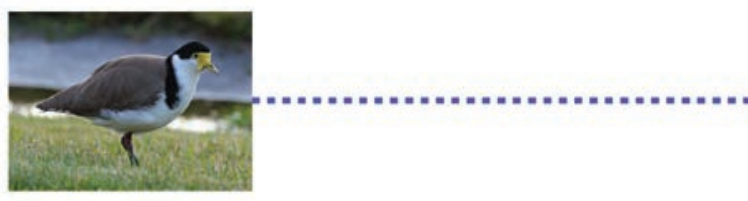

Plovers

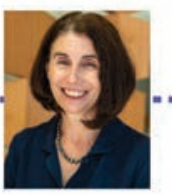

$\mathrm{Me}$

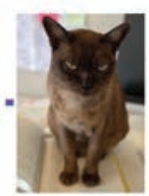

Cat

What the plovers had brought forward for me, in a very practical way, was an ethical dilemma and a concrete example of where my values had not driven my decision making. My values said the stewardship of creation had priority, and in the New Zealand context that meant no cat. Yet even with this knowledge and conscious value, I instead fed my personal emotional needs. Given that my doctorate is examining how leaders can enact values in decision-making, especially the value of social justice, my values failure was disappointing. If I could not even stick to my personal values in my personal life, what hope in my leadership life? And what hope of building systems/processes to support values-based decision-making out of my study?

To help my critical self-reflection, I returned to the literature and to the data from the leadership interviews I had undertaken so far. The literature suggests that leadership is a complex and contradictory mix of the personal and the professional, of your own values, the organisation's values, and simple pragmatism (Berkovich, 20l4). Balancing these is difficult, and in a sense the art that is leadership (DePree, 1989). Much of the literature sees leadership as the task of setting vision, direction, ethics, values, and culture, whereas managing is seen as the task of doing (Paton et al., 2007; Crosby \& Bryson, 2005; Finn \& Jacobson, 2003; Ryan, 2000; Schein, 2010). Some literature, and my experience of practice as a leader, would debate this distinction as artificial - leaders manage, and managers lead - especially in smaller organisations with flatter structures (Mintzberg, 1971; Pervin, 1997). The literature shows that values do require leadership and not just management (Mills \& Spencer, 2005). To make a definitive difference, values can never just be a management tool, they require belief and embodiment. Enacting values, achieving something with them, is therefore as much of a challenge as developing them (Ryan, 2000). I did not enact my values when I got my cats, and the plovers or other wildlife will pay the price. 


\section{RECOGNISING PLOVERS WHEN YOU SEE THEM: HOW DO LEADERS COME TO HAVE AND TO HOLD ON TO VALUES?}

"Why is it so hard to do all the good I want to?" I asked, as my husband and I plodded a little dejectedly around our suburb after yet again seeing only two plover chicks. "I want to do right by creation, I believe that we are stewards, but I seem to constantly make choices that are good for me, and not so much for the planet. Like I am not going to pick up those stray paper face masks un-gloved," I said, looking at a couple of soggy blue masks caught in a hedge, "despite what they'll do to the fish if they get into the sea via the drains."

"So self-critical as usual," said my husband. "At least you think about what is right and wrong, I meet people in my work who have no idea about that. Knowing that there are choices between right and wrong behaviour is a place to start."

He was right of course, but also wrong. In my experience of leadership, knowing right from wrong is not all that is required. Right and wrong decisions are simple - children make them. In leadership, and in life, we are often called on to make what Kidder calls "right versus right" decisions and these are difficult (Kidder, 1995). These take an ability to judge fine nuances. They take values consciousness.

How then do leaders come to have values that can assist them to lead through complex decisions? As we walked during lockdown, I thought about my own experience and the experience of the nine leaders I had interviewed ${ }^{2}$ about social justice leadership. These leaders were focused on shifting whatever context they found themselves in towards justice, equity, and the common good. To achieve these outcomes, all the interviewed leaders identified personal values as a key driver. The organisational values were important but the source of their identity and actions, lay in strongly held, deeply embedded personal values. But where did they get these? Are values-driven leaders born or made?

The literature, in a nature/nurture type debate, is divided as to how leaders come to have strong values. Some suggest that leaders come to leadership with these values inherent in themselves (Mills \& Spencer, 2005), cite religious belief (Ryan, 2000), or point to the ability for life events and social context to embed values (Russell, 200I). Others suggest that values can be nurtured in leaders through training (Finn \& Jacobson, 2003), and the way morality and ethics are discussed within organisations (Dempsey 2008). Kidder argues that morality is innate, and that there are some universal values that transcend time and culture (Kidder, 1995).

The experience of the interviewed leaders is largely in agreement with the literature around the origins of their values, but they described this differently. The leaders identified with these sources:

- Context - geography, economic situation, social situation, and culture all impact on which values leaders hold as most important. The organisational context of leadership is also critical, especially the interaction between leader values and organisation values.

- Family - for most of the interviewed leaders, family background was important because the values they held had been demonstrated in childhood. For two leaders however, it was rejecting some of the values they had been raised with that shaped them most strongly. This rejection was precipitated by a particular event and led them to choose different values for their adult life.

2 Ethics approval for this research was obtained during the Learning Agreement phase of the DProfPrac. Signed consent was obtained from interviewed leaders to allow use of their words but without identifiers. 
- Whakapapa - for Māori leaders that I interviewed, their strong sense of knowing where they come from was a primary source of their values. Values were interwoven with their knowledge of history, ancestry, the example of their ancestors and current kaumatua.

- Education and Training - for some leaders, their profession, training and/or codes of practice impacted significantly on their values. Over time, the professional values come to be identified as personal values.

- Faith/spirituality - for many leaders interviewed faith, in particular Christianity, was core to their values.

- Innately human - some leaders felt that certain values were so innate to being human that perhaps they were not values, as in conscious concepts, but akin to being part of our brains, hard wired.

While the literature and my research might agree that there are many sources of values, my personal plover/cat dilemma suggests that enacting values is not as easy as espousing them. There are multiple pressures on each of us as individuals and as leaders, some of which drive us towards and some away from our values. The leader interviews identified attributes or approaches that supported them to uphold their values.

- Reflective critical thinking

The interviewed leaders discussed the importance of reflecting on their leadership, and how decisions and actions might be impacted by personal and organisational values. This understanding that reflection and critique are important functions of a leader was common to all the leaders interviewed, despite diverse backgrounds and leadership contexts.

- Learning and knowledge

Related to critical thinking, was a leadership commitment to learning and knowledge. Through deliberate learning, formal and informal, leaders sought to refresh their ethical toolbox, tease out assumptions and find new models.

- $\quad$ Letting life impact on practice

Described by most leaders interviewed, and cited within some literature (Finn \& Jacobson, 2003; Ryan, 2000), is the importance of allowing what occurs to change thinking and then practice. There is a sense that the values that drive leaders who seek social good and social justice are both fixed, and fluid. Leaders reflected core beliefs that did not change, but their understanding of them, how they could be enacted, and the priority of one value over another, changed as experiences came to layer understanding and ability to act. Leaders felt the need to find an intersection between values and practicality.

- Meeting real people in real places

A subset of life impacting on practice, but an important one to the leaders, was the influence of meeting people within their own contexts, and how this changed or cemented leaders' values and their commitment to upholding values. People's actual lives, experienced by leaders either directly or indirectly through managing service provision, took theoretical knowledge of values into the arena of praxis.

- Curiosity

Only one leader explicitly used this word but nearly all the leaders expressed the concept - that curiosity was crucial to their values. Curiosity in this context meant a genuine interest in finding out about people and contexts that were unknown, 'other', and, to do this first-hand, not through books or theory. Curiosity for leaders is an innate need to know and to understand before 'judging' or acting. The values arising from the ontological approach of curiosity, seemed to be more strongly held, able to stand up to organisational, societal, or political opposition. 
- " "I know who I am. But it's not about me."

Leaders and the literature indicate that a combination of self-knowledge and selflessness is seen in valuesbased leadership. Servant Leadership (Russell, 2001; Spears, 2010) in particular upholds this model. Developed by Robert Greenleaf in the 1970s (Greenleaf, 2002), aspects of Servant Leadership are referenced in many theories and discussions of moral, ethical, and effective leadership, where the leader has both drive and humility (Collins, 2005). Many of the leaders interviewed indicated that once they knew that the focus of their leadership was not themselves, but always the commons, then the enactment of values was easier, because leadership became focused on mission not personal achievement.

\section{PLOVERS IN THE REAL WORLD - ENACTING VALUES IN LEADERSHIP PRACTICE}

Taking a break from study a few days after thinking about how leaders come to have values, my husband suggests we go by the plovers and see how they are doing. I say no. "I don't want to know. What if there are no chicks left? I can't face it."

"Running away won't change nature," said my husband.

"Yes, but I don't have to see the grim reality of it," I said. As we walked, avoiding Plover-town, I did reflect, "I wonder what Aristotle, Kant and Mills would say about the choice between cats and plovers?"

"OK so that is way too big a question for one walk, and also we need Glen if you want to talk about this," said my husband. Glen is a friend of ours who is a Professor of Moral Philosophy.

"It's just I know from my study that these ethical dilemmas are not new," I said. "They go back centuries and there are loads of erudite books on how to resolve them. But in the moment, when I am at work, I don't have time to remember or invoke all that. And in the moment when I had to choose between getting a cat or not, my emotions won. Ethics always seems easier in theory than in practice."

"Maybe if we'd known about the plovers when we moved in, your decision might have been different," said my husband, "Aren't decisions often contextual?"

"Well, that's one theory," I replied.

The literature is full of theories on how to hold to values and resolve the ethical dilemmas they bring. Some clearly come from a particular branch of moral philosophy, focusing leaders towards Aristotle's focus on character (Covey, 1989; Greenleaf, 2002), Kant's view of right action (Kidder, 1995), Mills' concern with future benefit for the many or a combination of all of these (Collins, 2005; Schein, 2010; Bird \& Waters, 1989). Others focus on methodologies for supporting values-based decisions such as frameworks or questions (Fischer, 2006; Kidder, 1995).

Michael McCuddy tries for a practical middle ground between many of the theories by offering up the concept of self-fullness (McCuddy, 2008.) A mid-point between selfishness, which he views as negative except where survival is required, and self-lessness, which he views as unattainable by most, self-fulness is the simultaneous pursuit of self-interest and the common good. Described by McCuddy as a "both/and moral orientation" selffullness recognises "the need for human beings to make decisions and take actions that reflect both self-interest and service to others" (McCuddy, 2008, p. 4). 


\section{MCCUDDY'S CONCEPT}

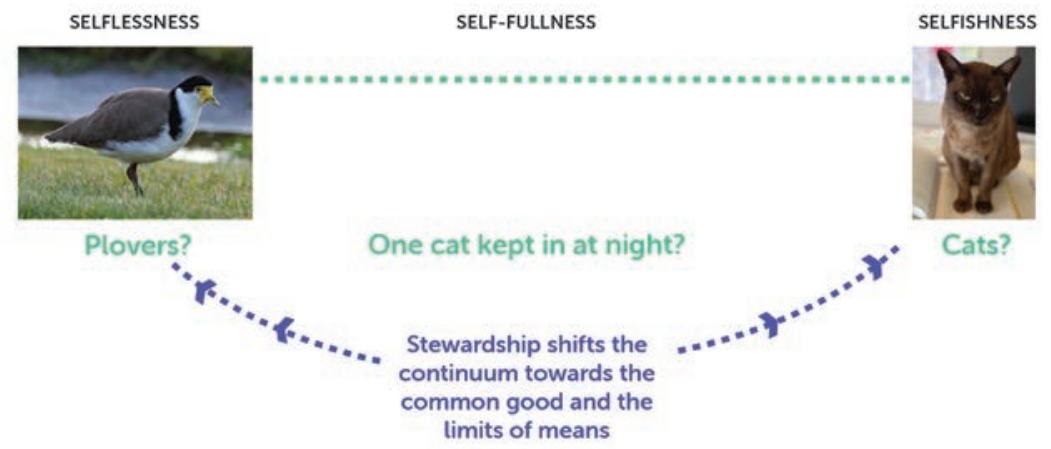

This is of course a noble ideal and, on the surface, a workable solution to the potential conflict between individual and community needs. However, as I pondered my plover/cat dilemma, it felt like this middle ground could be just a moral justification of action that is still primarily orientated to my personal needs. Self-fullness could be an 'almost anything goes' approach because you could manipulate the continuum, until you add in McCuddy's ultimate moral basis for decision making - stewardship, which pushes the continuum strongly towards selflessness. For McCuddy, stewardship "Reflects the wise use, development and appropriate conservation of resources that have been entrusted to the care of human beings... [it is] a protective restraint that humans impose on themselves" (McCuddy, 2008, p. 5). Using stewardship, my dilemma would therefore be more likely to be pushed in favour of the plovers and no cats.

McCuddy's self-fullness is one theory or construct of how to enact values. But as I walked the lock-down walks I thought about what my interviewees had said about what impacted on their ability to use their values in decision-making.

\section{LEADER INTERVIEWEE EXPERIENCE IN PRACTICE}

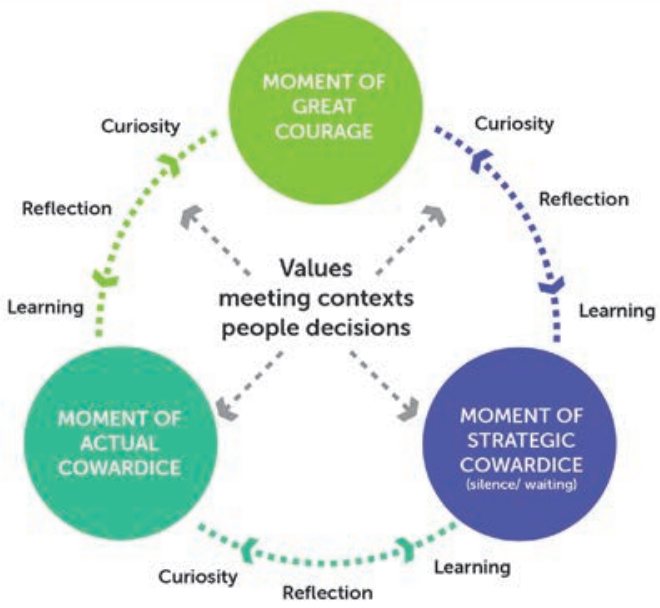


What the leaders described was a continual cycle of action, reflection, and learning, strengthened by curiosity. Leaders' values, personal and organisational, met existing and new contexts, issues, and people, which required decisions to be made, that presented challenges to, or confirmation of values.

In applying their values to these varying contexts, people and decisions, leaders noted at least three general approaches:

- Moments of Great Courage: there were moments when the leaders made decisions and felt that in doing so, they upheld their values - at times in the face of opposition and in situations where there might be a personal or organisational cost.

- Moments of Strategic Cowardice: there were moments when the leaders did not make a values matched decision or when they remained silent. This was deliberate and strategic because they judged that the time was not right. They needed to wait for support or information, so that they had a better chance of being able to achieve a values-based practical outcome.

- Moments of Actual Cowardice: these were moments when the leaders felt they had not acted in accordance with their values. They had gone against their values because of fear, a lack of power or agency, reputational issues, or the need to keep a job.

The diagram is a circle because what leaders described was not a linear process. While they learnt from each experience and courage might be gained, there would still be moments ahead of cowardice, especially strategic cowardice. This therefore reflects McCuddy's framework, where no-one can always live within self-lessness (courage) but nor should they always live with selfishness (cowardice).

\section{FLY LITTLE PLOVERS - IMPLICATIONS FOR RESEARCH AND LEADERSHIP PRACTICE}

Reflecting on the interview findings, and McCuddy's framework, I decided to solve my plover/cat dilemma. I was driven to do so by the inevitable. One day we could not see any chicks at all. Not that day nor any other for the rest of lockdown. I was dejected, and then resolute.

"How are those conversations with the giants of moral philosophy going?" my husband asked.

"I've made up my mind," I said, "When M dies, no more cats. I'll do fostering for the SPCA or the Guide Dog people instead."

"That will take great emotional resolve on your part," said my husband.

"Values seem to take that. That's why I need to do more work out of this whole episode."

So much had arisen out of my plover story, its interaction with my leader interviews and the literature around values in leadership. If I am to make this useful for my own practice and the practice of other values-led leaders, I need to focus on one or two key discoveries.

\section{Curiosity}

The concept of curiosity is worthy of further reflection and research, especially around its relevance for supporting values-led decisions. Curiosity in this context seems to be about more than learning. Some leaders described it as almost a way of living, of approaching the world, and ethical issues. Curiosity denotes an openness to the 'and/and' space, where there are more possibilities than are known, and resolution to issues can be found in the 'we', in the collective space, in the places where people meet. The place of curiosity and how to nurture this in leaders is worthy of further exploration. 
2. Putting 'l' into ethical reflection by leaders

Bird and Waters, in their research on the moral muteness of managers stated:

It is an idealistic misconception to suppose that moral reasons by virtue of their logic alone inspire the feelings of obligation and desire that make people willingly adhere to moral standards. (Bird \& Waters, 1989, p. 81)

My plover journey has shown me that I do not always operate by the logical truth of my values. To get beyond the singularity of logic and become open to plurality, the adoption of narrative methodologies and in particular the first-person story, has been practice-changing for me.

Writing a story in the first person gives transparency, but simultaneously allows for experimentation and the exploration of options. The practice of first-person narrative writing might therefore be a tool to enhance the ability of leaders to make values-based decisions. In writing my story of the plovers, I was prompted to examine deeply my personal values, and why I had failed in this instance to enact them. Beyond logic and rationality, I was able to see the power of emotion and personal need. Using this form of reflection in my practice, | deliberately placed myself in the 'story' of my difficult leadership decisions. Using narrative, I could become different characters and tell the decision story from varied perspectives. Like a $360^{\circ}$ view, story gave greater breadth and depth to my decisions. Given the nuance often required in decision making, this tool might be usefully explored and utilised by leaders in a wide variety of contexts, including the day-to-day leadership we all undertake of our own lives.

\section{PLOVERS VERSUS CATS - THE RESULT}

After giving up hope for the plovers I was out for a post lockdown walk and heard much squawking as I passed the wasteland. Looking around I saw Mum, Dad and two noisy teenagers. Perhaps in the contest between plovers and cats, or values and actions, right now it is a draw. Maybe if values are strengthened by narrative reflection and curiosity, in future the wildlife might win.

Bonnie Robinson is a student of the Doctor of Professional Practice at Capable NZ Otago Polytechnic. Her area of study focusses on support leaders of social justice around values-based decision-making. Bonnie has many years' experience working in the non-profit social service sector. Currently she is the CEO of a non-profit provider of services for vulnerable older people.

Email: Bonnierobinson036@gmail.com

Otago Polytech ethics approval reference number: 824

\section{REFERENCES}

Berkovich, Izhak. (2014). A Socio-Ecological Framework of Social Justice Leadership in Education. Journal of Educational Administration, 52(3): 282-309. https://doi.org/I0.1108/JEA-12-2012-0131

Bird, F. B, \& Waters, James. (1989). The Moral Muteness of Managers. California Management Review, 32(I) (Fall): $73-88$.

Collins, Jim. (2005). Good to Great and the Social Sectors. Jim Collins.

Covey, Stephen M. (1989). The 7 Habits of Highly Effective People. Simon and Schuster.

Crosby, Barbara C., \& Bryson, John M. (2005). A Leadership Framework for Cross-Sector Collaboration. Public Management Review 7(2): |77-20।. 
Dempsey, David. 2008. "The Path to Social Justice Goes through Politics and Economics." Journal of Policy Practice 7 (2-3): 94-105.

DePree, Max. (1989). Leadership Is an Art. Doubleday.

Finn, Janet L., \& Jacobson, Maxine. (2003). Just Practice: Steps toward a New Social Work Paradigm. Journal of Social Work Education, 39(1): 57-78.

Fischer, Marilyn. (2006). The Colour of Ethics. Thoughtful Fundraising: Concepts, Issues and Perspectives, January. https:// ecommons.udayton.edu/phl_fac_pub/I53

Greenleaf, Robert K. (2002). Servant Leadership: A Journey Into the Nature of Legitimate Power and Greatness. Paulist Press.

Kidder, Rushworth. (1995). How Good People Make Tough Choices. Harper.

McCuddy, Michael K. (2008). Fundamental Moral Orientations: Implications for Values-Based Leadership. The Journal of Values-Based Leadership, I (Winter/Spring).

Mills, Ann E., \& Spencer, Edward M. (2005). Values Based Decision Making: A Tool for Achieving the Goals of Healthcare. In Hec Forum, 17:18-32. Springer.

Mintzberg, Henry. 197I. Managerial Work: Analysis from Observation. Management Science, 18(2): B-97. https://doi.org/I0.I287/ mnsc.18.2.B97

Paton, Rob, Mordaunt, Jill, \& Cornforth, Chris. (2007). Beyond Non-profit Management Education: Leadership Development in a Time of Blurred Boundaries and Distributed Learning. Non-profit and Voluntary Sector Quarterly Supplement, 36(no 4): 148S-162S.

Pervin, Aron. (1997). A Conversation with Henry Mintzberg. Family Business Review, 10(2): 185-185.

Russell, Robert F. (200I). The Role of Values in Servant Leadership. Leadership \& Organization Development Journal, 22(2): 76-84. https://doi.org/10.1108/01437730110382631

Ryan, Leo V. (2000). Moral Aspects of Executive Leadership. International Journal of Value-Based Management, 13(2): $109-22$.

Schein, Edgar H. (2010). Organizational Culture and Leadership (4th ed.). Jossey-Bass.

Spears, Larry C. (2010). Servant Leadership and Robert K. Greenleaf's Legacy. In Dirk van Dierendonck \& Kathleen Patterson (Eds.), Servant Leadership: Developments in Theory and Research (pp. II-24). Palgrave Macmillan UK. https:// doi.org/l0.1057/9780230299184_2 


\title{
DESIGNED TO INSPIRE, DISRUPT AND TRANSFORM: REFLECTIONS ON IO YEARS OF THE GRADUATE DIPLOMA IN SUSTAINABLE PRACTICE
}

\author{
Alexa Forbes and Steve Henry
}

\section{INTRODUCTION}

This article presents a personal account reflecting the experiences of the facilitators of a start up graduate programme at Otago Polytechnic (OP) New Zealand over the period 2009-2019. The Graduate Diploma Sustainable Practice (GDSP) was developed to reflect the institution's prioritisation and embedding of sustainable practice into its operations and curriculums. A previous article reflected the detail of the programmes, research and consultancy that occurred (Henry \& Forbes, 2017a). This article brings the authors' and learners' voices into a form that is evocative to offer insight into how learning was designed, delivered and experienced. Over the 10 years, the programme has transformed from exploring sustainable practice into exploring sustainable practice as a pivot point into regeneration. The programme's nature too has transformed to become generative and emergent. In this Collaborative Autoethnography, the authors seek to present an emotional account of their change of meaning over time (Bochner \& Ellis, 2016).

The authors are motivated by gaining fresh insight which can result in their improved practice as facilitators of programmes designed to inspire, disrupt and transform. The authors' curiousity stems from the following questions:

- How can disruptive programmes have a licence to operate in risk adverse insitutions?

- How can learner transformation (leaps in learning rather than incremental change) be designed for?

As we progressed through a decade of delivering sustainable practice programmes, it became more and more evident that the word 'sustainability' had become a buzz word in the general public lexicon. This led to definition difficulties, what actually is sustainability and hence sustainable practice? While this question is out of scope for this paper, it was increasingly asked over the years and led to these programmes becoming more and more reflective as people dug inside themselves to understand their connections to their natural world and their relationships as part of that world. This led to an emotional journey for many learners which is why we have taken this particular methodological path.

Following the research phase, both authors wrote individually then shared drafts ahead of merging together in this manuscript. This method was chosen because of the deep emotional journey of reflection in the shared pathway of delivering these programmes.

The article provides a narrative constructed by both authors to bring a range of aspects into consideration. This is the main body of the text. The authors' voices are indicated by their names. Learners' voices are italised and centralised. Learner voices were gathered from a survey sent to the last known email of all 78 graduates 
asking learners to reflect on their experience of the programme. Twenty responses were received. In addition, 15 people attended three focus groups. The voices were gathered from the written response and what focus group participants said. Ethics approval was gained to collect and publish these voices anonymously.

\section{CONTEXT}

In 2008, Otago Polytechnic made a 'Simple Pledge' to "embed sustainable practice into all we do" (Otago Polytechnic, 2008). At the time, this was the only public learning institution in Australasia to commit to such a pledge. In time, there was demand from business, government and communities to learn how to deliver sustainable leadership because, as OP found, the pledge might be simple, enacting it was not.

OP wanted to lead sustainable practice education so there was significant senior executive support for the new programme. Steve Henry had been employed in 2006 to lead a culture shift that would embed sustainable practice into all OP's programmes. He was co-author of the Pledge. A timely $\$ 100,000$ gift to OP to develop sustainable practice qualifications gave courage to design something very different, particularly as current efforts had not delivered sustainability education (Sterling, 200I). The focus turned to developing a programme that might inspire, disrupt and transform.

Steve: We knew incremental change in sustainable practice was not sufficient - we sought leaps and transformation. As we do not make transformative change without shifting our frames of reference (Mezirow, 1997) we knew there would be challenges. But we had a license to innovate, and were encouraged by our Chief Executive to be bolder. We knew education of a different kind was needed - one that takes us to the heart of things (Schumaker, 20II). The opportunity to embed this work in a public institution rather than private consultancy was rare. I am so glad I took it. A team designed the qualifications with learners' real projects at the centre, measured against sustainable outcomes. Projects were mapped using system thinking tools, success beyond financial was defined, then suitable strategies and action were designed, implemented and evaluated. Accurate audit tools meant learners were often painfully confronted with the knowledge that their dream project was neither socially nor ecologically sustainable. So learners faced change. What they did with that was the essence of the programme. Facilitating such a programme was exhilarating. I became programme leader. I was hooked by the possibility.

The model was designed to deliver real projects while doing research and actual consultancy work. Real projects brought by learners would work alongside national and regional projects led by the staff team. These included calculating New Zealand's Ecological Footprint, piloting biodiesel in Queenstown and facilitating community-led development amid rapid tourist growth.

The programme was articulated as a way to "gain the knowledge to promote and implement sustainable leadership in your community and workplace. Examine the social, economic, political and environmental implications of sustainability..." (Otago Polytechnic, 20I0).

This course was nothing short of life changing. What began as a career reset ended up in complete change of direction and opening of possibility.

Learning to think in systems serves me every day.

Alexa Forbes was a Queenstown-based public relations consultant initially contracted in 2010 to run a marketing campaign for a new graduate programme in sustainable practice. 


\begin{abstract}
Alexa: It was a very difficult thing to articulate although there was lots of interest, including my own. I enrolled in 2012. By 2013, I had sold my PR company and was working part time for the then Centre for Sustainable Practice delivering a community engagement contract for the Queenstown Lakes District Council using a framework for sustainable development. This was the logical extension of my student project (Henry \& Forbes, 2017b). I was eventually contracted as a programme facilitator and continued my own transformation through a Masters then a Graduate Diploma in Tertiary Education. I am contributing here as a facilitator so none of the learner comments are mine.
\end{abstract}

\title{
A DIFFERENT DESIGN
}

The programme design focused on learners customising how they wanted to use the programme. If they had a clear project in a workplace then that became the focus. If they were unsure then learners could support others' projects until they became clear. Being a peripheral observer is a powerful learning and on-boarding method (Lave \& Wenger, 1991). There were no campus classes, we gathered online. The technology wasn't great initially in 2011, but at last we could include anyone who lived anywhere. Optional learning intensives (two sessions of three days each year) provided physical connection. Some learners attended none, some all.

Steve: The fluid nature of the programme ensured learners were constantly challenged. This was intentional. A disorientating dilemma is seen as a precursor to learner transformation (Mezirow, 2000). When someone thought they had clarity there was always another layer of enquiry. The role of facilitators was to ensure a level of discomfort - to find that learning edge. When learners showed their edge to each other, it brought deeper inquiry, usually emotionally. 'Why is this project so important to me?' became the hidden curriculum. We varied the locations of intensives so we could visit each other's projects first hand and create opportunities for experiencing the unexpected.

Alexa: As a facilitator, I was learning, from Steve, from the learners, from the institution. This stage of my learning brought a dawning understanding that all learning is based in and shaped by our deep culturally informed values.

I went exploring down project rabbit holes and had to be reluctantly pulled out from them to not drown in the detail.

I began with a fixed idea and ended up in a completely different place I would never have expected... It wasn't what I was expecting. It was unconference style learning. It's what I needed.

\section{THE POWER OF RETREAT}

The creation of community on-line happened, surprisingly. It was evidenced by expressions of joy and whanaungatanga that emerged at every intensive. People who had never met in person found their relationships were in place. It was quite weird to experience. Sometimes people were very different in the flesh, sometimes exactly as expected. Again, thinking and judgement were suspect - not to be relied on. The intensives were intense. Packed with learning, full noise ako. We realised that if we could bring people together once or twice a year, we could maintain the relationships online throughout the rest of the year. Intensives were carefully planned, but included huge flexibility. The power was in giving learners control over their own explorations, our planning was mostly invisible.

Learning intensives were the juice of the programme for me - the most valuable learning at so many levels.

You are so much shorter than I imagined! 


\section{RESILIENCE IN POVERTY - EXPERIENTIAL LEARNING}

North Island learning intensives from 2012 to 2015 were intentionally held rurally in a setting with no electricity, compost toilets, simple cabin accommodation and food harvested from the land. Most participants were middle class Pākeha, so it felt like camping yet there was an important enquiry at play - could we live like this all the time? In the rain and the wind? The 10-hectare land we were based on, in Turangi, had food resilience. There were over 350 fruit and nut trees and gardens that today feed 100 kids at school every day. Lunch was "go and find it" and meet back here to share. To experience food in such abundance highlighted the truth of urban industrialized food systems more eloquently than any lecture. We cooked in steam or in a rocket stove - a type of stove with net zero carbon emissions. The generosity and trust to just go and see what you find, is rare among land owners. Awhi farm in Turangi is a remarkable piece of infrastructure for learning. Lisa Isherwood, Tüwharetoa, can track 26 generations on this land (whakapapa) which is owned by a Māori trust. There was a level of unspoken awe as those who visited glimpsed a collaborative ownership model so different from the norm.

The learning intensives at Awhi farm blew my mind.

Experiencing connection to the land and simplicity of living modelled, changed my mindset.

Awhi farm was a place of deep healing for me - it reconnected me to land.

Using a compost toilet was confronting.

I saw happiness amid material poverty so saw wealth in a new light.

I was thinking: Why are we doing weird stuff? Because it was so raw and new, it was energised. It was really quirky - challenging.

Steve: By experiencing connection through simplicity of good design of land use and food systems, learners understood the normalisation of commercialised land and food systems. We were like kids exploring a new frontier - frontiers of perspective. What initially appeared to be poverty was wealth. Paradox. I considered leaving the programme in 2013 - burn out. I spent nine months living at Awhi farm in 2013-14 as a way to cope with being. Professionally, I went from holding a narrative of "clever expert" to an "enquiring facilitator". It was such a relief to show up without the answers, but with questions. It added a lot more value to learners. This coincided in sharing facilitation on the programme with Alexa. I recognised, and moved on from, my founder's syndrome. I realised the programme could only develop if it was not dependent on me. The irony was palpable as this is what I had been saying to learners for so long - can you design your project to operate without you? I now knew the programme could operate without me.

Alexa: What is poverty? What is wealth? Once the foundation of our 'normal' land and food systems were challenged, what else could be? Everything.

\section{TE AO MĀORI}

In 20II, we had curiosity, but little true regard for Te Ao Māori. This started changing with our relationship with Awhi farm, and also as consultation with the office of the Kaitohutohu at OP became compulsory in all degree level courses. We were gently nudged toward a wider view of the world. Alexa began learning Te Reo Māori in 2015 as and when courses became available in Queenstown. In 2021, she finished her Level 5 but is still working on recognising and stripping back her colonialism. Recognising Māori has been unsettling, disorientating but ultimately enriching and grounding. We bring this to our learners, not as experts, but as learners ourselves - ngā manu hou - the new birds. Transformation is occurring to us and our community and it is based in four pou: Whanaungatanga, Manaakitanga, Kaitiakitanga and Ako. 
Whanaungatanga in our practice: Establishing community, creating an environment and practice that invites people to bring their whole selves and be present - based in Mason Durie's model of Te Whare Tapa Wha (Durie, 1998). Relationships to everything, are everything.

Manaakitanga in our practice: Upholding the mana of every individual, ensuring respect for their position. Making it safe for views to be challenged and beliefs shaken.

Kaitiakitanga in our practice: Looking after people. Guarding their rights to their feelings and values. Respect for their narratives. Being reliable and ensuring the values of the institution are upheld as learners take responsibility for their own learning. Setting up frameworks for people to explore within.

Ako in our practice: We as facilitators are not expert in our learners' learning. We support, but we also learn from learners. We learn in community, it is a social activity. We respect everyone's knowledge. Learning is shared up and down the power structure - tuakana /teina relationships. He kākano - a seed. From somewhere, full of potential to become.

Intersectional lens: looking at an issue from its systemic structures. Lenses of racism, sexism etc. We were looking at things from privilege perspective. We weren't grounded in the issues of race or other intersectional lenses.

\begin{abstract}
Alexa: "E kore au e ngaro, he kākano i ruia mai i Rangiātea" Māori whakatauki loosely translated as; I will never be lost, I am a seed descended from Rangiātea. "A long-lived overstory can dominate the forest for generations, setting the ecological conditions for its own thriving while suppressing others by exploiting all the resources with a self-serving dominance. But, all the while it sets the stage for what happens next and something always happens that is more powerful than that overstory: a fire, a windstorm, a disease. Eventually, the old forest is disrupted and replaced by the understory, by the buried seedbank that has been readying itself for this moment of transformation and renewal" (Kimmerer n.d.). I also learned from Wall Kimmerer that science is not as rational as I had been taught and the observation cannot be independent from the observer. He mihi atu ki a koe! Māori studies from Te Tiriti acquainting, through to Te Ao Māori and and Te Reo Māori - have slowly shown me how much of how/what I think, know and do is within the context of that overstory.
\end{abstract}

Steve: How naive I was and am naive regarding matters of Te Ao Māori. There is much to learn.

\title{
TRANSFORMATIONAL LEARNING
}

To support learners to think in systems and not get overwhelmed, staff invited learners to frame and reframe their projects. Key frameworks were used to measure sustainable practice or change capability. Staff introduced critical autoethnography and wayfinding as methods to map their journey of meaning-making. What am I in relationship to the chosen project and how have I changed?

The programme was set in a context of enabling change to meaning-making structures for each person. If learners were unable to drop their assumptions, the programme became challenging and confronting for them. Those learners who withdrew were generally unable to cope with the diversity of other learners or with the confrontation of their own changing narrative.

Disorientation is considered a cornerstone condition of transformational learning and how learners respond to challenges to their traditional frames of reference (Mezirow, 2000) is key to their breakthrough success. When a learner was blinded by passion for their project, there was a loss of criticality. Often the passion projects were immense, such as an audit of the sustainability of New Zealand or a suitable response to climate change or the establishment of a business. 
Steve: Some learners resisted change. They wanted learning about sustainable practice knowledge and not too much, thank you. They were catered for, yet on the whole attended fewer learning intensives and class sessions. Of the 78 graduates, approximately one in three made it clear they were there for professional change not personal change. I am not convinced one can happen without the other.

Alexa: Sustainability for me starts with the internal work of recognition and acknowledgement of values and culture. Often this includes a period of grief when the understanding of human systemic damage comes into focus. Until I understood my own ways of believing and understanding, sustainability was an external concept. Once I could allow an internalisation of sustainability, even when it contradicted other beliefs, much more became possible. Frameworks help people to operate from wherever they are, and to access true thinking while avoiding overwhelm. Frameworks also help people keep the concept externalised, if they so wish, as they head down the professional change pathway without having to peer too deeply into themselves.

The FSSD [framework for strategic sustainable development], four principles. Backcasting image.

I've brought it out over the years. If someone's struggling with something, it's easy to map the system. If someone is leaping straight to solutions, can apply this to pull them back from solutions and think stuff through.

\section{ON SKINNY DIPPING}

On a hot February day in 2012 in Wanaka, Central Otago, a group of 12 learners had spent two hours visiting a farm focused on what is now called regenerative agriculture during a learning intensive. As we drove past the lake, someone said "let's go for a swim." Within minutes, a group of women and a group of men were in the water, some wearing something and some wearing nothing. The genders were apart, together and some did not swim. There was laughter and relief at the heat.

Fast forward to 2018, in Coromandel at Karuna Falls, an intentional community of some forty years, a group of 12 learners at a learning intensive were swimming in the water hole in the February heat. Everyone wears togs and one, born and raised in that community said "this is the first time I have ever worn togs in this pool." The group had agreed to wear togs so everyone felt comfortable to participate and because the risk of offence in a formal learning programme was too high to be nude together.

Steve: These incidents may not seem a big deal, but they raise the dilemma of the behaviour of a group of adults in a formal learning community. Where does the institutional responsibility start and stop? At the time Otago Polytechnic used the 'front of the paper' test for such dilemmas - how would this look if it was presented by media in a critical light? The 2012 incident showed how casual and naive we were, the 2018 one how we made an important choice of inclusion.

Alexa: Something lost, something gained. Social and institutional norms add a layer of safety by maintaining a reliable expectation. I've learned that this is ok, because my culturally formed norms are not the same as everyone else's but it's important all situations are safe for whoever has entrusted us with their learning environment. We were unable to cater for the level of diversity we might have liked - that had to be accepted. Inclusion is a core belief of mine, but inclusion at extreme ends of norms means exclusion for others - paradox.

The retreat course in the Coromandel was one of the most significant learning experiences of my life - I had experiences that were unexpected and conversations and thought and felt in a way I had never before. 


\title{
ON ADHERING TO INSTITUTIONAL POLICY
}

The brief for the GDSP was to provide new insights into the integration of ecology with social, cultural and financial success. We believed this required a transformational mindset (Mann et al., 2017) which was not welcomed by all senior managers at the institution. One senior executive was clear that we should innovate, then act, and request forgiveness if needed. Another executive questioned the quality control yet could not argue with the learner feedback as exemplary. By 2016, an executive asked "why do we keep trusting you?" following two complaints that year from learners not getting what they expected. As a publically funded course, we were expected to take anyone who had a degree or equivalent. A willingness to change was the biggest tension and constraint to learning.

Steve: We had a trusting manager who was delighted with the programme, but knew little of the detail of learning intensives and their intentional design to challenge. A new policy of risk management for every offsite facility meant going to Awhi farm became very difficult as no building there was code compliant. What if there was a fire or earthquake? We stopped going for this reason. A small tragedy to avoid fear of a bigger one. Some learners wanted knowledge to change systems rather than being personally involved in any change, others wanted transformation as a career reset. Attempting to meet this need was difficult. We created a scale from I to 10 for those with fixed $(1)$ or flexible mindsets $(10)$. It was sad to me we could not cater for all. In 2012, we had learners from range 2 to 9 and by 2016 we realised the course could only cope with a range of 3 to 7 if it was to survive a risk averse institution.

\begin{abstract}
Alexa: An institutional level of behaviour that can be relied on makes for a safe institution. If we go outside of that, it's not safe for everyone because people rely on those levels. While it was challenging to not be in control of those levels, l've discovered that transformational learning is well possible within the boundaries of a national institution. Our job is to ensure learners have the tools and space to investigate, recognise and judge their own values and assumptions. Institutional norms are surprisingly no barrier to disorientation and transformation.
\end{abstract}

Transformational - get my own house in order first before working on the business idea. Discovery and rawness was a part of it....

[It] opened a diverse way of applying thinking.. There are many ways to apply the thinking, not just environmental. Applies to every aspect of life.

\section{THE FUTURE}

By 2016, paradoxes in the taught programme became untenable. Taught courses were too inflexible to deliver transformational outcomes - prescription was an enemy of transformation. We moved to Capable NZ - a part of OP's College of Work-Based learning where experienced practitioners unpack their learning for credit in degrees. This suited the GDSP because more transformational learning is possible when the whole qualification learning outcomes are assessed rather than individual courses (Ker, 2017) and learner-centric programming needed flexibility.

By 2021, the programme was superseded by the Graduate Diploma in Professional Practice (Sustainable Practice) which gives learners more autonomy to focus on their practice capabilities such as leadership and change rather than be over-focused on specific 'courses' that may or may not be relevant. The future is a maze of complex challenges and a programme that requires reflection and critical thinking skills builds the resilience needed to address those challenges. We recognise the need to move from passion projects of individuals to established communities of practice where learners work with stakeholders towards solving challenges. This will need a structure that helps us move people from rigid positioning and into deeper understanding that supports 
collaboration and finding unknown capability. It also needs vertical integration of courses. We are committed to bicultural expression through the programme. Working as a Treaty of Waitangi ally underpins this process.

Steve: The move to assess at whole of qualification level means learners have more autonomy in their projects. Capable NZ processes have given us a structure to work within that we can work within.

Alexa: Resilience and biculturalism are the ways of being that will serve us well into the future. We have learned much through our mistakes and the guidance of others.

\title{
CONCLUSIONS
}

We return to the earlier questions:

- How can disruptive programmes have a license to operate in risk adverse insitutions?

- How can learner transformation (leaps in learning rather than incremental change) be designed for?

For a licence to operate when pushing boundaries, there needs to be constant buy-in from all stakeholders, especially the most senior decision makers. The value and impact needs to be continuously articulated for any programmes that is pushing boundaries. Learner transformation can be designed for by moving away from assessing courses, to assessing at the whole of graduate profile outcome level.

\section{FINAL THOUGHTS}

Steve: The programme served a purpose to provide a vehicle for sustainable practice learning and to embed transformation and resilience. What a ride! I am grateful to all the learners and OP staff who have enabled such difference in a programme to have a home. Transformational learning is now business as usual in Capable NZ but there's still much to do. The professional practice suite institutionalises the transformation needed for embedding sustainable practice right through the levels of learning from Bachelors to Doctorate.

Alexa: Bring it on.

It's interesting to see things we worked on and were interested in come full circle.

We burned out on communal food initiatives [because there were so many

of them in our project lists], but now they're everywhere.

The enduring nature of the relationships formed.

\begin{abstract}
Alexa Forbes is a learning facilitator at Capable NZ and is also an Otago Regional Councillor.
\end{abstract}
(C) https://orcid.org/0000-0002-2637-6925

Steve Henry is a learning facilitator at Capable NZ at Otago Polytechnic's College of Work-based Learning. He is acting programme lead for the Bachelor of Leadership for Change and facilitates in the professional practice suite. His doctoral research is focused on learner transformation in formal vocational education.

Email: steve.henry@op.ac.nz 


\section{REFERENCES}

Bochner, A., \& Ellis, C. (2016). Evocative autoethnography: Writing lives and telling stories. Routledge.

Durie, M. (1998). Whaiora: Maori health development. Oxford University Press.

Henry S., \& Forbes, A. (2017a). Development of the Centre for Sustainable Practice at Otago Polytechnic. Scope: Learning \& Teaching, 4, 38-45. https://www.thescopes.org/assets/Uploads/cl50294686/SCOPE-LearnTeach-4-5-Henry-Forbes.pdf

Henry S., \& Forbes, A. (2017b). Creating social infrastructure for Community led development in the Queenstown lakes district. Scope: Learning \& Teaching, 4, 53-77.

Ker, G. R. (2017). Degrees by Independent Learning: A case study of practice at Otago Polytechnic, Dunedin, New Zealand. (Doctoral thesis, Middlesex University, London, UK.).

Kimmerer, R. W. (n.d.). Skywoman Falling. Emergence Magazine. Retrieved 28 November 2021, from https://emergencemagazine. org/op_ed/skywoman-falling/

Lave, J., \& Wenger, E. (1991). Situated learning: Legitimate peripheral participation. Cambridge University Press.

Mann, S., Eden-Mann, P., Smith, L., Ker, G., Osborne, P., \& Alexander-Crawford, P. (2017). A transformation mindset as the basis for sustainable community development, 59-72. Paper presented at the International Conference of the Association of Community Development, Auckland. http://www.unitec.ac.nz/epress/wp-content/uploads/2017/07/ ACDA-IACD-2017-proceedings.pdf

Mezirow, J. E. (1997). Transformation theory: theory to practice. New Directions for Adult and Continuing Education, (74), 5-12.

Mezirow, J. (2000). Learning to think like an adult. Core concepts of transformation theory. In J. Mezirow and Associates, Learning as transformation. Critical perspectives on a theory in progress, 3-34. Jossey-Bass.

Otago Polytechnic (2008). A Simple Pledge. https://www.op.ac.nz/assets/Uploads/Sustainability/47f55b760a/A-Simple-PledgeDocument.pdf

Otago Polytechnic (2010). Graduate Diploma in Sustainable Practice programme handbook. Otago Polytechnic.

Schumacher, E, (200I). Small Is beautiful: a study of economics as if people mattered. Random House.

Sterling, S. (200I). Sustainable education: re-visioning learning and change. Schumacher Society Publishers. 


\title{
EMPOWERING VOICES OF ENTREPRENEURIAL/ENTERPRISE LEADERSHIP FROM WITHIN: A LEARNING JOURNEY
}

\author{
Sandy Geyer and Jan Hendrik Roodt
}

\begin{abstract}
WARM UP
The thesis presented for investigation in this paper is that entrepreneurial and enterprise leaders of the future may be better served with early-life self-awareness interventions than by current leadership training initiatives. No assumption is held by the authors that everyone exposed to such an intervention might be headed towards a future entrepreneurial/enterprise leadership role. However, practitioner experiences suggest that self-awareness learning can be relevant to all students as a foundation for effective self-leadership through high school, diverse future career choices and in being positive influencers of others. The voices of successful practitioners are arranged alongside the proto-voices of young personas. The insights gathered through surveys and interviews are considered and the first iteration of a 'Leadership Literacy for Life' course is developed, ready for trial in New Zealand and South Africa from June 2021. Future work will use the outcomes from the trial to modify and refine the intervention for the next stage of delivery.
\end{abstract}

\section{OVERTURE}

The question that this research sets out to explore begins with the solo voice of the professional practitioner and asks "How can we better prepare our future entrepreneurial/enterprise leaders earlier in their education?"

I am an entrepreneurial leader. I was also a student leader. In my professional practice, I work daily with entrepreneurial leaders and student leaders in both New Zealand and South Africa. Through this dual-lens, I have become aware of a fundamental void between the two environments of leadership that my question seeks to illuminate. As I draw on my own experience, I am conscious that my writing is auto-ethnographic in orientation. I recognise that my solo call lacks a broader range of harmonies, with the perspective and experience of other educated and cooperative voices appropriate to the nature of the transdisciplinary enquiry, stimulated by this question. And so, "I" becomes "we" as this journey of learning begins with the insightful undertones of my research supervisors. Through deep discussion, we co-construct an appropriate learning agreement to encompass as many voices as we can to seek an educated and practical answer towards earlier empowerment of our future leaders. Our plan through the flow of the research path is to explore the conduits of our future leaders, from birth, through the traditional school structure towards an entrepreneurial/enterprise environment in which there is currently a very high failure rate in both New Zealand and South Africa (Bushe, 2019; Mansfield, 2019).

The entrepreneurial environment presents, from practitioner experience, as one which requires a strong sense of individuality (Geyer, 20I3) and creativity that the traditional school structure has not been designed to encourage or facilitate (TED, 2007). This traditional structure, as an environment of nurturing for such skills, was questioned early and rigorously by American philosopher John Dewey. Dewey described it in the early twentieth century as reflective of "traditional patterns of organisation" where "the attitude of the students must be, upon the whole, one of docility, receptivity, and obedience" (Dewey, 1997, p. 28) 
Through the development of the research strategy, three other voices in the form of student personas join Dewey's voice in the lived experience of the school structure as it remains in their reality today. A reality that requires silence in disagreement or at the most mimicking in agreement. To break their silence, the personas speak through the voice of the practitioner to narrate their first experiences of leadership within a hierarchical school structure, where the concept of leadership is mostly disclosed as transactional (Archard, 20 I2; Coffey \& Lavery, 20 8; Hine, 2014; McNae, 20 II). Jordan expresses his uncertainty about his fit to the transactional model which requires of him certain traits to uphold its hierarchical structure. He describes an uncomfortable tension between what his school structure demands of him and what his friends truly know him to be. He wonders if simply enforcing rules which he did not have any say in is really leadership. Tom openly expresses his disdain for the student leadership role towards which he has been assigned, purely as the last family member to pass through a long line of previous school leaders. He recognises the lack of any valuable learning longevity from this role designed for those not at all like himself, and he withdraws in quiet contempt. Tiffany, in her desire to please and gain recognition, embraces the role which deposits her at the beginning of her college experience with no sense of her authentic self with which to make the transition into a less structured environment, with fewer rules. Their voices, whilst uniquely different, join ours in a call to bridge the gap between their experience of student leadership, tightly bound in traditional hierarchical expectation, and the demands of a possible future enterprise/ entrepreneurial leadership role, which presents itself with no traditional boundaries whatsoever.

\section{SETTING THE STAGE - RESEARCH STRATEGY AND METHODS}

The research supervisory team turns from explorative discussion to deeper debate in consideration of an appropriate research design. A set of methodologies is considered including grounded theory, pragmatic qualitative methodology, and constructivism to expand our lens of enquiry and interpretation as we prepare to engage in the first cycle of an action research approach. With its dual aim of addressing real-world problems and improving professional practice by means of combining scholarly observations with practical interventions, we deliberate the five principles of canonical action research (Davison et al., 2004). The fourth principle of ensuring that the research is appropriately actioned to improve the client's problematic situation presents some challenges, with regards to the pragmatic assumption of the presence of a clear client, as we cross disciplines to collect our contributing voices (livari \& Venable, 2009). Who will our collective voices of enquiry be calling to?

\section{INTERLUDE - BRIEF LITERATURE CONTEXT}

If we are to build a bridge over the fundamental void that our question illuminates, we feel it is more constructive to clarify the endpoint and look first to where we are calling 'from.' The path of enquiry thus begins with the exploration of existing scholarly voices to help us understand how they have experienced, understood, and explained concepts of entrepreneurship and entrepreneurial leadership. Within the guiding framework of our research question, however, we hear only what can best be described as echoes from past academic enquiry within the vast, unstructured, and largely misunderstood spaces of entrepreneurship. The explorations included in our review appear to assume that successful entrepreneurship happens by means of an outside-in process. The notion of successful entrepreneurship is hence explored with attention to the effectiveness and replicability of systems, processes, and methods (Moroz \& Hindle, 2012). Entrepreneurial teaching methods, explored as possible ways to prepare for the diverse nature of the demands of the entrepreneurial environment too, point their focus of enquiry to processes, models, and systems to present an academically proven approach for future entrepreneurs (Neck \& Corbett, 2018; Nieuwenhuizen et al., 2016). Studies that do consider the possibility that successful entrepreneurship may be an inside-out process, seek to pursue common traits to explain success or failure with the idea that one is or is not born with entrepreneurial traits (Caliendo et al., 20ll; Kolb \& Wagner, 2015). An opposing voice points out that there seem to be more trait differences within a group of entrepreneurs than between entrepreneurs and non-entrepreneurs (Gartner, 1985). 
The continued call from researchers in the field of entrepreneurship for future research to uncover a proven process strikes a disharmony in the choir of voices we seek, and underestimates the impact of each entrepreneur as a unique individual and the nature of successful entrepreneurship as a wicked problem in a dynamic crossdisciplinary field (Crowley \& Head, 2017; Neck \& Greene, 2011; Rittel \& Webber, 1973). Entrepreneurial leadership, it is agreed though, is a relatively new concept, differing from other more traditional styles of leadership such as transactional, authoritative, and transformational leadership, and it deserves stand-alone attention as a unique form of leadership (Chung-Wen, 2008; Johnson et al., 1998). Practitioner experience in working with many entrepreneurial leaders, across diverse business sizes and industries, suggests that entrepreneurial leadership is an overarching umbrella form of leadership that encompasses many different styles of leadership to suit different circumstances and industry dynamics.

Following the literature review, our next phase of research calls for more practically experienced voices to address the nature of successful entrepreneurial leadership directly from a purposeful sample selection from the field. We choose a mixed-methods approach that seeks the combined voices of currently successful entrepreneurs in both New Zealand and South Africa by means of a wider sample from an online anonymous survey and a smaller sample of one-on-one interviews. COVID-19 acts as an unintentional context to the understood definition of 'currently successful' which requires participants to have successfully navigated the challenges of the COVID-19 pandemic, so far.

\section{THE CHOIR - SURVEY RESULTS}

Two hundred and sixteen anonymous voices speak to us through the online questionnaire designed to identify the most common sources of positive influence to their currently successful entrepreneurial leadership experience (reflected in Figure I.). There are six categories of influence tested: self-awareness; self-leadership; collaboration/social co-construction; business structure; and industry expertise. The participating voices recognise self-awareness as their highest form of positive influence (indicated below by the lowest mean score of 8.79) and student leadership experience as their lowest (indicated below by the highest mean score of 23.46). What seems significant about these voices is that they do not change in this response pattern from a small sample size of 50 to a larger sample size of 216 . Whilst the many voices from both male and female entrepreneurs from New Zealand and South Africa seem consistent, we are mindful that their views present more as a collective choral hum of agreement through a framework of enquiry, with certain assumptions, which could represent barriers to different perspectives (Patton, 20I5). We have asked them to speak with a limited vocabulary and improvisation is controlled. In the background of this study, Tom, Jordan, and Tiffany who are still voiceless, raise their heads with interest as we consider these findings. In moving to the next phase of the research the question lurks "what did we not ask in this survey?"

Figure I. Summary of the most common sources of positive influence to successful entrepreneurial leadership experience.

\begin{tabular}{|c|c|c|c|c|c|c|}
\hline 31st March 2021 & Self-Awareness & Self-Leadership & Social CC collaboration & Business Structure & Industry Expertise & Student Leadership \\
\hline Mean & 8.79 & 13.72 & 12.13 & 10.68 & 13.25 & 23.46 \\
\hline Standard Error & 0.17 & 0.30 & 0.26 & 0.24 & 0.28 & 0.45 \\
\hline Median & 8 & 13 & 12 & 10 & 13 & 24 \\
\hline Mode & 8 & 11 & 10 & 9 & 11 & 30 \\
\hline Standard Deviation & 2.45 & 4.38 & 3.86 & 3.47 & 4.06 & 6.61 \\
\hline Sample Variance & 5.99 & 19.19 & 14.94 & 12.02 & 16.50 & 43.69 \\
\hline Kurtosis & 1.50 & -0.11 & 0.71 & 8.72 & 0.49 & -0.74 \\
\hline Skewness & 0.94 & 0.55 & 0.83 & 1.80 & 0.60 & -0.20 \\
\hline Range & 14 & 21 & 20 & 29 & 21 & 28 \\
\hline Minimum & 5 & 5 & 5 & 5 & 5 & 7 \\
\hline Maximum & 19 & 26 & 25 & 34 & 26 & 35 \\
\hline Sum & 1898 & 2964.48 & 2621 & 2307 & 2860.95 & 5068.31 \\
\hline \multirow[t]{2}{*}{ Count } & 216 & 216 & 216 & 216 & 216 & 216 \\
\hline & 1 & 5 & 3 & 2 & 4 & 6 \\
\hline
\end{tabular}




\section{THE SOLO VOICES - DOCUMENTARY REFLECTIONS}

"A questionnaire is like a photograph. A qualitative study is like a documentary film" (Patton, 2015, p. 60).

Phase two of the research is qualitative and delivers the strongest, untenured voices to the research process through interviews with 20 currently successful entrepreneurial leaders. Each voice is powerful, unique, and certain of its own version of the truth. Constructivism, purposely addresses the concept of 'truth' and allows for multiple truths whilst calling to the credibility of the researcher interpretation through prolonged and persistent observation, triangulation, and negative case analysis (Miall et al., 2005, p. 145). The supervisory research team debates the experience of the practitioner as an entrepreneur, an entrepreneurial trainer and a student leadership trainer. Does this experience lend towards persistent observation or innate bias? We settle on a mix of both with the awareness of the value of ongoing self-reflection as the auto-ethnographic researcher in a unique space for experienced and insightful interpretation opportunities (Ellis et al., 20I0). Essentially the research question will direct what is included through the lens of what can be considered to be helpful in the earlier preparation of our future business leaders.

Through this question lens, the Interview participants are encouraged to explore their thinking and experiences with a set of questions both prepared and spontaneous. These questions are not related to the nature of their business but to the nature of their views of their entrepreneurial leadership journey. The practitioner's voice speaks quietly, probing to open spaces for thinking and reflection from hard-won experience as an interested observer with limited offered opinion. Some spaces are deemed comfortable by the participants and some not, but at times the silence also speaks. These voices are impactful not because they are loud but because they are free. They are free to explore their paths and they are free to construct their own realities as they wish. Strong patterns emerge as these spirited if previously isolated voices relate their stories, their experiences, their challenges, and their triumphs.

\section{UNACCOMPANIED - INTERVIEW RESULTS}

We now invite a selection of these voices to speak unaccompanied into this article. Each voice represents a successful entrepreneurial leader, captured in their raw form, to further explore our two outermost points of positive sources of influence to entrepreneurial leadership identified in the survey. Self-awareness being the highest and student leadership experience being the lowest.

"How important do you think self-awareness is to entrepreneurial leadership" is asked first, to further explore the personal feelings and experiences of the concept of self- awareness.

Voice \#4: Everything,... it's everything..

Voice \#I: I think it's huge. You know, no-one's perfect. So if you're aware of where your weaknesses lie, and you work on them, and sometimes environment will force you to work on things you don't want to do.

Voice \#2: Huge, that's critical. You've got to know where you are, first of all in terms of your thinking and then your emotional states.

Voice \#6: That's very important. Now, if you're not self-aware, and you're not self-aware enough to understand where you're going and how you're going about that, things can fall on a task very quickly.

Voice \#8: It all comes down to self-awareness, doesn't it ...

Voice \#9: Massive. I think it's one of the core principles that every entrepreneur needs is selfawareness. And to put a lot of time into it. 
Voice \# I0: Oh, god, yes. Absolutely. If you don't you die.

Voice \#II: 198\%. It's not the hard skills, it's the soft skills.

Whilst only in the early stages of analysis, it becomes obvious that these responses all reflect on three common themes. The first is that self-awareness is recognised as fundamentally important to their success. The second is that they have different interpretations of self-awareness and the third is that they felt theirs had been hardwon by experience. None of the interview participants related any experiences of having been taught about self-awareness during their formative educational years.

Voice \#18: It isn't important!

One voice does not resonate with the harmonious messages of the others. This is an unexpected response and we follow it to see where it leads. Upon further exploration, it appears that the cultural background of the participant treats the collective concept of leadership with more focus than an individual concept of leadership. Through their framing, it did not seem relevant and they did not seem to have the language for it. Further questions revealed that they did in fact have a high level of self-awareness. This striking difference in understanding of the relevance of the term indicates necessary attention to the manner in which we approach leadership training within different cultural backgrounds who chorus differently to a definition central to our enquiry. We remain mindful of the value of this voice to the pragmatic value of our research as it translates ultimately into a professional practice product.

Tom stands quietly in the shadows through the interview process but as they come to an end he is standing taller. His growing sense of self, whilst still silenced suggests that it is through these versions of himself, further down the track that he is finding his voice.

We then turn the focus of our enquiry to the area of student leadership as a positive source of influence, with the question

\section{"How did your experience of student leadership at high school help to prepare you for your entrepreneurial leadership role?"}

Voice \#3: Not at all. I think. I personally think that the education system in the world is broken. And I think that stuff that they never taught anybody in leadership they should teach in schools.

Voice \#4: Next question.......zero. So they're (the teachers) trying to teach you, you know, what you should do and all that. But truthfully, they've just, you know, they've just seen it in a picture somewhere or read it in a book.

Voice \#I: l've often seen by looking just at my own schooling career, a lot of the people that have been successful in my year, were not prefects were not head boys.

Voice \#2: So it didn't. Probably from a negative side.

Voice \#6: I learned everything about what not to do. Yeah, it was negative.

Voice \#7: Very badly. Next question?

Voice \#5: Made me tougher. Made me realise that you're not going to rely on anyone else. So it was I guess a reverse..... reverse influence if you like.

Voice \#9: I was head boy in my last year. But the, the sense of leadership when you're at high school, you know, head boy, head girl, or prefect, or whatever it is, to me now feels very fictitious and very, very staged. I didn't experience leadership at school. To me, I experienced a title and a badge. 
Voice \# 10: Not in a positive way. And yeah, they just had their views that, you know, fit in our ways, or, you know, you can beat it. I don't know how to change it, because the school system is going to take a very, very long time to change.

Tiffany and Jordan move forward now too as they listen carefully to these accounts which unwittingly echo their own thoughts, habitually buried in their journey of self-identity discovery so far. As before, they are happy for others to speak for them but they are grateful for the opening of a new dialogue.

In the early stages of our analysis, a common response theme develops quickly. The question is framed "How did your school experience help you?" which is intended to encourage a positive response as we are wary of leading any negative association. The immediate and pivotal swing from positive to negative of "it didn't" from the participants is decisive and abrupt. These responses suggest that the fundamental void identified between the two environments of leadership that our question seeks to illuminate has been experienced and navigated with difficulty by these participants.

Voice \# 19: So, you just were this ordinary person, I guess, you know, yes, worked hard and did your thing. But you didn't think that you would be that person, you know, top eight other high school. So I definitely think that almost led to me thinking I should you know, I have a little bit more to offer. And I think maybe that's what's then led me to, you know, the position that l'm in currently.

There is this one exception. One voice out of the twenty interview participants strikes a sharp and loud discord in the response pattern which to this time is harmonious. Responding to the familiarity of the term "top eight" and the location of the participating voice, a question is added which is more personal than any of the others "which school did you go to?" The same school is named that the practitioner attended as a student. Critical reflection clashes with objective observation in this moment of discourse as two versions of truth stand out clearly from what seems a similar foundation of experience. We ponder the differences. The intensity of harmonious volume from other sources of enquiry cannot sound this lone voice out though, and again we are reminded of the value of its efforts to also be heard, most critically within the mind of the auto-ethnographic researcher.

\section{MOVEMENT - INTERVENTION ONE}

With exceptions aside but under consideration at this point in the research, the united voices are sufficient to reach a crescendo of proportions suited to a professional practice intervention designed for positive change. Our question of "How do we better prepare our future entrepreneurial/enterprise leaders earlier in their education" now whispers back a suggested answer in the form of another question. What if we could lay a foundation of self-awareness early enough in their developmental years to prepare them better with an inner voice, to navigate how the concept of leadership currently structured, communicated and insisted upon by our traditional school structures influences their own self-identity and leadership identity formation? Whilst the research supervisory team idles momentarily on the practical enormity of tackling such a project within a three-year study, the voice of one of the panel assessors to the learning agreement rings out, "don't limit your expectations. A doctorate of professional practice is exactly the place to go big." And so, we do. COVID-19 has also taught us that an on-line option is needed to be practical, accessible and affordable, and from a professional practice perspective we initiate and progress the digital design by inviting in the experienced voices of e-learning development.

In the next few weeks, students from eight high schools in New Zealand and South Africa, who are currently in their first year of high school are planning to trial the 'Leadership Literacy for Life' online course. The sample schools were gained through the interest of teachers who had already joined this conversation, recognising that schools could play a greater role in the preparation of our future leaders. Jordan, Tom, and Tiffany agree that 
the voices of the students who participate in the trial might be untested and faltering, but their voices are a significant start. We will be listening carefully for the harmonies, the true notes, and the discords in what they are able to tell us.

\section{FINALE}

Through the choir of voices collected by means of this research path, we hope to call loudly and distinctly to facilitate a fresh flow of research, information, and learning resources to better prepare our future entrepreneurial/enterprise leaders in New Zealand, and South Africa.

Sandy Geyer is the founder of EnQPractice and works in the area of entrepreneurial leadership development and student leadership as a speaker and trainer in New Zealand and South Africa. She is the co-founder of Allcopy Publishers PTY Ltd, an educational publishing company, and Quickvest, a property investment company in Cape Town, South Africa. Based in Auckland, she is currently undergoing her Doctorate of Professional Practice at Capable NZ.

Email: sandy@enqpractice.com

(D) https://orcid.org/0000-0003-01/2-230।

Jan Hendrik Roodt is a transdisciplinary systems design engineer with business interests in New Zealand and Finland. He acts as postgraduate supervisor and assessor of masters and doctoral students in professional practice and applied innovation at the Otago Polytechnic and Waikato Institute of Technology in New Zealand. Based in Dunedin, he is a member of the Institute of Electrical and Electronics Engineers (Systems Council), the International Council on Systems Engineering, and Information Technology Professionals New Zealand.

(D) https://orcid.org/0000-000I-5250-8066

\section{REFERENCES}

Archard, N. (2012). Student leadership development in Australian and New Zealand secondary girls' schools: A staff perspective. International Journal of Leadership in Education, 15(I), 23-47. https://doi.org//0.1080//3603124.2011.605472

Bushe, B. (2019). The causes and impact of business failure among small to micro and medium enterprises in South Africa. Africa's Public Service Delivery and Performance Review, 7(I). https://doi.org/l0.4102/apsdpr.v7il.210

Caliendo, M., Fossen, F., \& Kritikos, A. (201 I). Personality Characteristics and the Decision to Become and Stay Self-Employed. IDEAS Working Paper Series from RePEc. http://search.proquest.com/docview/1698182369/?pq-origsite=primo

Chung-Wen, Y. (2008). The Relationships Among Leadership Styles, Entrepreneurial Orientation, and Business Performance. Managing Global Transitions; Koper, 6(3), 257-275.

Coffey, A., \& Lavery, S. (2018). Student leadership in the middle years: A matter of concern. Improving Schools, 21 (2), I87-200. https://doi.org/10.1177/1365480217732223

Crowley, K., \& Head, B. W. (2017). The enduring challenge of 'wicked problems': Revisiting Rittel and Webber. Policy Sciences, 50(4), 539-547. https://doi.org/10.1007/s II077-017-9302-4

Davison, R., Martinsons, M. G., \& Kock, N. (2004). Principles of canonical action research. Information Systems Journal, 14(I), 65-86. https://doi.org/I0.1111/j.1365-2575.2004.00162.x

Dewey, J (1997). Experience and education (Reprint Edition). Simon \& Schuster.

Ellis, C., Adams, T. E., \& Bochner, A. P. (2010). Autoethnography: An Overview. Forum Qualitative Sozialforschung / Forum: Qualitative Social Research, 12(I), Article I. https://doi.org/10.17169/fqs-12.1.1589

Gartner, W. (1985). A conceptual framework for describing the phenomenon of new venture creation. Academy of Management. The Academy of Management Review (Pre-1986), 10(000004), 696. 
Geyer, S. (2013). Path of the lion: Build your EnQ. Build your business. Allcopy Publishers.

Hine, G. (2014). Student Leadership Development: A Functional Framework. Journal of Catholic Education, 18(1), 79-110. https://doi.org/10.15365/joce.1801052014

livari, J., \& Venable, J. (2009). Action research and design science research—Seemingly similar but decisively dissimilar. $1642-1653$.

Johnson, A. M., Vernon, P. A., McCarthy, J. M., Molson, M., Harris, J. A., \& Jang, K. L. (1998). Nature vs nurture: Are leaders born or made? A behavior genetic investigation of leadership style. 8.

Kolb, C., \& Wagner, M. (2015). Crowding in or crowding out: The link between academic entrepreneurship and entrepreneurial traits. The Journal of Technology Transfer, 40(3), 387-408. https://doi.org/l 0. I007/s 10961-014-9346-y

Mansfield, M. (2019, March 28). STARTUP STATISTICS - The Numbers You Need to Know. Small Business Trends. https:// smallbiztrends.com/2019/03/startup-statistics-small-business.html

McNae, R. (20ll). Student Leadership in Secondary Schools: The influence of school context on young women's leadership perceptions. Leading and Managing, 17(2), 36-51.

Miall, C. E., Pawluch, D., \& Shaffir, W. (2005). Doing ethnography: Studying everyday life. Canadian Scholars' Press.

Moroz, P. W., \& Hindle, K. (2012). Entrepreneurship as a Process: Toward Harmonizing Multiple Perspectives. Entrepreneurship Theory and Practice, 36(4), 78I-8I8. https://doi.org/I0.1 III/j.1540-6520.201I.00452.x

Neck, H. M., \& Corbett, A. C. (2018). The Scholarship of Teaching and Learning Entrepreneurship. Entrepreneurship Education and Pedagogy, I(I), 8-4I. https://doi.org/I0.II77/25I5I274I7737286

Neck, H. M., \& Greene, P. G. (20II). Entrepreneurship Education: Known Worlds and New Frontiers. Journal of Small Business Management, 49(I), 55-70. https://doi.org/I0.1III/j.1540-627X.2010.00314.x

Nieuwenhuizen, C., Groenewald, D., Davids, J., Janse van Rensburg, L., \& Schachtebeck, C. (2016). Best practice in entrepreneurship education. Problems and Perspectives in Management, 14(3), 528-536. https://doi.org/l0.2151I/ ppm.14(3-2).2016.09

Patton, M. Q. (2015). Qualitative research \& evaluation methods: Integrating theory and practice (Fourth edition). SAGE Publications, Inc.

Rittel, H. W. J., \& Webber, M. M. (1973). Dilemmas in a general theory of planning. Policy Sciences, 4(2), I55-I69. https://doi. org/10.1007/BF01405730

TED. (2007, January 7). Do schools kill creativity? I Sir Ken Robinson [Video]. YouTube. https://www.youtube.com/ watch? $=$ iG9CE55wbtY 


\title{
EXTENDING THE PROFESSIONAL TOOLKIT: A CASE STUDY OF WORK-BASED LEARNING IN RESEARCH MANAGEMENT
}

\author{
Lesley Brook
}

\begin{abstract}
This article presents a narrative account that contextualises and captures the impact of my Master of Professional Practice research project for me, in my role as Research Projects Coordinator at Otago Polytechnic, and for my profession of research management. Narrative descriptions of research impact are used in the United Kingdom's Research Excellence Framework (Brook, 2018; Research England et al., 2019, pp. 75, 95-98), and in Australia's Engagement and Impact Assessment (Australian Research Council, 2017). Narrative accounts have also been used to construct, compare and convey meaning from the experiences of research managers working in research impact (ARMS, n.d.(a); Westerlund \& Barrett, 2020).

For my Master of Professional Practice, I undertook a work-based learning project in my role and about my institution. My research evaluated the emotional responses of 25 participants to contemporary artworks related to environmental issues which were displayed in an exhibition at my institution. This article considers the current state of my profession of research management and the specialisation of research impact practice in particular, then the contribution that my work-based learning project makes for my professional development and for research impact practice.
\end{abstract}

\section{THE PROFESSION OF RESEARCH MANAGEMENT}

Research management is an emerging professional field which has undergone considerable change in recent decades. As a result, there is no agreed set of responsibilities for the role, no agreement even on whether it is a profession yet, and no consistent nomenclature internationally (Acker et al., 2019; Agostinho et al., 2020; Bayley et al., 20 I8; Berman \& Pitman, 20 I0; Collinson, 2007; Derrick \& Nickson, 20 I4; Shelley, 2010). Despite this state of affairs, research managers can and do form their own professional identities (Acker et al., 2019; Collinson, 2007; Shelley, 2010); indeed the state of flux arguably gives them greater opportunities to develop and influence their professional identities (Acker et al., 2019).

A person's identity is their own answer to the question "who am I?", and "identity work" is the activities that people engage in that form, reinforce or influence their identity (Brown, 2015). The identities of research managers, as of other workers, can be chosen by a person for themselves or ascribed to them by others (Brown, 2015; Collinson, 2007). Research managers negotiate their identity vis-à-vis academic staff and other professional staff in their institution (Agostinho et al., 2020; Berman \& Pitman, 20I0; Collinson, 2007; Shelley, 2010). Two key factors emerge from recent literature about the identities of research managers:

I. Research managers see themselves as helping academic staff (Acker et al., 2019; Derrick \& Nickson, 2014). At Otago Polytechnic, the Research and Postgraduate Directorate, in which I work, sees researchers as our internal customers. These are mainly but not exclusively degree-teaching academic staff. 
2. Research managers serve the institution, with the result that their contribution to researchers' success is unacknowledged (Acker et al., 2019; Agostinho et al., 2020; Collinson, 2007; Derrick \& Nickson, 2014; Shelley, 2010). Our Directorate's work benefits the research reputation, academic rigour and financial position of Otago Polytechnic, which then indirectly benefits the researchers themselves.

Having a Masters or Doctorate is advantageous for the identity work of research managers, not just for the skills learned in acquiring the qualification but also for their credibility and relationships with researchers (Acker et al., 2019; Agostinho et al., 2020; Berman \& Pitman, 2010; Collinson, 2007; Derrick \& Nickson, 2014; Shelley, 20I0). Research management is becoming more professionalised. The Australasian Research Management Society (ARMS), for example, has its own conference, professional development training modules, an accreditation process, and Special Interest Groups (ARMS, n.d.(b)).

\section{WHY RESEARCH IMPACT MATTERS}

Four primary purposes for impact assessment of research in higher education and research institutions have been identified: allocation, accountability, analysis and advocacy (CSIRO, 20I8; Morgan Jones et al., 2013). The allocation of research funding is informed by prospective anticipation of the impact which the research might feasibly have, including how that might be achieved. Research impact assessment provides accountability for the use of public money, either research funding or generally for public institutions. Analysis of research impact helps maximise impact from research in the future. Research impact assessment also informs advocacy, helping researchers and institutions show what they have done and can do.

The New Zealand government is following international trends in expecting a return on its investment of research funding, a move which I have followed and supported (Brook, 2017)! After consultation, in 2019 the Ministry of Business Innovation and Employment (MBIE) released a Position Paper "The Impact of Research" which promotes robust measurement of impact based on a 'results-chain' framework. Impact is defined as "A change to the economy, society or environment, beyond contribution to knowledge and skills in research organisations" (Ministry of Business, Innovation \& Employment, 2019, p. 7).

For the Performance-Based Research Fund's Quality Evaluation round in 2018, the Tertiary Education Commission defined "Uptake and Impact," one of the range of Research Contributions recognized, as items which "provide an indication of the contribution the staff member's research has had outside of academia," and the list of examples includes "social or environmental well-being" (2018). "The 2019 review of the PerformanceBased Research Fund (PBRF) includes examining options, costs and benefits of introducing further impact measures into the PBRF" (Ministry of Business, Innovation \& Employment, 2019, p. 9).

MBIE anticipates that applying the results-chain framework will involve research institutions in the following activities:

- Articulate your institution's contribution in terms of the results-chain

- Work with MBIE towards systems that capture linkable data along the results-chain, following NZRIS [National Research Information System] common data standards

- Support researchers to plan for and increase impact from their work (Ministry of Business, Innovation \& Employment, 2019, p. II)

I I prepared a submission on behalf of Otago Polytechnic for MBIE's consultation about research impact in 2017. 
"As a steward of the research system, MBIE would like funders, researchers and research institutions to be able to confidently assess and convincingly articulate the contribution their research has made to New Zealand." (Ministry of Business, Innovation \& Employment, 2019, p. 16).

Achieving impact from our research also matters fundamentally at Otago Polytechnic because it is one of the ways in which researchers can fulfill our institution's Vision: "Our people make a better world."

\section{HOW RESEARCH IMPACT IS CHANGING RESEARCH MANAGEMENT}

As governments and other research funders increasingly expect research impact, research managers need to support researchers in their institutions to achieve and evidence impact. 'Engagement and Impact' is one of the seven 'Core Areas of Knowledge' for research managers that have been defined by the Australasian Research Management Society, the other six being: Relational, Technical, The Research Funding Cycle, Higher Degree by Research Candidature, Ethics and Integrity, and Data and Information Management (ARMS, n.d.(b); ARMS, 202I). Each Core Area of Knowledge might form separate specialised roles in research management in a large university.

My role at Otago Polytechnic encompasses a wide variety of tasks in all seven Core Areas with a particular emphasis on Engagement and Impact with and for people outside our institution. I am responsible for some outward-facing research events each year and help promote many others. I am editor of the Relevant Research magazine and raise awareness of research through social media. I maintain not only our team's webpages but also departmental research and postgraduate webpages. I have supported researchers to develop impact plans, and I run workshops and have developed resources for them to use. The professions, industries, businesses and community organisations with whom we engage are external customers for whom we hope our staff and student research has impact.

Research impact has become a specialist area for research managers internationally (Bayley \& Phipps, 2019). Those employed in research impact roles have the same issues as research managers generally, with job titles, job descriptions and professional identities, however research impact practitioners commonly experience greater precarity because fixed term roles are common if funding is dependent on grant income (Andrews et al., 2019; Lightowler \& Knight, 2013; Watermeyer \& Rowe, 2021). As a result there is no career pathway and limited investment in training and development for research impact staff (Andrews et al., 2019; Lightowler \& Knight, 2013).

It does not have to be this way. Ghent University, for example, has responded to the 'impact agenda' by establishing ten interdisciplinary consortia (IDC) which aim to achieve societal impact, with an emphasis on partnerships with non-academic stakeholders (Ghent University, 202I). An IDC Co-ordinator is associated with each consortium to drive interdisciplinary and societal impact, and, although these roles do not necessarily include any research, appointees are deemed to be high status research staff with job security and a defined career pathway (Ghent University, 2019a; Ghent University, 2019b).

Bayley and Phipps advocate for investment in 'impact literacy' for research impact practitioners, including academic researchers as well as research support staff. Impact literacy covers what, how and who: what is impact and what is evidence of impact; the "Processes and elements by which impact is achieved;" and the "Skills and people-based factors which facilitate achievement" of impact (Bayley \& Phipps, 2019). Evidence of the impact of research impact practitioners would help address the value accorded to them (Watermeyer \& Rowe, 2021). 


\section{EXTENDING MY TOOLKIT AS A RESEARCHER}

Doing my Master of Professional Practice has extended my "toolkit" as a research manager in several different ways. It has informed my understanding of the experience of our postgraduate students. Gaining a research qualification and having more published journal articles to my name will also enhance my professional identity as a non-academic staff member within a tertiary education institution, and gives me added credibility with the academic staff who are my internal customers.

I have extended my skills as a researcher, working at the intersection of many disciplines and using a methodology that was new for me (Q Methodology) in a way that has not been done before, to evaluate emotional responses to artworks after participants had experienced the original artworks. The research skills that I have developed and demonstrated in my Master's research will help me to give appropriate advice to emerging researchers at Otago Polytechnic.

I am using these improved research skills already in my role, for example informing my work on research data governance. In addition, late last year I proposed another research impact study which is now under way as part of a wider research project. I am leading a team of four School of Nursing staff to evaluate the impact of a book about rural nursing practice in New Zealand. As well as using the skills I have gained already, that project will extend me further.

\section{EXTENDING MY TOOLKIT IN RESEARCH IMPACT PRACTICE}

Bayley et al. have developed a framework of competencies for research impact practitioners (2018). By analysing four existing frameworks, they identified 80 separate competencies in 11 categories. These categories are: (I) change management; (2) communication; (3) creating, sourcing and synthesising (research) knowledge; (4) evaluating impact of knowledge transfer; (4) facilitating and negotiating; (6) leading, managing and driving knowledge transfer; (7) managing legal issues and intellectual property; (8) managing partnerships and relationships; (9) networking and engaging stakeholders; (10) training and capacity building; and (II) understanding, creating and using knowledge transfer tools, products and practices. Not all competencies will be required in all research impact practitioner roles, but this framework offers individuals "a means to develop a clearer and enhanced professional and academic identity critical skills in an increasingly professionalised domain" (Bayley et al., 2018, p. 735).

My research project for my Master of Professional Practice provided an opportunity for me to extend some of my competencies in research impact. Not all of the competencies identified by Bayley et al. were relevant. For example, my project did not include contributing to optimization of impact, being a summative evaluation of the emotional impacts. I have extended my skills in the following areas:

\section{Category: Communication}

a. Competency: Active listening, ensuring your response is tailored to the other

I met with 25 participants individually, conducting semi-structured interviews about their strongest positive and strongest negative emotional responses to the artworks. My participants also shared with me why they had particular emotional responses to the artworks, and what they thought and felt about the environment, about additional artworks and about the exhibition generally.

b. Competency: Media engagement skills

I have been interviewed about my research in a live radio show, the Arts Hub on Otago Access Radio (Forde \& Robinson, 2021).

c. Competency: Reporting and presenting knowledge

I am presenting some of my findings at a public seminar at the Dunedin School of Art. 


\section{Category: Creating, sourcing and synthesising (research) knowledge}

a. Competency: Research knowledge assessment and management: Combining organising and summarising relevant knowledge

My literature review identified interest in the contribution of art to environmental behaviour change from psychology, environmental or geographical studies, art, and sociology. Working at the intersection of the various disciplines, I have independently and critically evaluated information and ideas with a range of theoretical and empirical frameworks.

b. Competency: Capturing tacit knowledge

Q Methodology captures participants' tacit knowledge by having them sort items on a two-dimensional scale. In this study participants arranged a numbered set of 54 laminated photographs which I had taken of the artworks in the exhibition. This captured non-verbally information about the relative strength of their emotional responses, positive and negative. The strength of Q Methodology is that statistical analysis of these $\mathrm{Q}$ sorts revealed patterns in participants' emotional responses.

c. Competency: Creating new research knowledge

I also conducted semi-structured interviews, asking each participant about their strongest positive and strongest negative emotional responses (identified in the $\mathrm{Q}$ sort) and additional questions about themselves and about the exhibition. The interviews were recorded and transcribed, and participants given an opportunity to amend the transcripts.

d. Competency: Evaluating research knowledge

The interview data explained the differences between the five groups of participants that emerged from statistical analysis of the $Q$ sorts. Thematic analysis of answers to interview questions also produced rich information about the factors influencing participants' emotional responses, about how artworks can contribute to their sense of connectedness (with the environment, with other people and internally), and about how artworks could represent what participants thought and felt about environmental issues. I have interpreted and applied my findings for a range of audiences.

\section{Category: Evaluating impact of the knowledge transfer}

a. Competency: Evaluating impact of knowledge transfer strategies and approaches

The knowledge transfer strategy which I was evaluating was a public exhibition of about 60 contemporary environmental artworks by 48 different artists, held at the Dunedin School of Art.

b. Competency: Planning impact pathways

From my reading and from discussions with lead curator Bridie Lonie, I gained an understanding of how art might achieve behaviour change through emotional engagement, which informed the research design both with respect to the choice of Q Methodology and the questions to ask participants.

\section{Category: Managing partnerships/relationships}

a. Competency: Stakeholder communications: coordinating regular communications to link groups with information relevant to their current topic of interest

I have sent participants a link to the podcast of the radio show and will invite them to the Dunedin School of Art seminar. I will also send copies of journal articles about my research to the artists whose artworks feature in photographs accompanying those articles.

b. Competency: Developing and maintaining professional relationships

My relationship with exhibition curator Bridie Lonie has been critical to this project. I needed to do my own research but evaluate the extent to which the exhibition meets her goals for it. As this was a work-based learning project, I also needed and benefitted from my line manager's support. 


\section{Category: Networking and engaging stakeholders}

a. Competency: Making contacts with the (right) people

With ethics approval from the Capable NZ Research Ethics Committee, I engaged with visitors to the exhibition, inviting them to participate in my research. Two participants I approached afterwards, having seen them at the exhibition, and one approached me afterwards, having heard of my research project. Individual meeting times were arranged with each person at mutually convenient times and locations.

\section{Category: Understanding, creating and using knowledge transfer tools, products and practices}

a. Competency: Practical application of knowledge mobilization/knowledge transfer tools, techniques and frameworks

I described the inputs, activities, outputs, outcomes and impacts from this exhibition in a logic model. The emotional impact of the exhibition, evaluated within two weeks of the exhibition closing, is an outcome which it is hoped will support environmental behaviour change as a longer term impact.

b. Competency: Sector-specific application: applying knowledge to improve processes and outcomes in a specific field

I have learned more about how art emotionally engages viewers, which will help me to support artists and curators to achieve and to evidence impact from their creative research outputs. This will help position the Dunedin School of Art at Otago Polytechnic within a new national framework for vocational education that focuses on employers' needs rather than self-employment for graduates (Tertiary Education Commission, 202I), and within a national research system that places "a significant focus" on commercial benefits for New Zealand (Ministry of Business, Innovation and Employment, 20 I5).

My experience suggests that work-based learning can be an effective tool for professional development for research managers, to build impact literacy competencies.

\section{EXTENDING THE RESEARCH IMPACT TOOLKIT FOR RESEARCH MANAGERS}

Assessment of the impact of arts research is particularly challenging (Belfiore \& Bennett, 2007; Johanson \& Glow, 2015; Westerlund \& Barrett, 2020). The results of my research will inform research impact assessment internationally, by contributing to increased understanding of what impact art has and how. My research into the emotional effects of artworks contributes valuable insights because I assessed the impact of many artworks by various artists in a curated exhibition rather than of a single artwork. By shedding light on the factors influencing participants' emotional response to artworks, and how the artworks contributed to connectedness and represented their thoughts and feelings about the environment, my research improves understanding of how artworks emotionally engage and hence informs research impact planning and assessment. These results are relevant to artists, curators and arts managers as well as research managers, and are being published in other articles and conferences.

My research will also inform research impact assessment because of the novel use of Q Methodology with artworks. Q Methodology has been used with images to measure emotional responses ( $O$ 'Neill et al., 2013; Schultz et al., 20I8; Sleenhoff et al., 2015) and with statements to measure emotional responses to art (Burke et al., 2018). It has been used with images of artworks (Beck, 2017; Gauzente \& Good, 2019; Stephenson, 1936), but my research is unique in using $Q$ Methodology with images of artworks to evaluate emotional responses to artworks after participants have seen the original artworks.

One of the challenges in assessing the impact of the arts is that audience members feel a sense of responsibility to show appreciation, which makes it difficult to elicit negative responses (Johanson \& Glow, 2015). My study asked about negative as well as positive emotional responses, and revealed a difference amongst participants in 
their perception of their negative emotional responses. Boredom with some artworks was a negative emotional response, and some reported other negative emotions as a positive experience because the artworks moved them. Participants also commented negatively as well as positively when asked about the whole exhibition. My study therefore adds another valuable tool for the assessment of the impact of arts research, by demonstrating that Q Methodology can successfully be used in this context to show patterns of responses amongst participants and to elicit negative responses.

\section{CONCLUSION}

This article has focused on the impact of my work-related research project for me and for my profession of research management. My research has been a significant opportunity for professional development for me as a researcher, research manager and research impact practitioner. I have a new understanding of my profession, to which I now feel I belong. My own research makes a valuable contribution to my profession with respect to the evaluation of the impact of art research.

I have also gained a greater sense of appreciation of the value of the research ecosystem in which research managers work. This ecosystem includes researchers, for example Caro McCaw's suggestions that I submit to a particular conference, non-academic staff, for example Paula Petley who advised me about such practical matters as laminating and transcription, and other research managers like Esther de Smet at Ghent University. My learning journey as a research manager will continue with the next research impact project, which I have already embarked upon.

\section{ACKNOWLEDGEMENTS}

I would like to thank my supervisors, Martin Andrew and Glenys Forsyth, who have encouraged and challenged me as I renegotiated my professional identity. Thank you Bridie Lonie for entrusting me with this research project, and Leoni Schmidt for your support for my Master's. Thanks too to the many other members of the research ecosystem who have encouraged me.

Lesley Brook is Research Projects Coordinator in the Research and Postgraduate Directorate at Otago Polytechnic. Her research interests are in the impact of research beyond the academic community.

Email: lesley.brook@op.ac.nz

(D) https://orcid.org/0000-0001-6678-5179

\section{REFERENCES}

Acker, S., McGinn, M. K., \& Campisi, C. (2019). The work of university research administrator: Praxis and professionalization. Journal of Praxis in Higher Education, I(I), 6I-85.

Agostinho, M., Moniz Alves, C., Aresta, S., Borrego, F., Borlido-Santos, J., Cortez, J., Lima Costa, T., António Lopes, J., Moreira, S., Santos, J., Trindade, M., Varela, C., \& Vidal, S. (2020). The Interface of Science: The Case for a Broader Definition of Research Management. Perspectives: Policy and Practice in Higher Education, 24(I), 19-27. https://doi.org/l0.1080/I3603 108.2018.1543215

Andrews, H., Noble, M., \& Dunleavy, K. (2019). The emergence of the publicly engaged research manager. Research for All, 3(I), 105. https://doi.org//0.18546/RFA.03.1.09 
ARMS. (n.d.(a)). 2020 Research Impact Case Studies. Retrieved May 29, 2021, from https://www.researchmanagement.org. au/2020-research-impact-case-studies

ARMS. (n.d.(b)). ARMS Professional Development. Retrieved May 29, 2021, from https://www.researchmanagement.org.au/ professional-development

ARMS. (2021). Program Guide, ARMS Foundation Level Accreditation Program. https://www.researchmanagement.org.au/ sites/default/files/uploaded-content/website-content/arms_foundation_level_accreditation_program_brochureupdated_20_april_2021.pdf

Australian Research Council. (2017). El 2018 Framework.

Bayley, J., \& Phipps, D. (2019). Building the concept of research impact literacy. Evidence \& Policy, 15(4), 597-606. https://doi. org/10.1332/174426417X15034894876108

Bayley, J., Phipps, D., Batac, M., \& Stevens, E. (2018). Development of a framework for knowledge mobilisation and impact competencies. Evidence \& Policy, 14(4), 725-738. https://doi.org//0.1332/174426417X14945838375124

Beck, P. D. (2017). Using Works of Art to Give a Voice to Culturally Diverse Students: Q-Methodology Study. Journal for Leadership and Instruction, 16(2), 18-25.

Belfiore, E., \& Bennett, O. (2007). Determinants of Impact: Towards a Better Understanding of Encounters with the Arts. Cultural Trends, 16(3), 225-275. https://doi.org/I0.1080/09548960701479417

Berman, J., \& Pitman, T. (2010). Occupying a 'third space': Research trained professional staff in Australian universities. Higher Education, 60(2), I57-169. https://doi.org/10.1007/s10734-009-9292-z

Brook, L. (2017). Assessing Research Impact Beyond Academia: A New Zealand Introduction. Scope (Learning \& Teaching), 3, 55-67.

Brook, L. (2018). Evidencing Impact from Art Research: Analysis of Impact Case Studies from the REF 20I4. The Journal of Arts Management, Law, and Society, 48(I), 57-69. https://doi.org/10.1080/10632921.2017.1386148

Brown, A. D. (2015). Identities and identity work in organizations. International Journal of Management Reviews, 17, 20-40, https://doi.org/10.1 III/ijmr.12035

Burke, M., Ockwell, D., \& Whitmarsh, L. (20I8). Participatory arts and affective engagement with climate change: The missing link in achieving climate compatible behaviour change? Global Environmental Change, 49, 95-105. https://doi.org/I0.1016/j. gloenvcha.2018.02.007

Collinson, J. A. (2007). "Get yourself some nice, neat, matching box files!" Research administrators and occupational identity work. Studies in Higher Education, 32(3), 295-309. https://doi.org/I0. I080/0307507070I346832

CSIRO. (20I8). How CSIRO ensures it delivers impact.

Derrick, G., \& Nickson, A. (2014). Invisible Intermediaries: A Systematic Review into The Role of Research Management in University and Institutional Research Processes. Journal of Research Administration, 45(2), II-45.

Forde, B., \& Robinson, T. (2021, April 8). Lesley Brook's Research. In Arts Hub. Otago Access Radio. https://accessmedia.nz/ Player.aspx?eid=2f3c07a0-06e8-4a08-888c-0a4d0।4b8299

Gauzente, C., \& Good, J. M. M. (2019). Q Methodology, William Stephenson and postdisciplinarity. In T. Pernecky (Ed.), Postdisciplinary knowledge (pp. 165-182). Routledge.

Ghent University. (2019a). Portfolio for the Evaluation of IDC Co-ordinators.

Ghent University. (2019b). Regulations of Ghent University for IDC Co-ordinators.

Ghent University. (2021, May 20). Interdisciplinary research consortia aimed at realising societal impact. https://www.ugent.be/ en/research/science-society/idc/overview.htm

Johanson, K., \& Glow, H. (2015). A virtuous circle: The positive evaluation phenomenon in arts audience research. Participations: Journal of Audience \& Reception Studies, 12(I), 254-270.

Lightowler, C., \& Knight, C. (2013). Sustaining knowledge exchange and research impact in the social sciences and humanities: Investing in knowledge broker roles in UK universities. Evidence \& Policy, 9(3), 317-334. https://doi. org/l0.1332/174426413X662644

Ministry of Business, Innovation \& Employment. (2019). The Impact of Research. https://www.mbie.govt.nz/dmsdocument/6983the-impact-of-research-position-paper-october-20I9-pdf\#: :text=In\%20this\%20paper\%2C\%20MBIE\%20 introduces,stages\%20leading\%20to\%20research\%20impact

Ministry of Business, Innovation and Employment. (2015). National Statement of Science Investment 2015-2025. https://www. mbie.govt.nz/assets/2eaba48268/national-statement-science-investment-20I5-2025.pdf 
Morgan Jones, M., Castle-Clarke, S., Manville, C., Gunashekar, S., \& Grant, J. (20 I3). Assessing Research Impact: An International Review of the Excellence in Innovation for Australia Trial. RAND Europe. https://www.rand.org/pubs/research_reports/ RR278.html

O'Neill, S. J., Boykoff, M., Niemeyer, S., \& Day, S. A. (2013). On the use of imagery for climate change engagement. Global Environmental Change, 23(2), 413-421. https://doi.org/10.1016/j.gloenvcha.2012.11.006

Research England, Scottish Funding Council, Higher Education Funding Council for Wales, \& Department for the Economy, Northern Ireland. (2019). Guidance on submissions REF 2019/01.

Schultz, T., Fielding, K., \& Newton, F. (2018). Images that Engage People with Sustainable Urban Water Management. Science Communication, 40(2), 199-227. https://doi.org/10.1177//075547018760902

Shelley, L. (2010). Research Managers Uncovered: Changing Roles and 'Shifting Arenas' in the Academy. Higher Education Quarterly, 64(I), 4I-64. https://doi.org/I0.1 III/j.1468-2273.2009.00429.x

Sleenhoff, S., Cuppen, E., \& Osseweijer, P. (2015). Unravelling emotional viewpoints on a bio-based economy using Q methodology. Public Understanding of Science, 24(7), 858-877. https://doi.org/l0.1177/09636625/351707|

Stephenson, W. (1936). The Inverted Factor Technique. British Journal of Psychology. General Section, 26(4), 344-361. https:// doi.org/l0.1III/j.2044-8295.1936.tb00803.x

Tertiary Education Commission. (2018, April). Performance-Based Research Fund Guidelines for tertiary education organisations participating in the 2018 Quality Evaluation.

Tertiary Education Commission. (2021, March 31). Reform of Vocational Education (RoVE). https://www.tec.govt.nz/rove/ reform-of-vocational-education/

Watermeyer, R., \& Rowe, G. (202I). Public engagement professionals in a prestige economy: Ghosts in the machine. Studies in Higher Education (Dorchester-on-Thames), I-14. https://doi.org/I0.1080/03075079.2021.1888078

Westerlund, H., \& Barrett, M. (2020). Narrating arts education research impact in and through research policy: Affordances and constraints for professional transformation. Arts Education Policy Review, I-13. https://doi.org//0.1080//06329/3.2 020.1811819 


\title{
“A REALLY IMPORTANT ROLE”: USING A PARTICIPANT- VOICED POEM TO EXPLORE STUDENTS' EXPRESSION OF SOCIAL WORK'S PROFESSIONAL IDENTITY
}

\author{
Mandy Pentecost and Karlin Austin
}

\section{INTRODUCTION}

This paper takes a creative writing approach (Phillips \& Kara, 2021) to focus on a secondary issue arising out of research conducted in 2019. The research used focus groups to explore the experiences of social work students in fieldwork placements, within an interdisciplinary team (Austin \& Pentecost, 2020). The secondary issue discussed here relates specifically to how the observation of social work practice in the 'real world' interacts with and affects the students' emerging sense of professional identity. The focus group conversations in the initial research demonstrated that the students displayed a mixture of idealism and pragmatism. They had observed and participated in a range of team settings in which social workers played a role, and they reported that the roles both assigned to and claimed by social workers varied across the teams. Some students had been placed with high-functioning interdisciplinary teams where they felt the contribution of social work was both understood and valued. Some of the students were somewhat disillusioned with what they had experienced, especially when the roles they saw available for social workers to occupy seemed at odds with what they had been taught.

A number of them were eloquent and articulate in communicating their understanding of the role, work and ethical orientation of social work. Lecturers in the School of Education and Social Sciences at the Eastern Institute of Technology (EIT) involved in teacher and social work education have long grappled with the probability that students in work placements will observe some less than optimal practice, and have worked hard to mitigate this. That students are also observing the ways others see and treat members of their future profession is inevitable in practicum placements. The paper outlines how re-analysing the original data with a different lens and methodology created new insights about the students' processing of their experience.

\section{CONTEXT}

Initial undergraduate education provides an induction into a profession's values and to the work of that profession. Classroom-based and workplace-based learning provide two sites for the development of professional identity. Liddell et al. found that while skills development and theory was more likely to be attributed to classroom learning, practicum was vital in "helping participants understand the institutional culture and political landscape of a workplace" (2014, p.78).

Students' pre-practicum positive enthusiasm about their future role is not always balanced with an understanding of the complex realities of the workplace (Beltman et al., 2015). Social workers who supervise students in workplace practicums are likely to view the real world setting as the site where students "actually acquire their identity as social workers" (Shands-Baab, 2008, p. 154). This view is endorsed by students (Shands-Baab, 2008). 
In writing about student teachers in practice-based education, Trede and McEwen (20I2) argue that "identity is knowing what one stands for" (p.30) and suggest that practicum placements provide a crucial opportunity for students to develop a critical professional identity. Placements are a site for them to try out their "possible or imagined future professional identities" (Haines, 2015, p.30), based on their developing understanding of the work of their profession.

The EIT social work programme is imbued with the two foci for social work practice, as defined by the Aotearoa New Zealand Association of Social Workers (ANZASW). These are:

(i) To enable and empower individuals, families, groups and communities to find their own solutions to the issues and problems they face;

(ii) To inform society at large about the injustices in its midst, and to engage in action to change the structures of society that create and perpetuate injustice (ANZASW, 2019, p.7).

They further assert that practice that has only the first focus may lead to imposing solutions on others, if it does not seek to identify and address injustice.

It had been an uncomfortable experience for the focus group facilitator in the original research project to hear words like "minimised" and "diminished" in some of the students' descriptions of the ways they saw social work and social workers positioned during their placements. In some cases, the opportunities they were seeing for social work practice seemed constrained and limited, and not fulfilling both foci of finding solutions and acting for social justice. We wondered what a revisiting the interview data might tell us about how someone on the cusp of entering a profession makes sense of what they see and fits it into their conceptualising of what it is to be a member of that profession.

\section{METHOD}

The data re-analysed for this article was collected during 2019 for the project investigating how social work students on placement experienced the positioning of social workers within a district health board setting (Austin \& Pentecost, 2020). The research was approved by ElT's Research Ethics Approvals Committee (reference 19/30), and supported by an EIT internal research grant. It involved focus group interviews with thirdand fourth-year social work students who had been on a sixty-day practicum in a District Health Board. All such students were invited to take part in the research by a person who did not teach on their programme. Of eight invited, a total of six students participated in the focus groups. The interviews were recorded, transcribed and thematically analysed to investigate the initial research question. Four main themes emerged: organisational and systems pressures; the different operations of multi-and inter-disciplinary teams; the positioning of social work within the medical model; and the importance of the social worker's articulation of their role. From these, we drew implications for social work education (Austin \& Pentecost, 2020).

We decided to re-engage with the data to explore a new focus of developing professional identity. Using a poetic approach to the recorded conversations, one researcher drew out phrases and sentences to produce a "participant voiced" poem (Phillips \& Kara, 2021, p. 127). Some of the phrases and sentences students said were re-arranged to produce an evocative composite account of the ways they talked about their experience and the impacts it had on their ideas about social work practice. This produces a found poem, one that is composed using the exact words participants said, but chosen and arranged by the researcher (Patrick, 2016; Richardson, 2000). Within the practice of narrative therapy, such poetic re-presentation of spoken words is known as a "rescued speech poem" (Behan, 2003), and the practice has migrated from therapy to research (Pentecost, 2006; Speedy, 2008). 
The interview transcripts were re-read may times, taking excerpts that Bird (2000) calls "talk that sings" and ultimately rearranging them, with no additional words, into a stanza form. The resulting poem produced a reading of the conversations which captured one researcher's sense of what the participants said about the professional activities and identity of social workers, the profession, and their own growing allegiance with its ethos. Successive drafts of the poem were reviewed by the second researcher, whose suggestions were incorporated into further iterations of the poem. One email had the subject line "Poem version 77", only slightly exaggerating the amount of playing about with word choice, placement, order and line length involved.

Presenting the words in a poetic rather than prose format makes the shaping hand of the researcher apparent: this is a re-presentation of the research data, obviously filtered for meaning by the researcher (Richardson, 2000). It is argued that poetic presentation of data allows for a more open-ended interpretation and representation of what was said (Behan, 2003), and that new insights into the data become possible through the process of presenting prose in a poetic format (Richardson, 2000). The production of a poem from the students' words opened a different window on the data and the students' experience for us as researchers. As Patrick (2016) and Richardson (2000) assert, poetic presentation both invites a different emotional response to material presented in prose, and allows us to see things anew. Our understanding of the student's feelings of disheartenment and diminishment was shifted in the process of carefully shaping some of their words into this format.

The findings are produced below as a poetic document, and aspects of the poem (in italics) are then linked in the Discussion section to the ANZASW Code of Ethics (2019) and to literature about professional identity and the social work role.

\section{I'm going to do that one day.}

Social workers are quite good at creating

a picture that takes into account

a lot of different things in a person's life:

the environment, history and upbringing, financial stuff.

All the different things that make up how someone might be in that situation now.

That's just because we have a different lens that we come from,

using things like the family system theory, and the ecological system theory.

All that kind of stuff gives us

a slightly different perspective to bring to the table, and

highlight different things.

We look at it from a wider view,

take in the whole context of

everything.

Don't see just the person and them being sick -

see their context, their family, and what's going on,

why they can't get to treatment,

why they've fallen through the gaps,

why they're not engaging.

How to then get them engaged. 
A definite big advocate role for the social worker.

How resourceful this particular social worker was, within her mahi,

and how fast it was and

important to those people.

It was their choice,

respecting people's choice, and their own self-determination

in what they want to do.

It's hard road for a social worker to gain respect...

Especially in the medical model I'm saying,

because in the hospital I saw it was just like a big machine,

and the social workers were more or less greasing the box.

I witnessed social work being minimised quite a lot

It gets diminished in other teams. It gets,

"Well, you're just there for

housing,

you're there for

finance."

You'll then make phone calls - basically you're the

receptionist.

When you see the social workers that you're working with

doing such an amazing job with people,

to then see in the next breath

someone diminish that work that they're doing,

to a chat

it's quite disheartening.

Yeah, have a chat, and that kind of thing.

You'd have quite a good chat!

We're just in study for four years to have a chat?

When it worked really well it was a really important role.

Things like the doctors understood that

the social worker will ensure that person attends the appointments,

and is living well enough that they can maintain the treatment plan.

They don't just see us as "just the social worker".

They see us as important people

in the roles that we play in their clients' lives,

and lives of people we see.

That was just really cool to see.

I'm like, 'I'm going to do that one day'. 


\section{DISCUSSION}

The students' words embodied "the dual focus" (ANZASW, 2019, p.7) of social work, empowerment of clients and addressing injustice. In line with the Code of Ethics (ANZASW, 2019), the students know that social work is about "respecting people's choice, and their own self-determination in what they want to do." And they also acknowledge that social work is concerned with systemic inequalities: that social workers "Don't see just the person and them being sick - see their context, their family, and what's going on, why they can't get to treatment, why they've fallen through the gaps, why they're not engaging."

Beddoe (2013, p.24) noted that social workers in a health setting "often argue that they must be professionally assertive in order to keep their values afloat in a stormy sea of change." The student participants in this project certainly observed that the ways social work role was carried out and given space varied in its allegiance to the social justice aspects of the profession. The position accorded social work ranged from high respect for the social worker's opinions and networking and advocacy skills ("Things like the doctors understood that the social worker will ensure that person attends the appointments, and is living well enough that they can maintain the treatment plan"), to expecting them to perform only administrative, and referral-related tasks ("Well, you're just there for housing, you're there for finance." "You'll then make phone calls - basically you're the receptionist"). The literature on the role of social work within interdisciplinary teams certainly supports this variation in the space available for performing the dual foci of the profession (Zerden et al., 2019; Ashcroft et al., 2018; Peterson et al., 2018). Peterson et al. (20I8, p.688) found, for example, that "other members of the multidisciplinary teams viewed the roles of social workers to be focused on being a conduit and coordinator".

It would seem that distinguishing the social work role as "diminished... to a chat" or to "receptionist" was possible for the students because of their clear grasp of the profession's claimed identity and functions, thereby enabling them to judge when it is not afforded space to carry out its vision. Liddell et al.'s (2014) finding that experiencing institutional politics is more influential than talking about them seems to be borne out by these students' observations about the way the hospital system functioned ("a big machine"), and the distinctions they drew between teams where social workers made a holistic contribution and those where they performed more constrained administrative roles. They could identify the "really important role" that "creat(es) a picture that takes into account a lot of things in a person's life."

\section{CONCLUSION}

The words we have captured in this poem demonstrate that these students have what Trede and McEwen (2012, p.29) characterise as the ability to "think for themselves, question and engage in dialogue so that they can claim control of their professional journey." That the participants were able to articulate a clear vision of social work "when it worked really well" implies that they may carry into multi- or inter-disciplinary teams the necessary assertion to create conditions for social work's unique contribution to a team to be valued (Beddoe, 20l3). They understand and value what the "different lens that we come from" can contribute to a healthcare team. They appreciate that the work of their profession must be based in theory (ANZASW, 2019), for example, "using things like the family system theory, and the ecological system theory". They value their education, and do not want to see social work's unique contribution constrained or diminished: "We're just in study for four years to have a chat?" Despite the "disheartening" effects of seeing "social work being minimised quite a lot", their intention is to step fully into the profession's dual focus. They aim to emulate the practice of those they observed doing so: "That was just really cool to see. I'm like, 'I'm going to do that one day'." 
Mandy Pentecost is assistant head of the School of Education and Social Sciences at the Eastern Institute of Technology, and a counsellor registered with New Zealand Association of Counsellors. She likes to bring her interest in poetry and creative writing into her research projects.

Email: MPentecost@eit.ac.nz

[D https://orcid.org/0000-0002-7038-981।

Karlin Austin is a Registered Social Worker and lecturer on the Bachelor of Social Work programme at the Eastern Institute of Technology, Hawkes Bay. She has extensive experience in the health sector where she has managed small to large interdisciplinary teams in both government and non-government organisations across New Zealand.

\section{REFERENCES}

Aotearoa New Zealand Association of Social Workers (ANZASW). (2019). Code of Ethics. https://anzasw.nz/wp-content/ uploads/Code-of-Ethics-Adopted-30-Aug-2019.pdf

Ashcroft, R., McMillan, C., Ambrose-Miller, W., McKee, R., \& Brown, J. B. (2018). The emerging role of social work in primary health care: A survey of social workers in Ontario Family Health Teams. Health \& Social Work, 43(2), 109-117. https:// doi.org/l0.1093/hsw/hly003

Austin, K., \& Pentecost, M. (2020, September 24-25). Earning your place in the world: Social work students' perceptions of the positioning of social work in interdisciplinary teams. [Paper presentation]. ITP Research Symposium, Rotorua, New Zealand.

Beddoe, L. (2013). Health social work: Professional identity and knowledge. Qualitative Social Work, 12(I), 24-40. https://doi. org//0.1177//4733250/1415455

Behan, C. (2003). Rescued speech poems: Co-authoring poetry in narrative therapy. http://www.narrativeapproaches.com/ rescued-speech-poems-co-authoring-poetry-in-narrative-therapy/

Beltman, S., Glass, C., Dinham, J., Chalk, B., \& Nguyen, B. (2015). Drawing identity: Beginning pre-service teachers' professional identities. Issues in Educational Research, 25(3), 225-245. http://www.iier.org.au/iier25beltman.html

Bird, J. (2000). The heart's narrative. Edge Press.

Haines, K. (2015). Imagining oneself: Narrative evaluations of the professional identities of learners in a transnational highereducational setting. Learning and teaching, 8(I), 30-49. https://doi.org//0.3167/latiss.2015.080103

Liddell, D. L., Wilson, M. E., Pasquesi, K., Hirschy, A. S., \& Boyle, K. M. (2014). Development of professional identity through socialisation in graduate school. Journal of Student Affairs Research and Practice, 5/(I), 69-84. https://doi.org/I0.15/5/ jsarp-2014-0006

Patrick, L. (2016). Found poetry: Creating space for imaginative arts-based literacy research writing. Literacy research:Theory, Method and Practice, 65(I). https://doi.org/I0.1177/23813369/6661530

Pentecost, M. M. (2006). The co-production of a literary therapy. [Unpublished Masters thesis]. The University of Waikato.

Peterson, E. B., Chou, W.-Y. S., Falisi, A., Ferrer, R., \& Mollica, M. A. (2018). The role of medical social workers in cancer clinical trial teams: A group case study of multidisciplinary perspectives. Social Work in Health Care, 57(8), 688-704. https://doi. org/l0.1080/00981389.2018.1477899

Phillips, R., \& Kara, K. (2021). Creative writing for social research: A practical guide. Policy Press.

Richardson, L. (2000). Writing: A method of inquiry. In N. K. Denzin \& Y. S. Lincoln (Eds.), Handbook of qualitative research. (2nd ed., pp. 923-948). Sage.

Shands-Baab, C. (2008). Professional identity development among graduate students during the field practicum. [Unpublished Doctoral thesis] Loyola University.

Speedy, J. (2008). Narrative inquiry and psychotherapy. Palgrave Macmillan.

Trede, F., \& McEwen, J. (2012). Developing a critical professional identity: Engaging self in practice. In J. Higgs, R. Barnett, S. Billet, M. Hutchings, \& F. Trede (Eds.), Practice-based education: Perspectives and strategies (pp. 27-40). Brill.

Zerden, L. D., Lombardi, B. M., \& Richman, E. L. (2019). Social workers on the interprofessional integrated team: Elements of team integration and barriers to practice. Journal of Interprofessional Education \& Practice, 17, 100286. https://doi. org/l0.1016/j.xjep.2019.100286 


\section{MY MAHI TOI}

\section{Kathryn Wright}
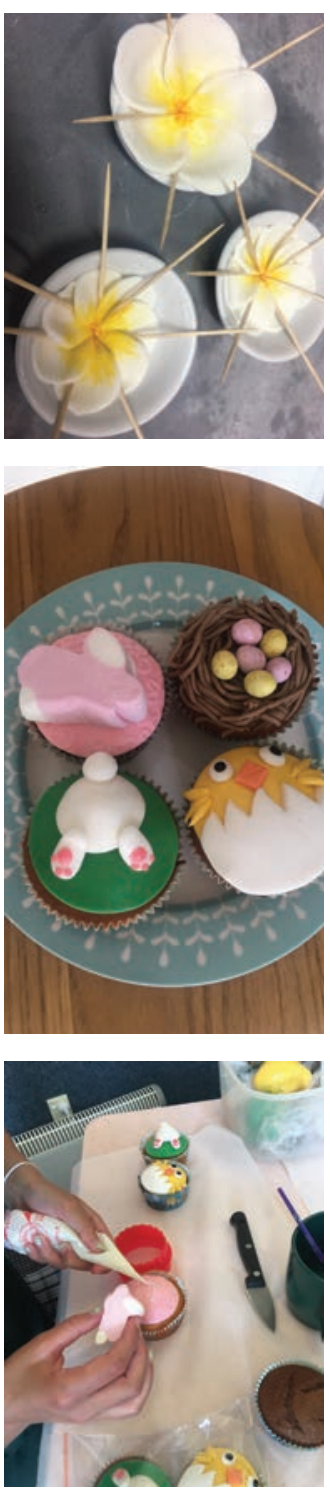

I am creative. I am patient. I teach. I am a writer. I am a counsellor. Some days, all of these things collide.

I work a 4 position as a guidance counsellor at Northern Southland College in Lumsden, one day a week at Te Anau School, and one day privately with adults in Te Anau. Before I went back to study, I was a professional cake decorator - I had a small mobile commercial kitchen placed at my home on our deer farm. You name the theme, I have made a cake to match. Probably several. Cake decorating is an art form and luckily I was never in it to get rich, as l'd be waiting a long time.

I stopped that career to study - a double degree in psychology and sociology with Massey, followed by a bachelor of social services (counselling) with Otago Polytechnic. The cakes were cast to the domain of only my own children's' cakes and the odd close friend or sometimes a charity raffle. That was six years ago, yet I still field enquiries.

Fast forward to actually working in the real world with children and young people. I knew that it was usual to bring some kind of art or craft into the counselling room - for many reasons - keeping hands busy and allowing the talk to flow, helping the client achieve completion of a project and conversing/ exchanging communication are some of the obvious ones. I am a creative soul anyway. I have always painted, created things, written poetry and other pieces of writing, and I have many happy childhood memories of being surrounded by art and craft supplies on a rainy day - it was real feeling of safety and satisfaction. So this practice came somewhat naturally to me.

During my Otago Polytechnic/Capable journey, I enlisted a wonderful cultural supervisor, Graham Green from Oamaru. Somehow we got talking about my old career, and Graham said suddenly: "Well why don't you incorporate your cake skills in the counselling room? It's like your harakeke weaving!" I had never considered this before. Why hadn't I? The art of making gum paste flowers was something that I had mastered, it was something that people are interested in - I could try it. During my graduation presentation with Capable, I demonstrated the making of gum paste roses in a way that symbolised my journey - starting off as a simple but formed bud, taking on layers of information (petals) and experimenting with different modalities (flowers), and how imperfections and irregularities make up who I am as a counsellor (fully formed rose). 

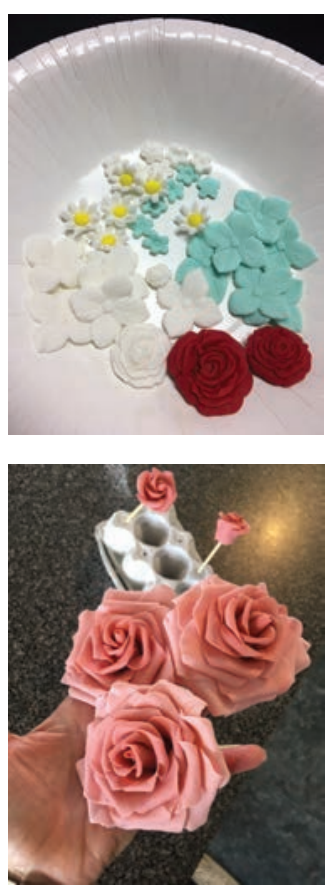

With my primary-aged children, I started with sugar Christmas-themed cookies. I had already baked the cookies and prepared the decorations. The children and I spent precious time communicating about how best to decorate the cookies, they learned skills that some of them had never had the opportunity to learn or see before, and they came away with a huge amount of pride and satisfaction at creating something extremely special. Activities like preparing food can be a great attachment-creating tool and I felt it acutely with my kids. Currently we are working on Easter cupcakes.

I brought gum paste flower making to the high school students at NSC. They sank into it with gusto - boys and girls, senior or junior, they have all loved it. I started with very simple flowers such as hydrangeas and daisies, and we move on to more complex ones such as frangipani's and poppies when they are comfortable. Roses come somewhere after that.

As far as I am aware, no other counsellor uses this medium - there is no literature that I could find suggesting that this is the case. Having me teach them one on one in the room is fulfilling many of their needs - connection, learning, completing a task and communicating. If a student is new to flower making, there is some dialogue at the beginning to learn the basics, but after that they can follow along with me. The conversation comes easily as in ways, they feel as though the pressure or the expectation to talk is removed from them, and then it comes naturally. Kneading malleable icing in their hands seems to be therapeutic to them - the icing yields to their touch, and in ways I wonder if the very fact that they are in control of what they create is empowering for them.

In some ways, flower making with the students in my counselling room feels nurturing - maybe it is connected to that primal need to teach and learn about food preparation, or maybe the closeness and connection that comes within this learning. I understand that this is not what you would call a conventional counselling activity, but just maybe it should be?

Kathryn Wright is a counsellor who works with children, teenagers and adults in the Te Anau area. She has special interests in rural mental health and in family violence prevention. She writes a regular blog on her website and many of her articles are published in other publications such as Young Farmers and in school newsletters.

Email: Kathryn@kathrynwright.co.nz 


\section{ODE TO AN EDUCATOR, WORK BASED LEARNER AND CHANGE AGENT}

Robert Nelson

\section{Part I}

Solving real problems with skills learned elsewhere The capstone project is the proof of learning The capstone project is the proof of application The real evidence learners can collaborate and grow

No more learning only to neglect all later The assignments and exams - all done and forgotten Knowledge so painstakingly gained, tossed to the wind Its relationship to real life only fleetingly perceived

On what foundation have I built this expectation? Is it a proof base, or is it convenience? After all the teams I've seen implode I should know enough to avoid this road

Forming a team must be so easy - NO! Please sir, can you do it for us? We've never had to do it for ourselves We don't want the wrong people with us

Nothing could be worse than the wrong people...

The problem is not us - it is them We can get along with anyone at all We are adults - we always behave that way There is no problem that we cannot solve

Graduate Profile, Course Prescription - must collaborate they say

Your team of peers you get to choose

Sell yourselves you must - tell the real truth

Any particular team choice not guaranteed - sell well

The choice is made, the die is cast

It's up to you to make this work

Standard Operating Procedures - rules to live by next Negotiate them, make them operable - they are yours
The project is chosen - full speed ahead now You have formed, you have stormed, even normed You are invincible - what could possibly go wrong? Claims from the start don't match performance now

Human foibles come out to play every day It's not me, not us - it is them! They wrote and signed the rules with us Now they won't obey - not even a bit!

We want them out, we want them gone No matter how hard WE try, THEY fail The better our work, the worse theirs gets We cannot make this work, not at all

Like all good stories, this has two sides THEIR expectations are unreal, THEIR support never there We asked for help, but got only scorn We can't do it; can't afford to fail

Like a saviour in battered armour, help arrives Sometimes asked, sometimes not, but always willingly given I've been right here so many times before Will this team be the one that's different?

If I had any doubts, I would not try Just let them implode, let them hate away And then tell boss "Painful way to learn" People damaged, maybe destroyed, but learning objectives met...

I will not abandon them in time of need I know too well where my responsibilities lie If they only learn to depend on me I have failed them, and also failed me 
On my shoulders lie so many heavy loads

So many stakeholders have invested belief in me

That what I told them is absolutely true

"No matter what - I am here for you"

To help people voice out is a must

The less I know, the harder to help

I still must earn your trust you see

You must experience I will listen to everyone

Do you want a listening ear or a decider?

What do your rules allow me to do?

You cannot win if things stay as are

Conflict is so frustrating, although invaluable learning comes

l've read your riles, listened to you all

There is some wrong, there is some right

I can help you solve this problem now

If you are willing to work with me

If you depend only on me, we failed

You have not learned to resolve conflict yourselves

You have not appreciated how negative becomes positive

You have not understood your wisdom and power

The best resolution is one YOU created

You will believe in it more than mine

The process is what you created yourselves

I only guided from my knowledge and experience

Remember what you've done, and how it happened

What it felt like in mind and heart

You have done what once you thought impossible

Hold fast to this knowledge, precious beyond compare

Not every team will experience such negative conflict For others - not a care in the world

Every challenge is met, ever goal is achieved

Harmony abounded, but how much did they learn?

Have they learned more or less than others?

Do they KNOW why negative conflict avoided them?

Was it something they did, or only luck?

But most of all - could they repeat it?

The project has run its course; solutions delivered

The marks have been awarded, the prizes too

The institution is happy, Project Sponsor as well

Little do they know the price we paid...

For the learners the experience is finished now

They have survived, they have grown - it's over!

They never have to live this experience again

Their collaborative lessons learned are ones for life

Some race to forget; others promise to remember

Some memories will stay with a learner forever
Remembered with varying degrees of clarity and depth

A foundation to guide future decisions and actions

Did your experience go beyond mandated course outcomes?

Not by my design, but by your choices

Have you emerged stronger because of what happened?

You are more experienced to graduate with confidence

What of your life once graduation is done?

The real world is not like a textbook

People don't always behave in predictable, logical ways

You've experienced them at their best and worst

You've had to deal with every strange behaviour

Trying to respect the person different to you

Trying to understand the person they really are

Keeping sight on the project, not forgetting that

At the start, you thought the course impossible

It required things you knew you couldn't do

Now at the end, how effective are you?

Employers want to know; point to your project

"What you see didn't exist before our team

Let me tell you about the part I played

How I led, managed, encouraged, empathised, and supported

How I will show how effective I am"

If you want someone who really backs themselves Capable and sound, driven but yet still human Someone who can see holistically, also act independently I'm your best candidate. When do I start'?

\section{Part 2}

All things equal, the learner does this once

Soon they will forget my name and face

But each next trimester, I do it again

Each new cohort, the same lessons to learn

The same process to use, same challenges to face

True, incremental changes made, based on previous experiences

While l've evolved the process, I haven't checked in

With the Number One Person facilitating the experience

Insidious and unappreciated, my passion my potential burnout

I joke about this with each new lot

"For an effective strategy, Do As I Say

Do NOT Do As I Do (unless necessary)"

Your project is important; not your whole life

Know when to step out, take a break

Go and smell the sunshine whenever you need

Working with no breaks - not recommended (unless

unavoidable)" 
I'm not superhuman; should have taken my advice Should have been able to apply my own lessons I've a mission you see, important to me To develop and grow next generation problem solvers

Did my passion blind me? Maybe it did I never "turned off", always focused on projects Holistic, collaboratively worked (and assessed where possible) experiences

Empathising with my learners, but never with me

Was I a "Legend In My Own Mind"?

Did my multiple awards mean anything at all?

Did I expect far too much from myself?

Could I make the course what it should be?

Fast forward now to the adventure called DPP

Where, at last, I have my greenfield site

Freedom, encouragement to think beyond the conventional constraints

To create not a course but an experience

To apply my passion, know how, and creative flair

To redefine what is possible - because it is

To build on the best from the past

To imagine, inspire, guide, consult, evolve as necessary

I should take my own advice to reflect

That action without reason is most often poor

But when is the best time for this?

It depends whose expert view you love most

Schön and Mezirow have taught me to reflect

Before I do a thing - will it work?

When I am in the middle of the action?

Or when it's all over and outcomes achieved?

The lessons I learn from valid experiences had Some will be "good", others will be "bad" I must record them in some permanent form Their maximum value lies beyond this one context

What has been taught is what l've learned

Our shared collaborative experience - different but similar You taught me as much as I you

What I create is your legacy as well

But between us still lies one crucial difference...

You were "students" and this was still "school"

Project thinking was always part time for you

It mattered not a bit what I did

"School projects" would never be your "Number One"

You wondered at my passion, you really did

Sometimes you probably thought l'd lost the plot

Why so intense - why not chill out a little?

Like the Blues brothers, I'm on a mission

\section{Part 3}

To integrate into a holistic, realistic learning experience From whoa to go, people and project indivisible Capturing the serendipity and magic of collaboration

On a scale not commonly done - although possible

Where my mission ends, I am not sure Perhaps it has no end; goes on evermore As long as learners must know of collaboration Experience it in practice, not just in theory

A sobering thing, to think of my legacy

To pay it forward, in present and future

In gratitude for the many experiences l've shared

The great, the disappointing, even those that hurt

Some told me I could not do this

It wasn't needed; I wasn't good enough

There were times when I believed those words

When I let them beat me down (repeatedly)

They hurt me more than I let them see I would not give them that sad pleasure Deep within me, well hidden, lay my conviction That I still had value, something to contribute

My mahi now on a much wider stage

Practitioner, learner - the line between roles has blurred

At once I am both; my being torn

I belong in both worlds, yet in neither

The imposter syndrome against which I do battle 'Justified by my coloured perceptions of past events Some days the imposter wins, some days me I have been through too much to capitulate

My mission is greater than me the individual The black dog of depression who haunts me Released through the reflective exercise called the ROL He shall not claim the victory he doesn't deserve

This critical mission is no longer mine alone It is a collaboration - it is us, we What I have conceived, now shared with others I am one voice, but can lead korero

My eyes and ears opened to new possibilities Many things I could never have dreamed alone The challenge excites me; I am accepted here The belief and encouragement of others supports me

Yes, I have hurt and I have grown

Our strength lies in our diversity and collaboration

You have not made me, any of you

You have shaped me, every one of you 
I am you, you are me, we are we

Collaborative learning and collaboratively assessed projects

our shared passion

If I have learned one transformational thing so far

It is this: I am truly part of we

Together we will achieve more than I ever could You are my soul mates, my mentors, my friends In your company I am permitted and expected to Challenge convention, provoke disobedient thoughts and incite rebellious actions

All in the sacred cause of experiential learning My comfort zone has become elastic - nay, dynamic I have found space filled with like minds I have come home...

\section{KEY THEMES WOVEN THROUGH THE ODE}

Having established the foundations of my collaborative Work-Based Learning journey thus far through verse, I'm now going to consider, in more detail, two critical themes both inherently and explicitly woven through it:

- change agency; and

- reflection through an autoethnographic lens.

My own Doctor of Professional Practice (DProfPrac or, informally, as above, 'DPP') journey started long before enrolling in the qualification. I moved from being a learner engaging with a course that is "Project Management" by another name, but with a significant focus on the development of leadership (self and others) skills in a collaborative context (New Zealand Qualifications Authority, 2002; New Zealand Qualifications Authority, 2018), to facilitating the same course. Having experienced the course from both sides has equipped me with the knowledge to be an effective change agent. It has also given me much to reflect on, which has inevitably found its way into other courses I have facilitated. The value of the learning has thus been multiplied many times over and benefitted a wider range of stakeholders both within and outside the teaching institution.

\section{CHANGE AGENCY}

A change agent is defined as "...the individual or group that undertakes the task of initiating and managing change in an organization..." (Lunenburg, 2010, p. I). This is a fairly typical definition of the term, to which it is possible to add other factors such as uncovering the causes of problems (Pascale \& Sternin, 2005), creation of a positive and integrative environment for change (van den Berg et al., 2019), collaboration (van der Heijden et al., 2015), the provision of technical knowledge and social support (McKinsey \& Company, 2017), and minimising the resistance to change (Gupta \& Singla, 2021). Whether they come from inside or outside the organisation, their role is to change the thinking and behaviour of individuals inside the organisation to some defined and desired state (Govindarajan, 2020).

When I went literally from being a student on a Friday to a teacher the following Monday, this last point was one that I taught in my various management courses. It was not reflective of how I saw myself. My students were customers of my organisation, but they did not belong to it in the same way I did as an employee. A 
change agent might manipulate me as an employee towards my employer's desired future state, but surely that was different to what I was doing with my students who would go on to be employed by many different organisations who were not hiring me as an external change agent.

It took some little time to appreciate that, as a teacher, I was - I am a change agent. This agency manifests itself in several critical ways:

- seeking to bring about change in the institution and the systems I have to work within to facilitate co-creating more authentic learning experiences;

- seeking to bring about change in commercial and non-commercial organisations by graduating learners who are not only capable of solving a diverse range of problems, but who are also capable of working collaboratively to do so;

- seeking to bring about change in individuals via increased self-efficacy when it comes to working collaboratively with others, whether in a leadership or followership role.

Bolam (1975, as cited in Badley, 1986) identified a number of specific roles played by a change agent in terms of what they deliver to the people who are the subject of the change process. In training people to collaborate, an essential skill for management of selves and others in a capstone project that exists mostly in the world outside the classroom, I would add other critical roles to Bolam's list:

- counsellor - being invited into learners' lives, sometimes outside the context of their project team, to help resolve issues negatively impacting their ability to take an effective part in their project teams;

- conflict manager - sometimes as a "court of last resort" where learners believed themselves unable to resolve intra-team and inter-team issues without external guidance.

A study by Stewart et al. (2018) found that, as much as process failures could be blamed for project failure, so could competence failures. Many of the cultural issues they highlighted revealed not only technical failures, but also failures of individuals to engage collaboratively within and across discipline areas. My own practice, therefore, has been to develop a culture within capstone cohorts that is essentially learner-centred, where I become a guide and facilitator rather than the authoritative fount of all knowledge they may have expected from a tutor.

Donnelly and Fitzmaurice (2005) identified the ability to work collaboratively to solve problems as an important outcome of project and problem-based learning scenarios. They further identified that such an approach actually required more rather than less tutor time being invested in a cohort to achieve desirable outcomes. It is not only the desire or willingness of the facilitator to deliver such a collaborative learning experience on its own that determines likely outcomes - as a change agent I must also work to change institutional systems such that the institution does not take this extra workload for granted and are instead able to meaningfully support it.

It is sometimes said of bureaucracies that it is easier to do something and ask for forgiveness later than to plan something and ask for permission. As a change agent, this is something I must be mindful of. Some boundaries are easier to push and more flexible than others. What I must never lose sight of, though, are the responsibilities I have to diverse stakeholder groups to ensure that authentic learning is not only relevant now, but also futureproofing as much as is practical participants in, and other beneficiaries of the learning experience. This leads to the second interwoven key theme: reflection on what happens and what the outcomes are. 


\section{REFLECTION THROUGH AN AUTOETHNOGRAPHIC LENS}

The autoethnographic lens enables me to see the world on my own terms; to be the hero of my own narrative, or the villain should that be appropriate. The distinction is important - I am forced to confront my own fallibility, my own 'normal human-ness' on a regular basis. As much as I like to think that my judgements are based on some sort of Mister Spock-like logic, I must acknowledge the role that emotion plays, consciously or otherwise. Buckley (2015) points out the need for beliefs about emotional influence to be triangulated - the difficulty as a practitioner is that my learners may not choose to reflect on the same events that I have reflected on. Add to that their reflections being produced as assessment pieces and not being perceived by them as part of an ongoing professional development strategy, and I must accept my reflections are likely to contain bias that cannot be easily countered.

A critical skill for an educator to develop as part of continuous professional development is that of reflection, yet little of my adult teaching training all those years ago focused on how to do this outside the context of the training course itself. There seemed to be an unspoken assumption that I already knew how to do this, which was never checked. Some reflection was enforced as a matter of institutional policy - the results summary at the end of a course, although this was more about identifying issues of student performance in order to explain their marks, with minimal emphasis on reflecting about my teaching practice. Reflection had been a compulsory component of my capstone experience as a student, but we weren't taught about the giants of reflective thinking - the likes of Mezirow (1990), Schön (1983), and Dewey (Dimova \& Kamarska, 2015) - or about how to apply their methods to our own experiences.

As facilitator of that same capstone project course, I decided that if the students were required to reflect formally on their own experience, I would do the same - a case of "one rule to rule them all." The writing would be to find a way to say what I know, to give voice to something that might otherwise not be described and captured; I would go further than that, though-I would share my thoughts with my capstone cohort after the end of each trimester, so they could know how I had been growing alongside them on, and learn from my experience, beyond the formal end of their capstone experience. Plack and Greenberg (2005) point to reflection as something that is simultaneously practised at multiple levels - dealing with the problem immediately in front of the practitioner while at the same time thinking about its potential causes, whether I am taking the most effective actions I can, and what the future implications of my decision are likely to be.

Having captured my reflections through events generic and common enough that participants other than me could not be identified, they can have another life as problem-solving tools. Munby (1989) identifies the importance of feedback as a part of Schön's reflective model and the way in which that allows me to reframe my understanding of events and outcomes. I would argue an important part of that reflective feedback (to me) is its authenticity. Its connection to ill-defined problems, even if the processes are relatively predictable; multiple sources and perspectives, collaboration and multiple possible outcomes (Pearce, 2016), means I am living in the same world my learners are experiencing, having similar reaction for (probably) similar reasons, and this gives value and credibility to the reflections.

Their permanence means I am creating an ever-growing library to which I can refer for dealing with future problems. The criticality of lived experiences is shown by Droege (2013) to be an important determinant of how memories are recalled and reassembled for conscious use. As a foundation-stone of my continuing professional development, these formal reflections formed an evolving journal allowing me to adopt a Janus perspective (Bates \& Wright, 2019), looking to the past and the future as necessary to understand the value of my present experiences. There is no single 'right' or 'wrong' answer to the questions prompted by my reflections - there are only answers that address particular circumstances at particular times, and which provide general guidance for facilitating future project teams. It is both my privilege and, I believe, my obligation to share such answers as I do have with learners and peers alike in order to multiply their value when they prompt others to think before they do. 


\section{FINAL THOUGHTS}

I have titled this article as an ode to a change agent. While I own the final thoughts that have given form and order to these words, I acknowledge they are not mine alone. As a lifelong learner and professional educator, they represent many years of mahi, many voices, much körero and many collaborations. They represent events deemed successes and failures. They represent relationships created, nurtured, and ended in various ways. They represent not only my growth as a collaborative Work-Based Learning practitioner to this point, but also the foundation of who I am yet to become. While they are not the only themes that could have been extracted from the ode they are, based on my own experience, the most critical when it comes to the success of workplace learning as a facilitator or as a learner. My experiences and my learning - these are my gifts to you to adopt, adapt and use as you will.

Rob Nelson trained as a printer, worked his way into management, later qualifying in management and then leadership as an adult student. He then embarked on a second career teaching management, and has significant experience in collaborative project-based learning.

Email: rob.nelson00।@gmail.com

\section{REFERENCES}

Badley, G. (1986). The teacher as change agent. Professional Development in Education, 12(3), 151-158.

Bates, S., \& Wright, V. (2019). Adopting a Janus perspective: moving forwards and backwards through our teacher professional experiences. International Journal of Lifelong Education, DOI: 10.1080/02601370.2019.1585394

Buckley, R. (2015). Autoethnography helps analyse emotions. Frontiers in Psychology, 6(209), I-3.

Dimova, Y., \& Kamarska, K. (20I5). Rediscovering John Dewey's model of learning through reflective inquiry. Problems of Education in the 21st Century, 63, 29-39.

Donnelly, R., \& Fitzmaurice, M. (2005). Collaborative project-based learning and problem-based learning in higher education: A consideration of tutor and student role in learner-focused strategies. In G. O'Neill, S. Moore \& B. McMullin (eds) Emerging issues in the practice of university learning and teaching (pp.87-98). Dublin: AISHE/HEA.

Droege, P. (2013). Memory and consciousness. Philosophie Scientiæ, 17(2), 17I-193.

Govindarajan, K. (March 19, 2020). Who is a change agent? Freshservice Blog. https://freshservice.com/change-agent-definitionroles-blog/

Gupta, S., \& Singla, A. (2021). Role of change agent in minimizing resistance and enhancing readiness for change. In S. Shruthi \& R. K. Gupta (Eds.), Perspectives on business management (Volume II) (pp.45-50). Archers \& Elevators Publishing House.

Lunenburg, F. (2010). Managing change: the role of the change agent. International Journal of Management, Business and Administration, 13(I), 2010.

McKinsey \& Company. (March 28, 2017). The change agent challenge. https://www.mckinsey.com/business-functions/operations/ our-insights/the-change-agent-challenge

Mezirow, J. (1990). How critical reflection triggers transformative learning. In J. Mezirow and Associates, eds., Fostering critical reflection in adulthood: a guide to transforming and emancipatory learning (pp. I-20), Jossey-Bass.

Munby, H. (1989). Reflection-in-action and reflection-on-action. Current Issues in Education, 9, 31-4I.

New Zealand Qualifications Authority. (2002). Prescription: 236 Applied Management. In New Zealand Diploma in Business Regulations Prescriptions. Wellington.

New Zealand Qualifications Authority. (2018). Prescription: 636 Applied Management. Wellington.

Pascale, R. T., \& Sternin, J. (May, 2005). Your company's secret change agents. Harvard Business Review. https://hbr.org/2005/05/ your-companys-secret-change-agents

Pearce, S. (2016). Authentic learning: What, why and how? e-Teaching April 2016 (10). 
Plack, M. T., \& Greenberg, L. (2005). The reflective practitioner: Reaching for excellence in practice. Pediatrics, I/6, I546-I552. DOI: 10.1542/peds.2005-0209

Schön, D. (1983). The reflective practitioner. Jossey-Bass.

Stewart, A., Nassif, A., \& Stewart, A. (2018). Education, a change agent for project failure? In J. Shiau, V. Vimonsatit, S. Yazdani, and A. Singh (Eds.), Streamlining information transfer between construction and structural engineering, ISEC Press.

van den Berg J., Zijp M. C., Vermeulen W. J. V., Witjes S. (2019). Identifying change agent types and its implications for corporate sustainability integration based on worldviews and contextual factors. Journal of Cleaner Production (2019). https://doi.org/10.1016/j.jclepro.2019.04.272

van der Heijden, H. R. M. A., Geldens, J. J. M., Beijaard, D., \& Popeijus, H. L. (June 2, 2015). Characteristics of teachers as change agents. Teachers and Teaching: theory and practice. DOI: 10.1080/13540602.2015.1044328 


\title{
COMMUNICATING TRUSTS
}

\author{
Johana Alexandra Nino Rodriguez \\ and Marianne Cherrington
}

\section{PREAMBLE}

Trusts are legally binding arrangements that transfer legal ownership of assets for beneficiaries. For the first time in over seventy years, reform has arrived, via the Trusts Act 2019 ('the Act'), which came into effect on 30 January 2021. The Act significantly changes trust law and communication underpins the changes. This research stems from a work-based learning project within an Auckland law firm, where the processes for communicating the Act's implications and variations were investigated. Stakeholder messaging became the unifying purpose for the research, beyond the need to understand the key effects of new statutory requirements. This paper summarises the key takeaways from the work-based industry project in terms of communicating trusts. Secondary research, semi-interview and observational methods established the Act's implications, as well as issues leading to key findings in terms of messaging and communication to build brand association and loyalty. The novel contribution of this research, realised in this paper, is the extension of the research via the use of coresearching partnerships to design a framework around the stakeholder communication network requirements for law firms as they implement a new Trusts Act regime for new and existing clients.

\section{INTRODUCTION}

Trusts are meant to protect assets for beneficiaries. In New Zealand, trusts have been criticised as tax loopholes for trustees that are inaccessible to stakeholders, especially beneficiaries (Law Commission, 2002). The Trusts Act 2019 is meant to encourage disclosure and discussion around trusts so that wealth is not hidden from beneficiaries, rather it informs beneficiaries and allows those involved in trusts to be aware and involved in financial affairs relating to trusts (Kenny \& Speight, 2020). In this paper, the notion of representing and unravelling the 'voice' of beneficiaries is examined via a work-based learning project in a professional practice. Opportunities to communicate are thoughtfully applied in the context of the new Trusts Act 2019.

In the environment of work-based learning, asset accumulation and protection are apt. For all workers, thought for the future with strong foundations for the next generation must be discussed and learned; trusts are a common means of safeguarding wealth, accrued over one's working life, for benefit of those we care about.

In the context of pandemic uncertainty and apprehension, legal firms are pivoting their organisational strategy; principals are reassessing professional plans. There is a need to create opportunity from a safe, secure foundation. This usually requires asset reallocation. The new Trusts Act 2019 (the Act) came into effect in 2021, compelling trustees and settlors to reassess existing trusts and how they operate, with new obligations. Significant changes to trust law profit from discussion with experts and stakeholders, predominantly in the context of family trusts and estate planning and including winding up of existing trusts (McLeod, 2020a). 
A critical component of this project was to assess implications of the new Act. Secondary research was undertaken under the direction of the principals of the law firm in which the project was undertaken. Following, interviews were undertaken with key members of the law firm to understand better how trusts were applied in practice, and to understand better the benefits and misuses of trusts from the viewpoint of a lawyer. In addition, key findings from the interviews concerned transformational change as well as possibilities to build and maintain client loyalty. Observational research methodologies established issues that related to implementation of the Act; these included process and systems barriers within the firm. The key findings from observational methods related to trust documentation, corporative trustee governance, and trustee power. For example, trustees must confirm that they can comply with all new trustee obligations and duties set out in the trust deed under the Act, which provides default administrative rules, mechanisms to resolve trust-related disputes, and makes the law of trusts more accessible (Speakman Law, 2020). Law firms must be proactive to avoid major risk from the loss of family trusts. Communication processes throughout the adoption of a preventive risk management action plan were key in avoiding such risk.

In particular, discussions concerning trust resettlement support alignment with the new Act. Trust resettlement occurs when a family trust completely restates the express terms of the trust deed, incurring potential tax consequences, as well as in changes in the rights and obligations of the parties (McLay, 2020). This has longterm consequence in terms of wealth creation for future generations. Trust resettlement is one of the biggest challenges for trustees nowadays because it can be done depending on the existing structure of each trust property. Internal system updates will be required at law firms in order to deliver trust file information for those involved. As well, the risk management process must be assessed, as a key to delivering practical preventative law for trust resettlement. Masterful communications can be transformational tools in preventative services, minimising negative implications while maintaining and building brand and client loyalty (Zaffron \& Logan, 20II).

\section{TRUSTS ACT 2019}

The Trustee Act of 1956 was originally meant to ensure family trust funds were cheaper and simpler to create (Hawes, 2012); it became dated, ill-managed and poorly constituted. Inconsistencies resulted in legal action.

The purpose of the Trusts Act 2019 is to reform trust law (Ministry of Justice, 2020) by:

- enforcing reform of New Zealand trust law through restatement of the law,

- making the law of trusts more accessible, and

- providing rules to improve family trust administration in the future.

The changes create implications such as winding up of family trust deeds and new obligations for trustees. For this reason, it is vital to reassess if existing trusts are fit for purpose or if variations are needed. Trustees and settlors must re-evaluate their roles and responsibilities. Therefore, trustees must understand key changes in order to deal with these new responsibilities for all existing and future trust funds in New Zealand.

One implication is that the trustees need to understand their new fundamental administrative obligations within the terms of the trust deed, and a second implication is the inevitable winding-up of some family trusts. Tax implications of trust resettlement will be a challenge for trustees. This project looked at practical preventive law for trust resettlement in order to minimise future risk, while building and maintaining client loyalty. Risk management assessment processes were examined, to identify implications of upcoming changes at a law firm. Law firms must fundamentally appreciate their client relationships and update internal systems for trusts, as part of an overall risk management process for the delivery of practical preventative law for Trust resettlement. 


\section{TRUSTS INFORMATION CATEGORIES}

This work-based learning project examined secondary research, reported in an extensive industry project report. The research was augmented with interviews and observational research methods, which were used to identify information categories or blocks for Trusts information within the law firm. From this primary research, key themes were extracted from data collected in context. Group blocks are depicted in Figure I.

Trust Documentation is a key consideration in the Trusts Act 2019 as a mandatory duty concerning record keeping, holding and availability of core trust documents (Costa \& Frankema, 2007); it may not be modified nor excluded by the terms of the trust. It means trust documentation matters to build a relationship between trustees and the trust because the terms of the trust are defined in the trusteeship (Walker \& Shahbaz, 2020). This is a communicative issue. The trust file in internal systems with a compulsory hard copy is an elemental duty for trustees, and in resettling and re-evaluating internal systems (Kemps Weir, 2020). Additionally, the Trusts Act mitigates the gap between the income tax rate and the trust rate. Trust documentation increases the power to exploit the trust system as trusts not only safeguard assets, they favour the dodging of tax obligations (Coughlan, 2020).

Figure I. Group blocks of information regarding trusts information in a particular law firm.

\begin{tabular}{l} 
Trust Documents \\
Mandatory \\
duties. \\
$\checkmark$ Build a \\
relationship \\
between trustees \\
and trust. \\
Trust Documents \\
\hline Opening gap \\
between the \\
income tax rate \\
and the trust \\
rate create. \\
$\checkmark$ Avoid dodging \\
tax obligations.
\end{tabular}
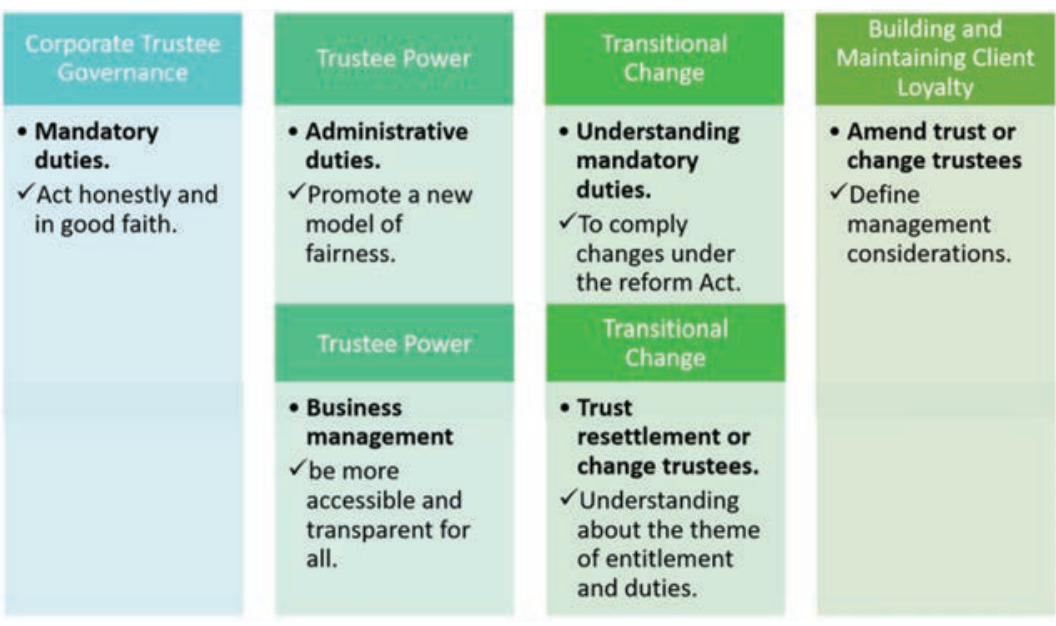

Trust documentation went through a three-stage process in the law firm. Firstly, the main information from the trust file was transcribed into a computerised format. The second stage was to complete a checklist sheet using a confirmation template to update client trust files in both record-holding information formats. The final stage was to create a data-entry form using a set of macros interlinked with the client sheet, containing core trust information in order to facilitate access to information effectively. The process is of huge importance in trust documentation, favouring effective facilitative access to information (Quill, 2020). It is straightforward to ease trust file updates for trustees, beneficiaries, resolution, or other documents. Under the Trusts Act 2019 , firms have mandatory duties regarding recording core trust information; penalties can be imposed otherwise.

Trustee power is key issue within the new Trusts Act 2019. It is associated with administrative duties having many implications (NZLAW, 2020). A trust may accumulate income to the extent that it is consistent with its terms (Parliamentary Counsel Office, 2019). A new model of fairness can be promoted with trust deeds that are restated, modified, or removed to minimise harm made by presumption or sham trusts, as when a trustee makes all decisions without the consent or benefit for all parties (Ammundsen, 2020); in that case, the new legislation will be more useful, with more flexibility in the default provisions (Parliamentary Counsel Office, 2019). 
Transitional change is needed for law firms updating their internal systems in favour of establishing their new obligations and duties under the Trusts Act 2019. It takes time to understand and communicate mandatory duties that are fundamental to complying with the wide range of duties and obligations reformed under the Act. The majority of trust deeds will likely need to amend or change trustees (McLeod, 2020b). This means that trustees have more obligations under the regulatory needs of the Act, as well as greater power over trust property management. Existing documents must be reviewed to ensure trusteeship complies with the list of requirements under the Act.

According to interview research, due to changes in the Trusts Act 2019 and tough times in 2020, the law firm wound out 20 per cent of the family trusts. Disinformation and bias negatively affected the trust business. With a more proactive communication strategy, the firm could have reformed of a good proportion of those trusts.

\section{FAMILIES, TRUSTS AND DISCLOSURE}

The simplicity of setting up family trusts years ago without notifying family members, now complicates trusts, as circumstances have changed. Some clients feel intimidated by possible changes in benefactor behaviour because the amount of wealth now accumulated is considerable; transparency is required in the new Act. It has been estimated there could be more than half of trust business lost in New Zealand (Stock, 2020). Many trustees will not fulfil requirements under the Act even if law firms can support their needs. Strategic transitional plans are needed and this must be communicated by law firms to build loyalty and brand image.

A key and important change for all existing and future trusts in New Zealand is the new face of trust law. The Act will provide mechanisms for trust disputes to be resolved outside of the courts, focusing on mediation and alternative dispute resolution (Gibson Sheat, 2019). Some notable changes to existing trust law include:

- an obligation to disclose basic trust information to the beneficiaries of the trust, by right as a beneficiary

- increased mandatory and default duties as trustee obligations; there are new obligations to disclose the existence of a trust and to provide trust information to the beneficiaries (Powell, 2020)

- enhanced trustee record retention requirements

- $\quad$ an ability to delegate duties and powers

- a maximum duration of a trust of 125 years

- clarification of the Court's powers concerning the trust and enabling the use of alternative dispute resolution for trustee/beneficiary disputes, that is dispute resolution

- a simplified process for replacing mentally incapable trustees from land titles, mostly avoiding the need to involve the High Court.

Experts consider that the small reforms made to the Trustee Act 1956 cannot stop fraudulent actions due to a lack of accountability; there are no checks or balances to stop losing financial resources (Bennett, 2018). As trust funds are one of the most flexible asset ownerships, the new Trusts Act 2019 will have more stringent rules for how trusts must operate (McLeod, 2020a). Therefore, New Zealanders who invest in a trust fund as a financial option must also invest in a better future for all beneficiaries (Norton, 2020).

Maintaining and building client loyalty is vital when creating stable client relationships. The majority of trust deeds may need to amend or change trustees because the core trust documents do not define many details about relevant considerations about managing the trust assets and investments (McLeod, 2020a). This opens a gap between beneficiary interest priorities and a correct application of the trust deed terms. Based on the trust deeds drafted, trustees must notify primary beneficiaries about basic trust information to clarify the beneficiary appointed and benefits under the family trust fund (Norton, 2020). Additionally, the duration of trust can be extended from 80 years to 125 years, accelerating internal trust changes only in existing trusts. Some trusts may 
not be well-created for resettlement (Yu, 2002). Family trusts that have a long lifespan must carefully identify any threats against any client's family trust. In other words, the trustees' main job is to protect the accumulated wealth of their clients through a transparent and flexible channel between beneficiaries and the trust in order to minimise interest conflict and potential issues between all parties. This gives a huge importance to an open communication about family trust files.

\section{KEY OPPORTUNITIES FOR COMMUNICATION REGARDING TRUSTS}

The Trusts Act 2019 will reduce trust business for legal firms; it is a real risk to manage. It is also an opportunity to build client trust and brand loyalty (Figure 2). Some key insights from the work-based learning project are:

- Law firms might fail to maintain and build positive relationships with clients if client perceptions or mindsets shift during transitional changes; a firm can influence preventive risk management by helping clients avoid winding family trusts by reframing the Trusts Act 2019 changes as beneficial.

- Clients are likely to benefit from a ready financial viability plan that limits costs and inconveniences involved in transitional change. Firms can temper risk management with a financial strategy that can minimise client risks over time.

- Firms can re-communicate their ethical obligations and duties of care at all levels as a model for their clients (Wang \& Li, 2019); a stronger relational culture can emerge from enhanced compliance to benefit stakeholders (Barclift, 2008).

Firms can use ADKAR (Awareness, Desire, Knowledge, Ability and Reinforcement) change management models to activate communications opportunities by brainstorming stakeholder relationships (see Figure 2).

Figure 2. Law firm communications ADKAR change management opportunities (Pearson, 2019)

\begin{tabular}{|c|c|c|c|c|}
\hline $\begin{array}{l}\text { Phase 1- Notify } \\
\text { stakeholders. }\end{array}$ & $\begin{array}{l}\text { Phase 2- } \text { Awareness is a } \\
\text { goal. }\end{array}$ & $\begin{array}{c}\text { Phase } 3 \text { - Change } \\
\text { management strategies } \\
\text { and suitable metrics. }\end{array}$ & $\begin{array}{l}\text { Phase 4- The } \\
\text { transformation period. }\end{array}$ & $\begin{array}{l}\text { Phase 5- } \\
\text { Reinforcement. }\end{array}$ \\
\hline $\begin{array}{r}\text { Promote open } \\
\text { communication } \\
\text { about transitional } \\
\text { changes can } \\
\text { increase } \\
\text { engagement } \\
\text { between all parties. } \\
\text { Free flow of } \\
\text { information } \\
\text { between different } \\
\text { parts. } \\
\text { Not highlight } \\
\text { hierarchy. }\end{array}$ & $\begin{array}{r}\text { Increase awareness } \\
\text { and knowledge } \\
\text { might be employed } \\
\text { in response to the } \\
\text { changes that are } \\
\text { occurring or } \\
\text { needed. } \\
\text { Listening to } \\
\text { suggestions, } \\
\text { answering and } \\
\text { asking questions } \\
\text { can foster a positive } \\
\text { relationship } \\
\text { between the client } \\
\text { and the trustee. }\end{array}$ & $\begin{array}{r}\text { Education and } \\
\text { communication can } \\
\text { help the adaptation } \\
\text { of changes easily. } \\
\text { Promote wishes for } \\
\text { change in order to } \\
\text { work as a team and } \\
\text { move forward. } \\
\text { Monitor a set of } \\
\text { parameters until } \\
\text { business outcomes } \\
\text { are achieved. }\end{array}$ & 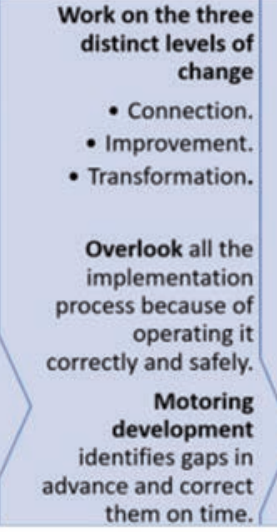 & $\begin{array}{r}\text { Reinforcement can } \\
\text { ensure change by } \\
\text { using new suitable } \\
\text { metrics over time, } \\
\text { enforcing change } \\
\text { management. } \\
\text { Measuring change } \\
\text { through a scope of } \\
\text { risk management } \\
\text { can reduce future } \\
\text { risks. }\end{array}$ \\
\hline
\end{tabular}




\section{DESIGNING A FRAMEWORK FOR STAKEHOLDER COMMUNICATIONS}

Communication management drives change and adds stakeholder value in organisations. Communications impact organisational culture, productivity, as well as profits. Law firms regularly deal with sensitive matters and good communication can help eliminate a greater range of risks in business.

There is no one-size-fits-all approach to the rich diversity of stakeholders involved in trusts. For trustees, maintaining a good ongoing relationship with stakeholders is relevant because trust files require amendments and legal compliance reviews on a recurring basis (Jayatilleke \& Lai, 20I8). A well-planned approach encourages effective communication management for all stakeholders and not just for those who make the loudest demands (Te Puni Kōkiri, 2007). All main information about trust management should be noted in a holistic stakeholder communication plan in order to avoid misunderstandings. For example, the lack of information about reviewing or amending trust deeds before the Trusts Act 2019 came into effect, brought on relationship splits, partly because of misconception. Therefore, the requirements of the Act, alongside formal, informal and technical communication, enable trusts to work constructively. The requirements set out by trust deeds need the correct contact channel from the client perspective, to prevent issues in trust management.

This holistic communication plan should be client centric, but the Act has a greater focus on beneficiaries as well, returning to the original intent of a family trust, as legally binding arrangements that transfer legal ownership of assets for beneficiaries. Behind that intent should be a desire for improved life quality for those involved in the trust. An interesting and holistic perspective could be developed from Te Ira Tangata framework (Te Puni Kōkiri, 2007). The framework develops Te Ira Tangata (life quality) as an additive equation:

Te Ira Tangata (life quality) = Mātauranga (knowledge) + Whakamana (influence) + Rawa (resources)

Te Ira Tangata (life quality) is what family trusts are all about; the new Act purposes to bring beneficiaries back into the discussion and make trusts more transparent for all stakeholders. The Act implications can fit into the Te Ira Tangata framework to focus key stakeholder communications as in Figure 3.

Figure 3. Trusts Act 2019 key knowledge influence and resource changes for communications planning.

\begin{tabular}{|l|l|l|l|}
\cline { 2 - 4 } \multicolumn{1}{l|}{ Te Ira Tangata } & Mātauranga (knowledge) & Whakamana (influence) & Rawa (resources) \\
\hline trustees & $\begin{array}{l}\text { Duty of care: specialised } \\
\text { knowledge or experience }\end{array}$ & Decide a range of factors & $\begin{array}{l}\text { Selection of information } \\
\text { to provide or withhold }\end{array}$ \\
\hline beneficiaries & $\begin{array}{l}\text { 'basic trust information' } \\
\text { available to beneficiaries }\end{array}$ & $\begin{array}{l}\text { Adult beneficiaries may } \\
\text { unanimously end a trust }\end{array}$ & $\begin{array}{l}\text { Can apply trust property } \\
\text { for beneficiary welfare }\end{array}$ \\
\hline legal advisors & $\begin{array}{l}\text { Legal and trust advice; } \\
\text { financial and tax support }\end{array}$ & Act as a specialist trustee & Wide-ranging paperwork \\
\hline
\end{tabular}

Although Te Ira Tangata is a holistic framework, the $3 \times 3$ depiction given in Figure 3 can be used as a starting point for legal firms to become more relational in their approach to trusts and their clients, as more than just trustees. Firms that have legacy values, that seek to build relationships with clients and for clients, can explore the 'Te Ira Tangata equation' as a synergistic means of creating lasting value and intergenerational wealth and development for all stakeholders linked through the trust structure.

A Te Ira Tangata communications framework for the new implications from the Trusts Act 2019 requires acceptance of the implications under the Act, such as reforms to trust governance, trust documentation, trustee power, transitional change, and maintaining and building client loyalty. Thus, a holistic communication plan is vital to enhance stakeholder confidence and value through a process of open and transparent communication 
in order to meet trust business outcomes under the Act for all stakeholders, including those who are not aware or informed about how much the trust is worth or how beneficiaries gain.

Continuity in relationships with dedicated contact spokespeople supports service and brand loyalty aims. Law firms should look at each trust holistically; trustees and beneficiaries can be united and speak with one voice (Te Puni Kōkiri, 2007). Typically, a spokesperson, such as a partner in the firm or representatives of the firm, can be appointed as spokespeople; they may be any director who is well aware of all levels of the organisation who are trustworthy, relationship builders. Processes that inform and support complex decisions that have major impact on the lives of clients and beneficiaries must include legal representatives who are empathetic, discrete and fair, in order to maintain and build good relationships with stakeholders, and encourage rich and valuable insights between parties. In this way, a comfortable and strong strategic advantage within the firm can be built from generation to generation, in the same way that the Act builds assets inter-generationally.

\section{CONCLUSIONS}

The Trusts Act changes will make trusts more transparent, communicative, inform up-to-date trust practice, and clarify trustee powers, duties, roles and requirements (Cone et al., 2019). While reviewing processes, law firms can uptake opportunities with superlative messaging practices with practical insights to benefit practitioners, settlors and beneficiaries. It will build loyalty and the brand.

As part of a work-based learning project within a law firm, a framework based on Te Ira Tangata is suggested due to its focus on life quality in a New Zealand context; the framework can highlight implications and variations in the Act. Law firms can overcome the loss of trust business by magnifying the opportunity to build intergenerational relationships with trustees and beneficiaries by focusing on the overall intent of trusts and asset benefaction. Te Ira Tangata has a life quality focus that aligns with trusts intent.

The Te Ira Tangata communications framework will require development in the context of evolving trust law. Each law firm will need to communicate trust information more proactively, and the framework has the potential to keep clients with the firm and build relationships into the future with beneficiaries and other stakeholders. Future research in the firm can evolve around this framework and even expand its use as Te Ira Tangata becomes part of the culture of the firm along with the communicative norms that define their brand.

Future work within the law firm can assess and refine the framework, notably in terms of its communications and relational value in a trusts context. The framework is a starting point to hone stakeholder messaging in terms of communicating trusts; it can be used similarly as a framework for similar stakeholder communication processes within organisations. 
Johana Nino is an Applied Management graduate from Otago Polytechnic. She previously completed a Bachelor of Finance and Foreign Trade in Bogota, Colombia. Johana aims to share her research with trustees and people interested in the implications of the new changes to the Trusts Act because her research interests include the financial sector in general and wealth management.

(D) https://orcid.org/0000-0003-4410-2992

Marianne Cherrington is a Principal Lecturer at Otago Polytechnic Auckland International Campus with a focus on sustainability as well as computer science and analytics. A lecturer in disruptive innovation, her research into machine learning feature selection algorithms applies in many fields, producing interesting collaborations with local and international partners in many disciplines and sectors.

Email: Mariannec@op.ac.nz

(D) https://orcid.org/0000-0002-1240-2010

\section{REFERENCES}

Ammundsen, V. (2020, February 26). Trust Series 2020 - Trust Fundamentals. [Original Broadcast] https://register.gotowebinar. com/recording/950649/53656037635

Barclift, Z. (2008). Preventive Law: A Strategy for Internal Corporate Lawyers to Advise Managers of Their Ethical Obligations. Journal of the Legal Profession, 33(3I), Paper 34I. https://open.mitchellhamline.edu/facsch/341

Bennett, L. (2018, May 17). Treaty Negotiations Minister Andrew Little concerned by lack of accountability on Te Arawa River Iwi Trust spending. New Zealand Herald. Retrieved from www.nzherald.co.nz/nz/treaty-negotiations-minister-andrew-littleconcerned-by-lack-of-accountability-on-te-arawa-river-iwi-trust-spending/YB4QCSSOVCB2VXMR5OJI7XNTRY/

Clark, D. (2021, April 16). Speech releasing the Digital Council's report 'Towards Trustworthy and Trusted Automated Decision Making in Aotearoa'. https://www.beehive.govt.nz/speech/speech-releasing-digital-councils-report-towardstrustworthy-and-trusted-automated-decision

Cone, G., Shan, C., \& Barber, S. (2019). A Trusts Act for New Zealand. Trusts \& Trustees, 25(9), 891-901.

Costa, A., \& Frankema, K. (2007). Trust and Control Interrelations: New Perspectives on the Trust - Control Nexus. Group \& Organization Management 32(4), 392-406. https://doi.org/I0.1I77//059601/0629387|

Coughlan, T., (2020, December 01). Revenue Minister David Parker says trust tax rate could be raised if people use it to dodge new top income tax. Stuff. https://www.stuff.co.nz/national/politics/300172160/revenue-minister-david-parkersays-trust-tax-rate-could-be-raised-if-people-use-it-to-dodge-new-top-income-tax

Gibson Sheat, (2019). TRUSTS ACT 2019 Information for trustees. GibsonSheat. https://www.gibsonsheat.com/site/ gibsonsheat/Trusts\%20Act\%202019\%20-\%20information.pdf

Hawes, M. (2012). Family trusts: The must-have New Zealand guide. Random House.

Jayatilleke, S., \& Lai, R. (2018). A systematic review of requirements change management. Information and Software Technology, 93, $163-185$.

Kemps Weir. (2020, March 09). Trusts Act 2019: Documents to be kept by trustees. https://www.kempsweir.co.nz/news/trustsact-2019-documents-to-be-kept-by-trustees

Kenny, J., and Speight, K., (2020, November 10). The New Trusts Act: What does this mean for settlors, trustees, and beneficiaries? https://srblaw.co.nz/new-trusts-act

Law Commission. (April 2002). Some Problems in the Law of Trusts. https://www.lawcom.govt.nz/sites/default/files/ projectAvailableFormats/NZLC\%20R79.pdf

McLay, G. (2020). How to read New Zealand's new Trust Act 2019. 13 Journal of Equity, 325-436. http://dx.doi.org//0.2139/ ssrn. 3771008

McLeod, T. (2020a, April 18). Trust lawyer Tammy McLeod says a large proportion of Trusts are now likely not needed. She backgrounds their rise, their ensuing irrelevance, and identifies the remaining reasons a Trust might still be valuable. https://www.interest. co.nz/personal-finance// 04600/trust-lawer-tammy-mcleod-says-large-proportion-trusts-are-now-likely-not 
McLeod, T. (2020b, May 10). Trustees need to ensure they comply with the prudent investor rule and take steps to ensure the trust they manage is set up to avoid potential claims by beneficiaries, says trusts lawyer Tammy McLeod. https://www. interest.co.nz/personal-finance/l 04933/trustees-need-ensure-they-comply-prudent-investor-rule-and-take-steps-ensure.

Ministry of Justice. (2020, December 07). Trust law reform: A new Trusts Act for Aotearoa New Zealand. https://www.justice.govt. nz/justice-sector-policy/key-initiatives/trust-law-reform/

Te Puni Kōkiri. (2007). Ngā Manu Kōrihi / Communicating with Stakeholders. Te Puni Kōkiri. https://www.tpk.govt.nz/en/a-matoumohiotanga/governance/communicating-with-stakeholders

Norton, M. (2020, January 22). Will a property trust really protect you if a relationship sour? https://www.canstar.co.nz/homeloans/how-property-trusts-work-in-nz/

NZLAW. (2020). The trustees' role. Retrieved from https://nzlaw.co.nz/the-closing-chapter/the-trustees-role/

Parliamentary Counsel Office. (2019). Trusts Act 2019: Schedule I Transitional, Saving, and Related Provisions. http://www. legislation.govt.nz/act/public/2019/0038/latest/DLM7383135.html\#DLM7383152

Pearson, S. (2019, June). What's the ADKAR Model and How to Use It. https://tallyfy.com/adkar-model/

Powell, R., (2020, February 04). Whether and what to disclose, these are the questions. https://www.lawsociety.org.nz/news/ lawtalk/lawtalk-issue-936/whether-and-what-to-disclose-these-are-the-questions/

Quill. (2020, July 30). How to Set Up a Family Trust. https://www.quillgroup.com.au/wp-content/uploads/2020/07/How-to-setup-a-family-trust-structure-diagram.png

Speakman Law. (2020, May 21). Is your Trust Effective Against claims on You? https://staticl.squarespace.com/ static/583ce3b0e3df28/220a77d38/t/5ecc863db4f8delf779bf5dd/I5904620I4650/ls+your+Trust+Still+Effective+Aga inst+claims+on+you+-+21+May+2020.pdf

Stock, R. (2020, February 09). Top NZ lawyer closed his family trust and others should follow suit. Stuff. https://www.stuff. co.nz/business/1192669/3/top-lawyer-closed-his-family-trust-and-others-should-follow-suit

Walker, N., \& Shahbaz, F. (2020, August 21). Trustees - Information Retention and Disclosure. https://www.russellmcveagh.com/ insights/august-2020/trustees-information-retention-and-disclosure

Wang, Y., \& Li, H. (2019). Moral Leadership and Unethical Pro-organizational Behaviour: A Moderated Mediation Model. Front. Psychol., 10, 2640. doi:10.3389/fpsyg.2019.02640

Yu, R. (2002, July). Trust Resettlement: The Law and ATO's Statement of Principle. https://raymondyu.net/pub/papers/ TrustResettlement.pdf

Zaffron, S., \& Logan, D. (20II). The three laws of performance: Rewriting the future of your organization and your life (Vol. I70). John Wiley \& Sons. 


\title{
A NATIONAL SNAPSHOT OF STERILISATION TECHNOLOGY: PREPARING STUDENTS FOR PROFESSIONAL PRACTICE
}

\author{
Campbell Macgregor, Alison Stewart, Mary Cooper, \\ and Pavitra Dhamija
}

\section{INTRODUCTION}

Sterilising technicians clean, inspect, package and high-level disinfect or sterilise surgical instruments and other hospital equipment, along with linen, in a reprocessing unit. These units are commonly known as a central sterile services department (CSSD), the term used in this paper, but may also be called a sterile services department (SSD) or central supply department (CSD). The CSSD comprises a vital service within the hospital in which medical/surgical supplies and equipment are cleaned, prepared, processed, stored, and issued for patient care. While sterilisation technology is not a regulated health profession, it requires a highly skilled workforce, and nationally recognised competency-based courses exist in New Zealand and Australia. A recent mandated review of the sterilising technology qualifications resulted in a suite of three qualifications, each addressing a need in the industry that aligns with the requirements of the relevant industry-standard (AS/NZS 4 I87 - Reprocessing of reusable medical devices in health service organisations) that individuals responsible for the reprocessing of reusable medical and surgical instruments and equipment must hold relevant qualifications.

Toi Ohomai Institute of Technology (Toi Ohomai) is the educational provider of the Level 4 New Zealand Certificate in Sterilisation Technology to technicians and the Level 5 New Zealand Diploma in Sterilisation Technology to managers of CSSDs. These programmes of study also incorporate elements of the Level 7 Graduate Diploma in Infection Risk Management offered through the Institute to promote a wider understanding of infection prevention and control in healthcare. The reprocessing programmes were conceived based on a commitment towards ensuring graduates are well-prepared and work-ready, which included listening to, and communicating with voices from professional practice to address industry needs. This paper describes research undertaken to gain an overview of how New Zealand's more than 40 CSSDs are operating to create a broad base of understanding of students, sterilisation practitioners and training requirements that are responsive to the sector.

\section{BACKGROUND: THE HISTORICAL ANTECEDENTS}

Until the 1940s, medical/surgical supplies were processed and maintained in the wards and patient care areas in which they were to be used. Staff were not trained for this role, with reprocessing often undertaken by junior nurses. Under this system, there was considerable duplication of effort and equipment, and it was difficult to maintain consistently exacting standards for sterilisation technique and product quality throughout the healthcare facility. Yet despite this growing concern, sterilisation technology continued to be undertaken mainly by nurses within the hospital and formed part of their work practices until the early 1980s (Simpson, 1984). Some smaller hospitals and/or ones with limited surgery functions still follow this practice. 
However, the development of specialised equipment and the detailed manufacturers' guidelines for the use of this equipment has led to the development of specific industry-based training (Rutala \& Weber, 2015). Loveday and colleagues (2014) in their study that investigated the reduction of infectious diseases across hospitals in England found that evidenced-based practice, along with specialist roles and training, led to the biggest reduction in preventable transmission of infectious diseases of any other intervention. With the sterilisation technologist role being developed in New Zealand from 1974, a nationwide course was developed to support the training and development of technicians over the following few years (Davies, 2017).

The next significant event for the profession in New Zealand occurred during 2004-2005, with the recognition that increased demand meant the New Zealand Sterile Sciences Association (NZSSA) could not continue to run the then 'Sterilising Technology Course' in-house. Letters were sent to various training establishments throughout the country, inviting them to put forward a proposal for administering the course. It was an important goal for the NZSSA Executive Body that whoever administered the course did so with the input and guidance from the NZSSA. In 2005, the Open Polytechnic in Wellington was appointed as the training establishment that would administer the course. A joint partnership was agreed, with input and guidance for all course material being provided by the NZSSA. The courses that were developed at this time also became competency-based including assessments but no exams (NZSSA, n.d.). This has increased the authenticity of assessments along with increased in variety of assessment methods, including video presentations and report writing. Since then, Toi Ohomai has also been appointed as the registered provider of the current qualifications at levels 4, 5 and 7, as described earlier. The programmes offered by both polytechnics are linked from the NZSSA website.

Alongside the development of professional credentialing programmes, hospitals too have changed their operationalisation of sterilisation technology. As the number and variety of surgical procedures have grown, along with demand, and the types of reusable medical devices, processing equipment, and supplies proliferated, it became apparent that a centralised processing unit was needed for efficiency, economy, and patient safety. There are now over 40 CSSDs across New Zealand, each responsible to ensure effective decontamination and infection prevention along with the appropriate handling of specialised equipment to ensure no physical damage is done. Specific and detailed training, whether part-time and work-based, or through full-time attendance in a campus-based programme, is critical to the function of a CSSD.

Sterile Processing Departments, or CSSDs are typically divided into four major areas to accomplish the functions of cleaning/decontamination, assembly and sterile processing, sterile storage, and distribution. In the decontamination area, reusable medical devices, and supplies are cleaned and decontaminated by means of manual or mechanical cleaning processes and thermal or chemical disinfection. Clean items are received in the assembly and packaging area from the decontamination area and are then assembled and prepared for issue, storage, or further processing (like sterilisation).

CSSDs are therefore becoming increasingly complex workplaces reflecting the demands of contemporary and emerging surgical practice with intricate surgical procedures often relying on the use of specialised, highly evolved instruments. The CSSD must accommodate and be responsive to the reprocessing of advanced surgical equipment often with exacting product specifications. Consistent with developments around reprocessing of medical instruments in sterilisation in recent years, the amount of research conducted in sterilisation sciences has increased, including an article on the history of sterilisation (Davies, 2017) through to investigating the practice of just-in-time delivery of sterilised surgical instruments (Guédon et al., 2016). Furthermore, there has been significant interest in ensuring sterilisation processes are both efficient and safe (Basu et al., 2018; Shettigar, 2019). While in 2008 there was a small investigation into the CSSDs in Australia as part of a larger national stakeholder review of Australian infection control programmes (Tropea et al., 2008), currently no recent data is available about the Australian or New Zealand CSSD reprocessing equipment or level of training undertaken. While these examples of research activity within the sterilisation service exist, there has been limited work exploring the sterilisation landscape within human and animal healthcare in New Zealand. 
This study was undertaken to gain an insight into the current practice and operations of CSSDs within a New Zealand context. This study sought to understand areas of CSSD operations that included hours of operation, staffing levels, education levels of the staff employed there and reprocessing equipment used within a range of CSSD facilities in New Zealand, to provide a snapshot of the industry throughout the country. It is intended that this snapshot will inform a broad educational agenda for the service to meet the training and development needs of staff working in the area, stakeholders including trainers, education providers and the professional body (NZSSA) to support quality and best practice within the industry. This preliminary investigation will support the development teaching practice by identifying strengths and gaps in sterilisation technology equipment, operational aspects of CSSDs including staffing levels and plant utilisation currently within New Zealand. This snapshot will act a springboard to stimulate further research inquiry in this area of healthcare, using a New Zealand lens to advance the industry in the local context.

\section{METHODOLOGY}

A mixed method, cross-sectional online questionnaire was used to gain information about reprocessing equipment, operations, and staff, within CSSDs across New Zealand. Participants, identified from the NZSSA members' database, answered a total of 63 questions around the reprocessing equipment, operations, and staff in their own CSSD. The wording of the questions was developed through a pilot study, again with the assistance of the NZSSA executive, who undertook to pilot the instrument, time themselves and give feedback on the content, size, scope, and complexity of the questionnaire. On average, the questionnaire took between 15-20 minutes to complete. Ethical approval was obtained from the Toi Ohomai Research and Ethics Committee.

The survey link was delivered by email to 61 registered CSSD managers by the NZSSA and a link to the online questionnaire was placed on the NZSSA website to allow easy access, in case some managers and their associated CSSD were for any reason, not within the NZSSA database. The accompanying email explained the purpose of the research, with a more detailed Participant Information Sheet attached outlining the usual ethical protocols around anonymity, confidentiality, secure storage of the data and intended use of the findings.

Informed consent was given initially by the managers starting the survey, as indicated by a statement on the first page indicating that completing the questionnaire items implied consent for the responses to be used, and also that they had the authority to supply this data. Finally, before they submitted their survey, participants were once more reminded that by submitting the information they were giving consent for this information to be grouped and reported.

Twenty-two responded to the survey, representing a 36\% response rate. While this is less than $50 \%$ of the possible respondents 20 of the 22 (90\%) represent hospital CSSDs. These respondents represent the spectrum of CSSDs and include participants from small hospitals through to large tertiary hospitals within both the public and private sector. This small sample could be considered representative of the medical reprocessing industry as $92 \%$ of the remaining possible respondents (39 non-responders) represent CSSDs providing services to surgical environments.

Data was analysed initially using Survey Monkey and its associated data reporting and analysis tool. Once this was completed, descriptive data was further analysed using Microsoft Excel to allow averages, means, and other statistical information to be extracted. Requesting the name of each location, although not the names of the participants, meant that where some sites had numerous managers, the research team was able to edit out duplicate data entry. Ultimately the research team were satisfied that the questionnaire tool had provided an appropriate mechanism to provide a demographic/pictorial representation of what the sterilisation technology landscape looks like in New Zealand. 


\section{RESULTS}

\section{Staffing}

A $36 \%$ response rate was obtained from 22 respondents $(n=22)$ from 61 requests. Figure I shows the primary area of service delivery for each of the CSSD responses. Over $90 \%$ of our respondents managed a CSSD within a hospital, with approximately $5 \%$ responses coming from veterinary services $(n=I)$ and with another $5 \%$ from GP practices $(n=l)$

Figure I. Participants' primary areas of service delivery

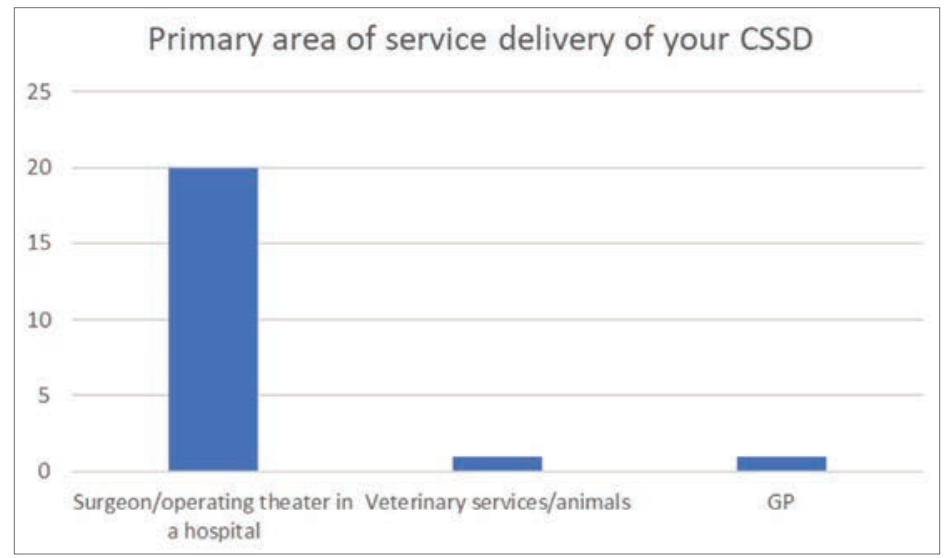

The CSSD managers reported that full-time staff turnover was very low with only $22 \%$ of staff being new or inducted into the workplace within the last 12 months (Figure 2). A similar trend was seen with part-time staff, with $33 \%$ of the part-staff newly employed within the last 12 months (Figure 3). This staff movement, new recruits and departures from the service may not provide a true picture of staff turnover. As new recruits present a training and development need and opportunity, this number is the focus on attention in the study.

Figure 2. Full-time staff turnover in CSSDs in the past 12 months.

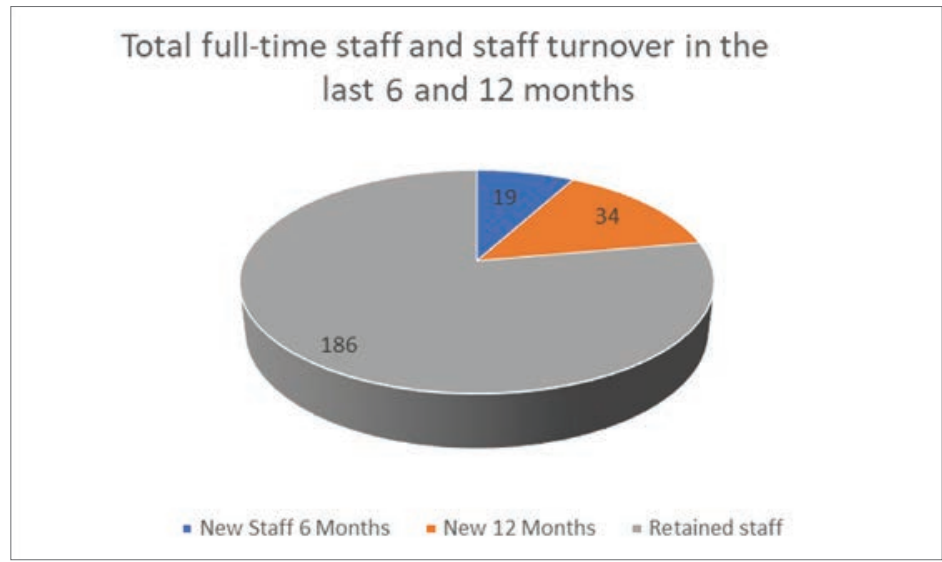


Figure 3. Part-time staff turnover in CSSDs in the past 12 months.

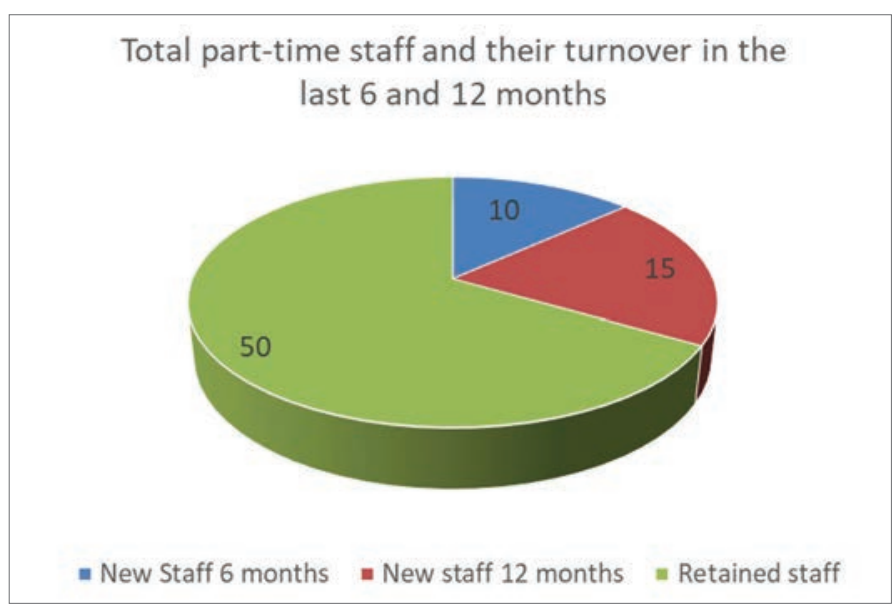

As part of the collective agreement with hospitals that have a CSSD, CSSD technicians need to have a Level 3 (the pre-20I8 qualification) or a Level 4 (qualification post 20I8) certificate/diploma within two years of starting work within a CSSD department. Our results indicated that 54\% of current CSSD staff hold one of these qualifications (Figure 4).

Figure 4. Percentage of staff holding the required qualification.

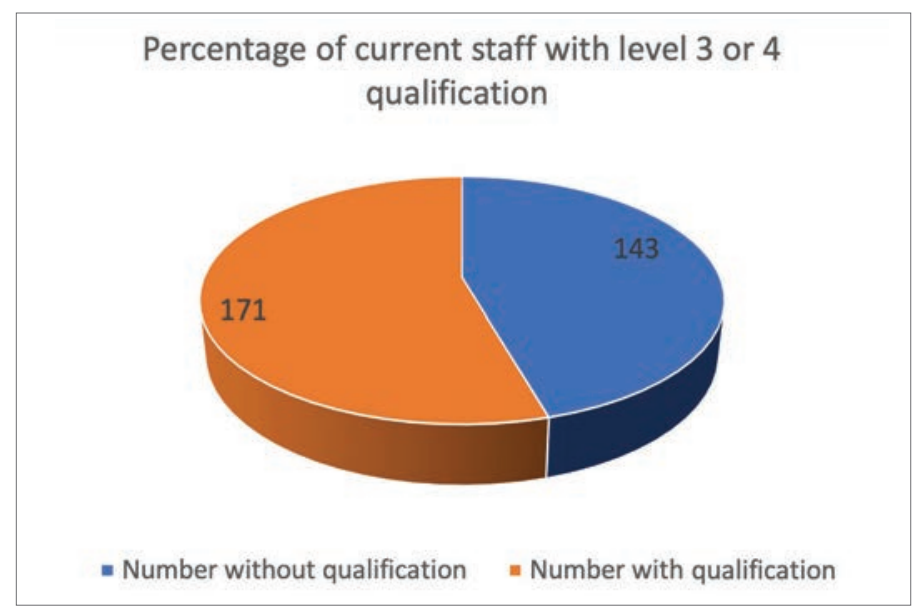

A final question related to staffing asked CSSD managers about the level of training uptake for the leadership qualification (Level 5 Diploma in Sterilisation Technology). While this was a new qualification, over 63\% of the CSSDs that responded have or are gaining staff members with this industry-specific leadership qualification (Figure 5). 
Figure 5. Percentage of CSSDs with staff who hold level 5 qualifications.

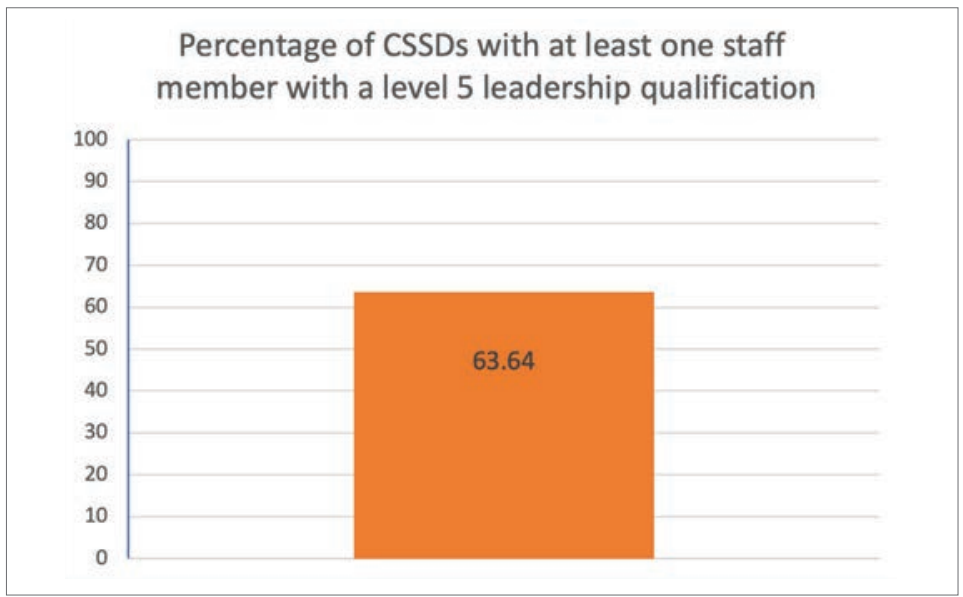

\section{Service Operation}

Figure 6 provides an analysis of plant utilisation among the participating CSSDs with a breakdown of the number of the average operating hours each day, per week. Further analysis of the daily operations shows CSSDs were functioning for 12.7 hours per weekday on average and 6.3 hours per each weekend day halved. While the majority of CSSDs operate five days a week, the results reflect that 2 larger CSSDs reprocess instruments 24 hours per day, seven days per week (Figure 7).

Figure 6. Days of operation per week per CSSD.

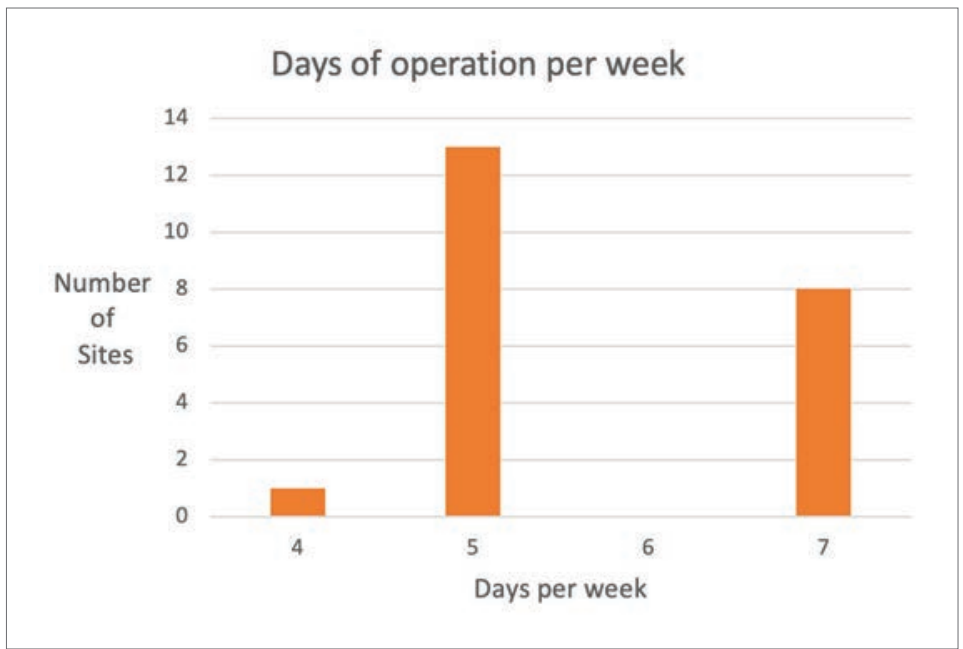


Figure 7. Hours of operation Monday-Friday (blue) and weekends (orange).

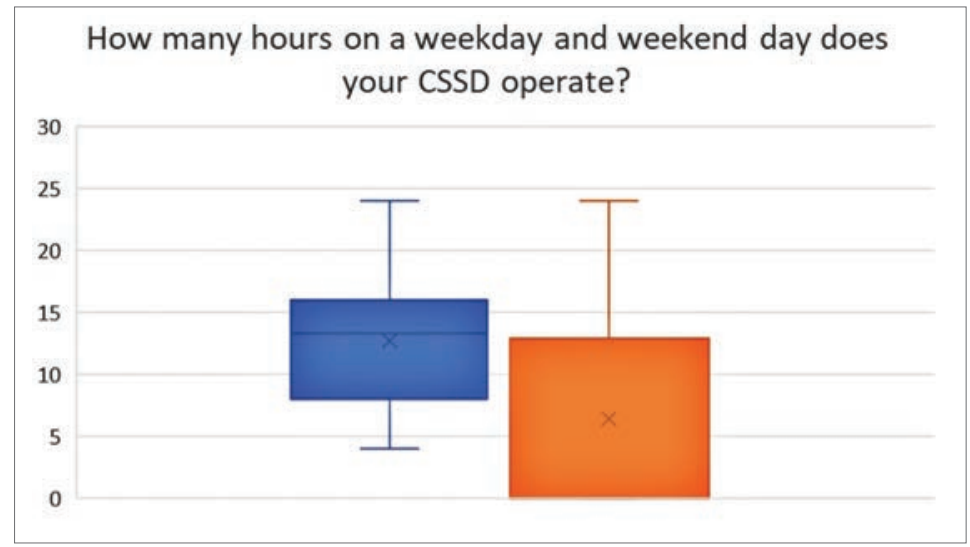

All CSSD departments that responded to the questionnaire were using autoclaves (sterilisers employing dry steam under pressure) for high pressure and high temperature sterilisation. However, of the $73 \%$ of CSSDs using low temperature sterilisation, a quarter of respondents were now using ethylene oxide (5\%) and the rest have switched to hydrogen peroxide (95\%) (Figure 8). To note is that six (27\%) of managers that responded identified that they did not have low temperature sterilisation option within their CSSD.

Figure 8. CSSDs using hydrogen peroxide sterilisation.

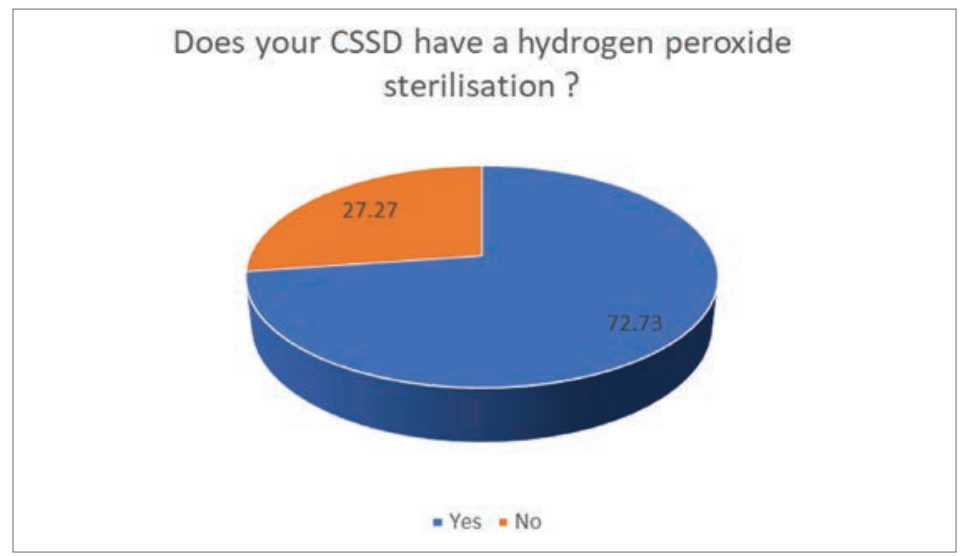

No CSSD in New Zealand has Ozone sterilisation. Ozone sterilisation is a technology that has been available as an antimicrobial agent since the early 2000s after being developed into a sterilising agent for heat sensitive medical devices (Dufresne et al., 2004). Ozone is an oxidising agent generated through application of electrical energy to a combination of water $\left(\mathrm{H}_{2} \mathrm{O}\right)$ and medical grade oxygen $(\mathrm{O})$. This splits some of the oxygen molecules in half into singlets of $\mathrm{O}$. These single $\mathrm{O}$ atoms attach to $\mathrm{O} 2$ for short periods of time before reverting to oxygen. While the atoms are attached, sterilisation is achieved through oxidisation of micro-organism carbon bonds. The residues are non-toxic oxygen (Tuttnauer, 2017, April 24). As this technology has been around for a while, managers were asked if they had heard of this: around $60 \%$ of the respondents said they had no knowledge of 
this development (Figure 9). Awareness of emerging technologies, such as ozone sterilisation, has been included in this research as an indicator of whether new knowledge of industry trends is being acquired and maintained.

Figure 9. Awareness of ozone technology.

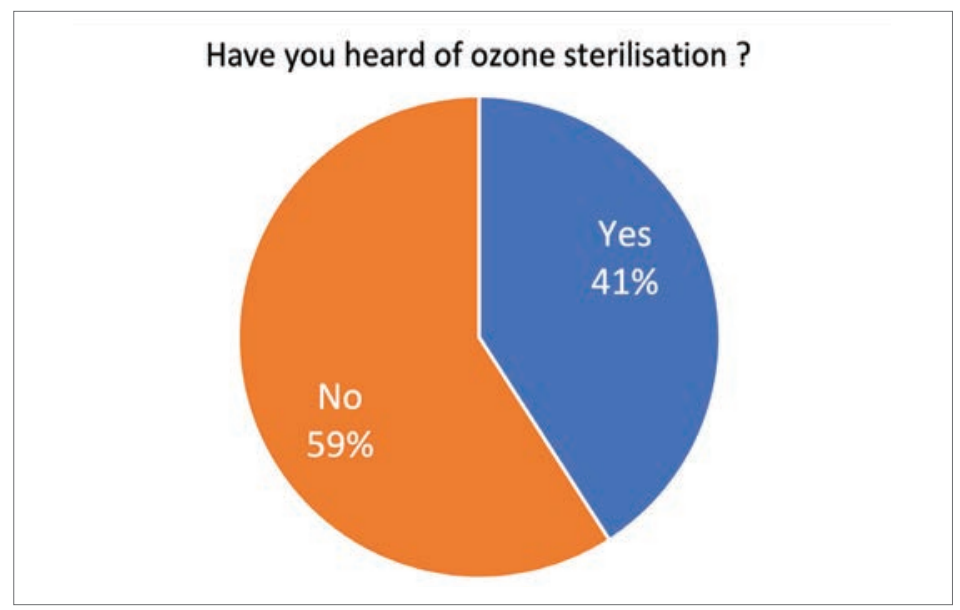

Finally, to complete the picture of CSSD setups, managers were asked if they used liquid chemical sterilisation, to which around $73 \%$ answered yes (Figure 10). Next, they were asked if they use high level disinfectant as well: 63\% did (Figure II). Questioning around these technologies is significant as CSSD was not naturally involved in the use of these sterilising and high-level disinfection options before the turn of the century. High level disinfection was primarily the domain of endoscopy services. The data demonstrates an increasing specialisation for some CSSDs is endoscopy reprocessing. Some hospitals and CSSD departments have set up specialist endoscopy suites, but over 71\% undertake endoscopy sterilisation within the CSSD department (Figure 12). This indicates a significant shift in service operation. If staff are being provided to specialist endoscopy suites this has an impact on how resources are used but is not necessarily an indicator of whether one option is better than the other (resourcing specialised endoscopy suites or centralised in CSSD).

Figure 10. Use of liquid chemical sterilisation.

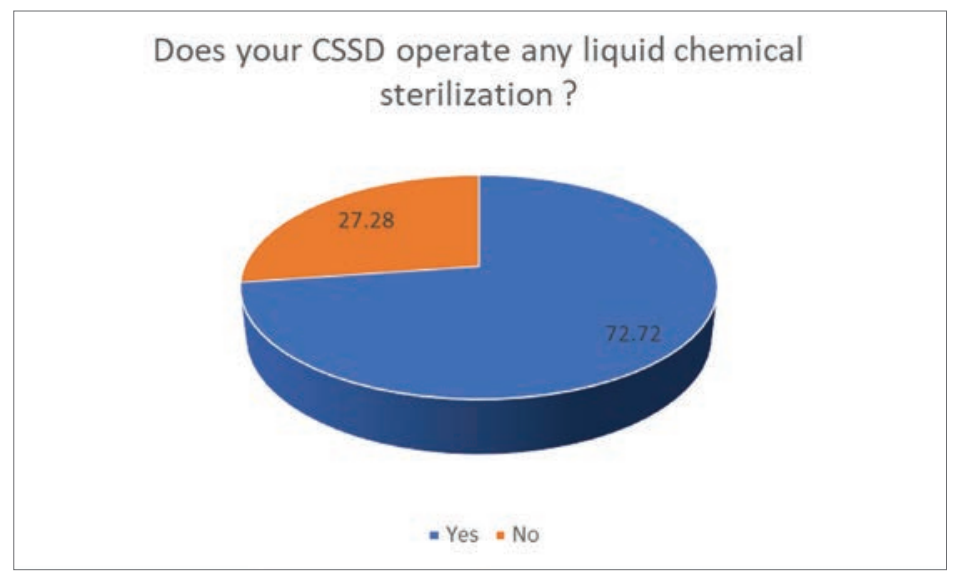


Figure II. Use of additional high level disinfection.

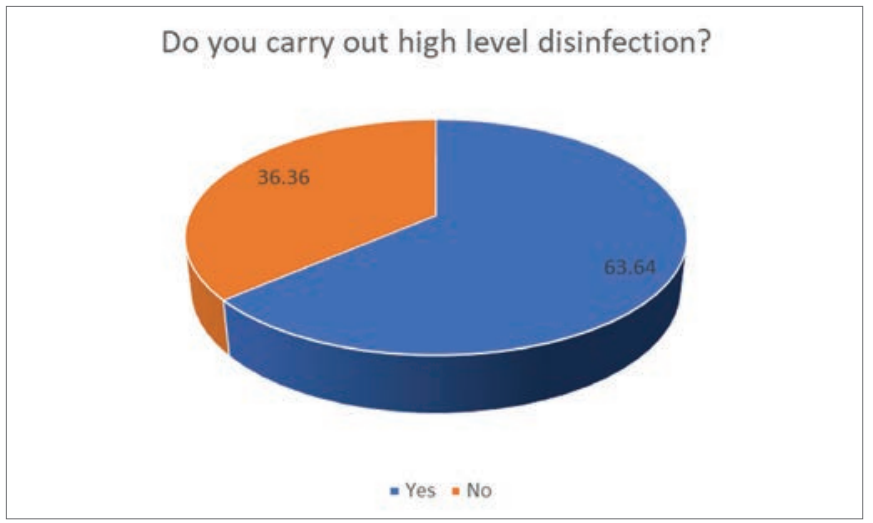

Figure 12. Where reprocessing is conducted in the hospital.

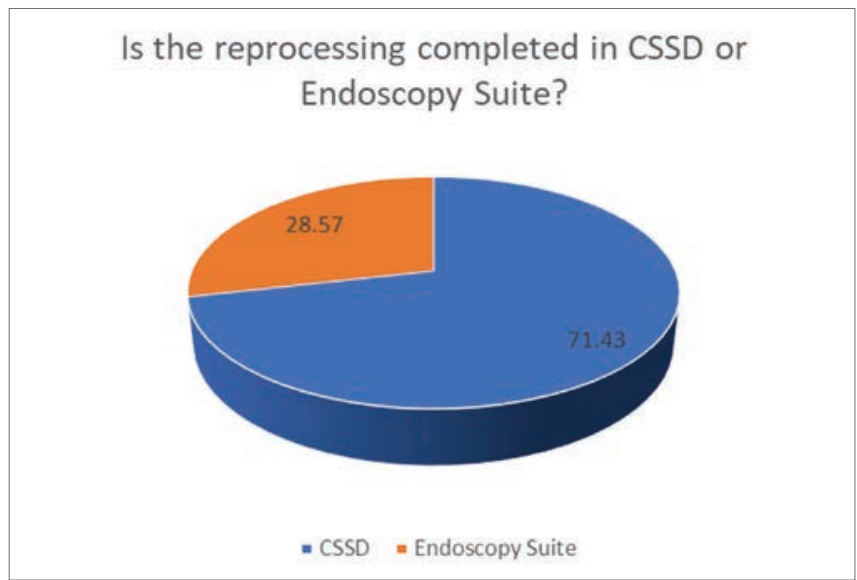

\section{DISCUSSION}

The current snapshot of sterilisation technology services across New Zealand appears to indicate an overall stability of staff within the industry with $22 \%$ of full-time staff newly employed within the previous 12-month period. The current annual employment rate across the processing sector suggests staff movement within this highly demanding area of healthcare remains at a lower level and at least equal to the New Zealand healthcare industry average of $18.8 \%$ for voluntary and involuntary staff turnover rate of 18.8\% (Lawson Williams, 2019). The turnover of staff was not a focus of this study and may only be indicative of the trend as recruitment of new staff may not only be a replacement strategy but it may arise in response to increased demand, development, or expansion within a CSSD.

The study revealed high levels of training within the sterilisation industry with over $50 \%$ of employed members holding an industry specific qualification. This is a significant achievement for a non-regulated health workforce that does not have a long history of a range of higher qualifications for staff compared with the regulated health professions in New Zealand. Addressing the training and development needs of new recruits and existing 
experienced staff focuses attention on the importance of industry specific and correct training and qualifications to ensure high levels of quality within a service dealing with reprocessing of technically advanced specialised equipment dedicated towards preventing the risk of infection. Inadequate training for those working in this demanding environment has been shown to have a flow-on effect within this sector of the industry and in healthcare in general, for example, among nursing and medical teams (Han et al., 20I4). With NZSSA making the qualifications mandatory within the first two years of employment in a CSSD unit, this highlights the need for industry-wide use of up-to-date, evidence-based practice and the importance of work-focused and workbased learning to be in line with industry requirements (Campbell et al., 2015). Newly graduated sterilisation technicians have a critical role, especially in a post-COVID-19 climate where they are recognised as essential workers. Understanding equipment, protocols and how to follow manufacturers' recommendations is hugely important (Alfred et al., 202I) to ensure safe and effective sterilisation while protecting instrument integrity and equipment longevity.

The snapshot using the online survey showed that there is capability within the New Zealand health sector for increased CSSD utilisation, according to the amount of reprocessing needed, as only a few represented in the survey were operating 24 hours a day, 7 days a week. While healthcare is recognised as an around-the-clock, on-demand service, sterilisation still follows more traditional business hours in most cases. While increased shift work might become more of an option as pressure on the healthcare sector in general continues to increase, stress levels and mental and physical health of staff may be affected. This is an important consideration for educators in this area to be mindful of, and in the future the impact of undertaking shift work may need to be included within training and development of staff in this sector (Melnyk et al., 2020).

While ozone technology is not currently in use in New Zealand, the response to the questions around its use and knowledge offers insight into the need to provide education to all managers to increase knowledge of current trends in sterilisation practices and the benefits and limitations of the use of technologies that are in use elsewhere throughout the world. Steels et al. (2020) in their connected cities study, found that understanding the global context and technologies allows for individuals within the health sector to make better and informed decisions related to practice. Training therefore needs to not just focus on what is being undertaken within the current CSSD that the technician works in, but should also consider the equipment available within a global context. This observation is supported by Bunn and colleagues' (2020) research on diabetes technicians and the importance of understanding worldwide techniques to improve their ability to meet the needs of their patients.

As technology has developed, a recent trend worldwide has been to move away from ethylene oxide replacing it with hydrogen peroxide treatment (McEvoy \& Eveland, 2020). The same trend away from this method of sterilisation was apparent in this study as only a small percentage (4.5\%) of CSSDs within New Zealand still use ethylene oxide. With the change to hydrogen peroxide, recent manufacturers' guidelines contradict each other on the risks to technicians and how the units need to be installed and operated safety (Kümin et al., 2021); all of which provides an opportunity for ongoing research. Work in this area is timely and especially important given the prominent level of uptake of this new technique for low temperature sterilisation revealed in this study with ethylene oxide usage decreasing and hydrogen peroxide being the preferred method of low temperature sterilisation in NZ.

\section{LIMITATIONS}

While this study is a first of its kind and offers important insights in the staff and operations of CSSDs in New Zealand, the study itself has some initiations. Data was gathered using an online service so bias is inherent in the self-selection of this method used for this online survey. The target sample of 61 CSSD managers registered on the NZSSA database invited to participate in the survey may not include all CSSD managers across healthcare facilities that reprocess medical equipment. Other sectors involved in reprocessing of medical equipment and those associated with non-human sterilisation may not be members of the association and as a result would not 
be captured in this survey. The $36 \%$ response rate is low for a nationwide industry with $90 \%$ of the responses gained from those associated with hospital-based sterilisation facilities.

There is significant diversity around the sterilisation of equipment used in human and animal healthcare. Despite its limitations, this study provides useful initial understanding of the sterilisation landscape to inform training and development and ongoing research activity within the industry.

\section{CONCLUSION}

This investigation into the CSSD environment in New Zealand has identified that there is some variation between CSSDs, related to staffing and operating processes and environments. This is exciting for students, who are often drawn to healthcare technology fields through an interest in systems and quality improvement. Sterilisation technology is an essential aspect of a hospital-based healthcare provider's delivery, and the qualified specialist staff who run the CSSD units are well-respected as skilled and essential employees in their role of supporting surgical teams and preventing the risk of infection. Tertiary education must provide students with the best possible platform to enter and engage in professional practice, which is achieved by listening to the voices of our industry partners. Working together to provide educational opportunities that enhance knowledge and skill plays a significant role in standards of practice and quality outcomes within the sector. The snapshot results of this research are useful for educators, and the sterilisation sector's guiding body, the NZSSA, who support this research project. Other healthcare specialties might also find this study useful as a starting point for their own national surveys. Finally, this research highlights opportunities for further pathways that may include the experience of staff working in the dynamic area of healthcare, health and safety within this technically driven environment and the introduction of new reprocessing technologies including the way in which hydrogen peroxide is phased into use, and the standardisation of implementation with CSSDs.

This snapshot provides a gateway for understanding a sector of the healthcare industry that is often hidden from the public gaze but is plays a pivotal role in the delivery of cornerstone and high-profile areas of healthcare delivery of human and non-human health related services.

Campbell Macgregor ko Tākitimu, ko Hananui kā mauka, ko Kāi Tahu kā iwi and is a principal lecturer and academic lead-health at Toi Ohomai Institute of Technology with an interest in incorporating Mātauranga Māori and cultural responsiveness. Campbell is active in research in the sterilisation sciences, bone health of older athletes and indigenous solutions.

Email: Campbell.macgregor@toiohomai.ac.nz

Alison Stewart has leadership roles in the sterile sciences community as a member on the Australian standards committee and Treasurer for the New Zealand Sterile Sciences Association. Alison also is a Lecturer and teaches on the New Zealand sterilising technology qualifications at Toi Ohomai Institute of Technology.

Mary Cooper is a senior lecturer within the Health Department at Toi Ohomai Institute of Technology, leading programmes in infection risk management and health, with a research focus in infection risk management and sterilisation sciences. Mary was part of the development team for the Diploma in Sterilising Technology and has taught on the programme since its inception in 2019.

Pavitra Dhamija is a senior academic staff member at Toi Ohomai Institute of Technology, with research interests in infection risk management. Pavi is currently teaching on the New Zealand diploma in sterilisation technology and has a leadership role in the sterilisation suite of programmes.

(Toi Ohomai ethics approval for the research reported in the paper: TRC 2020.018)

Scope: (Work-based Learning), 2, 2021 


\section{REFERENCES}

Alfred, M., Catchpole, K., Huffer, E., Fredendall, L., \& Taaffe, K. M. (202I). Work systems analysis of sterile processing: assembly. BMJ Quality \& Safety, 30(4), 27I-282. https://doi.org/l0.1136/bmjqs-2019-0I0740

Basu, D., De, M. S., Rafikul, S. K., \& Goel, G. (2018). Requirement of clinical waste autoclave in a healthcare institution: A minireview. Journal of The Academy of Clinical Microbiologists, 20(2), 74. https://doi.org//0.4l03/jacm.jacm_22_18

Bunn, C., Harwood, E., Akhter, K., \& Simmons, D. (2020). Integrating care: the work of diabetes care technicians in an integrated care initiative. BMC Health Services Research, 20(I), I-II. https://doi.org/I0.1I86/s I2913-020-05 I09-5

Campbell, J. M., Umapathysivam, K., Xue, Y., \& Lockwood, C. (20I5). Evidence-based practice point-of-care resources: A quantitative evaluation of quality, rigor, and content. Worldviews on Evidence-Based Nursing, 12(6), 313-327. https://doi. org/pdfdirect/10.1111/wvn.12114

Davies, M. (2017). Unwrapping the history of sterilisation. ACORN: The Journal of Perioperative Nursing in Australia, 30(4), 4I-46. https://doi/l0.3316/informit.317349524505125

Guédon, A. C., Rakers, T. J., Wauben, L. S. G. L., Meeuwsen, F. C., Hoeijmans, V., van der Elst, M., ... \& van den Dobbelsteen, J. J. (2016). Just-in-time delivery of sterilised surgical instruments. BMJ Innovations, 2(2), 58-64. https://doi.org//0.1/36/ bmjinnov-2015-00009|

Han, K., Trinkoff, A. M., Storr, C. L., Lerner, N., Johantgen, M., \& Gartrell, K. (2014). Associations between state regulations, training length, perceived quality, and job satisfaction among certified nursing assistants: Cross-sectional secondary data analysis. International Journal of Nursing Studies, 5I (8), II35-||14I. https://doi.org/I0.1016/j.ijnurstu.2013.12.008

Kümin, D., Albert, M. G., Weber, B., \& Summermatter, K. (2021). The Hitchhiker's Guide to Hydrogen Peroxide Fumigation, Part 2: Verifying and validating hydrogen peroxide fumigation cycles. Applied Biosafety, 26(I), 42-5I. https://doi.org//0.1089/ apb.21.921099

Lawson Williams. (2019). New Zealand staff turnover survey report 2019. https://www.lawsonwilliams.co.nz/cms/files/ Lawson-Williams-National-Staff-Turnover-Survey-Full-Report-2019.pdf

Loveday, H. P., Wilson, J. A., Pratt, R. J., Golsorkhi, M., Tingle, A., Bak, A., ... \& Wilcox, M. (20l4). epic3: National evidencebased guidelines for preventing healthcare-associated infections in NHS hospitals in England. Journal of Hospital Infection, 86, SI-S70. https://doi.org/I0.1016/S0195-670I(I3)600I2-2

McEvoy, B., \& Eveland, R. (2020). Vaporised hydrogen peroxide: A well-nnown technology with a new application. Biomedical Instrumentation \& Technology, 54(sI), 74-79. https://doi.org/l0.2345/0899-8205-54.s3.74

Melnyk, B. M., Kelly, S. A., Stephens, J., Dhakal, K., McGovern, C., Tucker, S., ... \& Bird, S. B. (2020). Interventions to improve mental health, well-being, physical health, and lifestyle behaviors in physicians and nurses: A systematic review. American Journal of Health Promotion, 34(8), 929-941. https://doi.org/10.1177/0890117120920451

New Zealand Sterile Services Association (NZSSA). (n.d.). Training and Education. https://nzssa.org/

Rutala, W. A., \& Weber, D. J. (20I5). Disinfection, sterilisation, and control of hospital waste. Mandell, Douglas, and Bennett's Principles and Practice of Infectious Diseases, 3294-3309.e4. https://doi.org/I0.1016/B978-I-4557-480I-3.0030I-5

Shettigar, M. S. (2019). A comparative study on efficiency of CSSD of selected hospitals. (Doctoral dissertation, Rajiv Gandhi University of Health Sciences), I-91. https://www.academia.edu/

Simpson, R. (1984). Priorities for hospital cleaning, disinfection, sterilisation, and control of infection. British Medical Journal (Clinical Research ed.), 288 (6434), 1898-1900. https://www.ncbi.nlm.nih.gov/pmc/articles/PMCI441747/pdf/bmjcred00506-0044.pdf

Steels, S., Ainsworth, J., \& van Staa, T. P. (202I). Implementation of a "real-world" learning health system: Results from the evaluation of the Connected Health Cities programme. Learning Health Systems, 5(2), el 0224. https://doi.org/I0.1002/ Irh2.10224

Tropea, J., Brand, C., \& Roberts, C. (2008). A national stakeholder review of Australian infection control programs. Australian Commission on Safety and Quality in Healthcare. Australian Government. https://www.safetyandquality.gov.au/sites/ default/files/migrated/20065-Review-InfectCtrIProg.pdf 


\title{
PROFESSIONAL DEVELOPMENT THROUGH THE HARMONY OF DIFFERENT VOICES WITHIN CONSTRUCTIVE CRITICAL CONVERSATIONS
}

\author{
Marcia Johnson
}

The question of relevance of constructive critical conversations to professional development emerged from a dual method autoethnographic and hermeneutic phenomenological enquiry into the essence of effective constructive critical conversations in the workplace from the perspective of tertiary education quality. For the purposes of the enquiry, constructive critical conversations (CCCs) were defined as those conversations which exist in a constructive environment which utilise criticality within an empathetic interaction to build upon existing knowledge or understanding. Discourse analysis through a transdisciplinary lens revealed CCCs play a crucial part in professional development in the workplace.

These findings fit within a concept of He aha te kai ō te rangatira? He Kōrero, he kōrero, he kōrero! (What is the food of the leader? It is knowing, it is sharing, it is communicating!) Constructive critical conversations allow for individuals' voices to harmonise in a communal chorus toward a socially constructed overture. While every individual voice is different, it is the sum of the voices which gives depth to the chorus. Further, each individual will have their own unique internal connectedness regarding the experience and what they have gleaned from hearing others' vocal parts within the harmony. The overture result of the CCC is professional development of the engaged participants.

\section{ENVIRONMENT OF CHANGE}

"And it's up to you to keep yourself engaged and productive during a work life that may span some 50 years" (Drucker, 1999, p. I). Drucker's advice over two decades ago was part of an acknowledgement across academia and industries that careers no longer sustained employees in the sense of one expertise being sufficient for the duration of a person's career. His advice was to the individual who is self-motivated and self-aware enough to continue to grow and contribute in relevant ways.

Similarly, and more recently, Zao-Sanders (202I) points out the need for employers to recognise a different approach to learning in the workplace. Lifelong learning is appealing to new employers, yet it could be difficult to assess. Zao-Sanders writes in the Harvard Business Review that employers should ask how a new recruit learns. The need for continual learning is crucial to the workplace, to an organisation keeping pace with unknown future changes, and to the sustainability of the organisation through the changes.

\section{ECLECTIC LEARNING OF THE INDIVIDUAL}

Facilitation of eclectic learning of the individual through engaging in CCCs points to an educative solution to professional development which is focused on an unknown future. Eclectic learning is not necessarily a new concept, yet no learning theory similarly encapsulates the entirety of internal connectedness that the individual 
brings to the workplace. This learning is eclectic in that it draws from the individual's different interests and learning within different contexts to form a unique connectedness within the individual. It is eclectic in the sense of the unique combination of perceptions and conceptions that the individual has, thus drawing upon both subconscious and conscious connectivity within the individual. These connections are made possible because of the individual's choices to take advantage of opportunities to engage in new experiences. When the individual experiences something new, reflection enables the individual to consider from within their unique connectedness toward learning. This reflective learning defines professional development in the workplace.

An analogy can be drawn between the eclectic learning of the individual and a vocalist or musician who learns as opportunities come up. A broad exposure across many different styles of music enables the musician to join impromptu jam sessions. This is where each individual adds value from within the musician's own range of musical understanding, yet within a shared musical structure. It is a spontaneous harmonising of skills across the group confined within the temporality of the event. The shared experience may draw upon elements from jazz, pop, rock, country, or any other genre which the musicians incorporate to add value in the moment.

Likewise, eclectic learning is prompted by the individual's unique combination of interests across multiple discipline spaces without regard to, or recognition of, developed disciplinary boundaries. The eclectic-ness of the individual's learning has a theme which can only be truly known by the individual. The eclectic nature of the learning emerges from the connections of understanding which the individual makes across their unique combination of interests and experiences. Further, the breadth of connections of the eclectic-ness over time adds value to the individual's overall ability to connect new experiences within their existing knowledge. Notably, the uniqueness of these combinations of connections does not mean the broad eclectic-ness of the individual's learning cannot be appreciated by the organisation. Rather, this uniqueness adds to an ability to innovate in a transdisciplinary way because the learning process itself has been transdisciplinary, forming internal connectedness which is irrespective of disciplinary boundaries.

Similarly, the musician is able to join in and add value to the overall overture from within their ability. If the individual knows how to play multiple instruments or sing different vocal parts, the contribution comes from the connectedness of those abilities, not from employing more than one instrument or vocal part simultaneously. Thus, the contribution is from the entirety of the individual's internal understanding and connectedness yet within the need of the context.

\section{REFLECTION}

The concept of reflection and the internal mechanisms and external impacts on internal processes are important in realising a notion of eclectic-ness. Moon (1999) offered a comprehensive review of theory and practice of reflection as a learning tool, asking questions of the repetition implied by the term. Namely, how is it possible to revisit something to learn through reflection, when the term itself infers that learning has occurred in the first instance. Whence cometh the initial learning upon which the reflection works? Moon has entirely answered the question within terms of reflection; however, there continues to be a gap regarding the accountability of the connectedness which informed the initial learning. This gap is the space which accounts for the individual's unique internal connectedness from the beginning of their existence.

The activity of reflecting on an experience can bring subconscious connectedness into the conscious realm for the individual to engage critically from within their unique connectedness. One simple example of this could be found in unconscious bias. An individual may have an experience which has influenced how they perceive, or think, about something or someone. Once the individual reflects on their inner feelings or ideas, they are able to consciously consider the matter with criticality. The original perception or conception does not necessarily change. This does not matter. It is the reflective outcome which matters. The individual's reflection allows the 
individual to make sense of a new experience in light of the earlier experience, thus forming a new conscious connectedness.

In terms of voices within a chorus, the reflective, eclectic learner is similar to the individual voice which has been purposefully developed over time to be responsive within different singing environments. The communal effort may require a strong solo voice to contrast while building toward a chorus which overtakes the solo. In the end, it is the entire performance which is beneficial with no one part able to be left out in the appreciation of the music.

\section{SOCIAL IMPACT}

Singing or playing an instrument in a group is a social event. Each individual not only contributes but listens for the impact of that contribution so as to be able to adjust. For example, volume may need to be adjusted, flat or sharp notes tempered.

Reflection, while seen as an individual method of learning, is enhanced through a socially collaborative process such as a community of practice where there is shared interest, knowledge and expertise, and members are active practitioners in the shared area of interest (Hatcher et al., 2016). In fact, Day (1993) contends that reflection requires a confrontation of some kind to mature to development. This could occur within a community of practice and impact as accelerated learning (LMhieu et al., 2017).

In the workplace, conversations provide social opportunities for transformation through 'dialogical sense-making' (Grzegorczyk, 2018). Goodwin (2013) agrees that, in the workplace, conversations are the point at which sense is made and collaboration reinforces the results of reflection. This highlights the value of conversations as an opportunity for learning in the workplace. Conversations take place naturally, occur in any workplace setting, and allow individuals to contribute or engage at a level they are comfortable with.

In a musical setting, this is similar to newer musicians taking on a range of notes which are not difficult to hit. Likewise, more experienced musicians are expected to tackle a wider range of notes or the more difficult high or low notes. Together, their combined work makes sense within the collaborative effort.

Awareness to what is happening is an integral part of reflection. This is where experience of a deep level of expertise gives an understanding or feeling for what level of awareness is required within a new context. This awareness adds depth to the ability to reflect (Roth, 20I5). Kahneman explains a deep concentration level achieved within a state of flow as "...maintaining focused attention on these absorbing activities requires no exertion of self-control, thereby freeing resources to be directed to the task at hand" (Kahneman, 20 I2, p. 4I). In practical terms within the workplace, this means that the individual who is interested in learning will maintain focus throughout the experience which is informing the individual's learning.

Similar to a choral group, where many individual voices are contributing, the mindfulness of reflection within a CCC seeks to find that place of harmony. This is where everything comes together in one concerted effort. The individual's voice adds value to the movement and blend of what is occurring within the chorus. As the individual hears others' voices, they respond from within their own connectedness and understanding of what is required, or what will add value. In this way, the overall harmony becomes complete.

\section{COMMUNITIES OF PRACTICE}

Singing different vocal parts at different times, and thus increasing the individual's repertoire, is similar to purposefully engaging in new experiences toward learning eclectically. Intrinsic motivation through eclectic personal interests allows the individual to have experiences in the blurred edges of multiple disciplines' boundaries 
through engagement in different communities of practice. Thus, the unique combination of experiences over time enables the individual's eclectic internal connectedness to impact the workplace context. A practised ability to adapt knowledge to new contexts is both anticipatory and evolving. Thus, as Heidegger (1953/2010) presented, there is a knowing before a matter is known.

In terms of voices within a shared chorus, the individual is sure of their own vocal part, yet able to adapt and contribute through harmonising and complementing others' vocal parts. Due to a deep understanding of how voices blend, the vocalist is able to anticipate within a musical work.

This is similar to understanding from different perspectives within the CCC. The individual's voice does not jar because there is purposeful harmonising within a shared chorus. There is a knowing of what is required before the moment comes when it is realised or known.

\section{CONSTRUCTIVE CRITICAL CONVERSATIONS}

Constructive critical conversations provide opportunities in the workplace for eclectic learners to reflect-inaction. Eraut (1995) argued that reflection-in-action events occur in real time without the opportunity to pause and consider what is happening. This is not a problem for the eclectic learner whose unique connectedness and reflective habit enables the individual to be in a state of flow, where a challenge is met by a level of expertise. Lave (2019) has built upon the concept of reflection-in-action and explains more readily the connection with a concept of flow as developed by Csikszentmihalyi (1997).

This is similar to the harmonic flow of an overture. It is powerful because of the reflection-in-action which is occurring simultaneously by all participants. The minute adjustments made by each individual as they respond at precise moments within a piece is similar to when individuals within a CCC recognise and respond from their eclectic connectedness in the moment.

Within the data from this enquiry were strong indicators for a need to engage in CCCs for professional development within the workplace. Education quality specialists noted CCCs "encourage reflection in the learner." This was in the context of teaching team members who were expert in non-education disciplines becoming more knowledgeable and effective in the context of tertiary education. One participant stated that, as an opportunity for learning, a CCC is "not something we just attend. The purpose for that attendance is what's important." This comment is in line with a need for mindfulness with intent to learn through the CCC experience. In other words, it is the individual's choice to engage in the event with purpose. This is also aligned to Roth's (2015) concept of becoming aware and that of reflection-in-action. However, eclectic learning as a concept goes beyond reflection-in-action. It is the connectedness of all prior experiences and learnings toward future anticipatory learning. It cannot be defined by the individual in words for others to understand. Yet the connectedness held uniquely within the individual's entirety is available for collaboration within a constructive critical conversation.

Collaboration is where dissonance can be addressed. Dissonance is when something jars against what is believed to be known. This must be resolved, and in the process learning occurs. The theory of dissonance has evolved (Bhat, 20I4; Chew, 2015), and is where eclectic learning and, later, tacit knowledge is able to contribute to CCCs. Reflecting-in-action requires not only resolving dissonance in the individual's own mind, but within the context of CCCs the individual is also attempting to understand and assist resolving dissonance in others' minds. It affords considering a matter from different perspectives, and from that ability predicting what may be useful within the context of the current conversation. This is entirely separate from what an ideal may be. It is a recognition that, in this moment, at this point in time, this CCC requires contribution in this way because it will benefit the CCC. This temporal urgency is important because it creates the focus for contextual reflection-inaction (Buonomano, 2017; Eraut, 1995; Heidegger, 1953/2010). 
If considered within Foucault's (20II) ideas of parrhesia and care of the self, the CCC could be seen as the catalyst for creating the emancipatory space within which the individual can be free to innovate on behalf of the organisation.

Within a musical context, this concept could be seen from the perspective of the ability of musicians to understand possibilities within the musical style and how their own abilities can contribute to the overall sound. It is also an empowering accountability of each musician to address dissonance within the combined work.

\section{PROFESSIONAL DEVELOPMENT}

Relationships are an important part of the complex human social interactions and therefore impact any professional development achieved through CCCs in the workplace. Ramachandrin and Blakeslee (2005) relate how patients who have suffered strokes may employ self-deception in their interactions with others. They begin with a quote from Thomas regarding social sciences: "Our behaviour toward each other is the strangest, most unpredictable, and almost entirely unaccountable of the phenomena with which we are obliged to live" (Lewis Thomas as cited in Ramachandrin \& Blakeslee (2005, p. 127). Ramachandrin is an example of an eclectic learner himself when he draws from biology and philosophy to discover answers to psychology questions. His work is an example for others to learn broadly as opportunities are presented because whatever it is could mean something substantial to the individual in future. His comments also allude to the significance of time and how the subconscious is aware of more than can be articulated until coming to an awareness within an event, similar to what Roth describes in his own narrative (Roth, 2015). The perceptions which are captured lend themselves to the conceptions of the conscious mind through reflection.

It is not unusual for individuals to know more than they can articulate until some point in the future. Connectedness is happening at both subconscious and conscious levels, and is not bound by disciplinary boundaries within the function of the brain. Lyotard (2004) recognised this in acknowledging that events cannot be fully represented. The relatability of what has occurred is only able to be represented by established language or symbols, whereas, the event encapsulates elements which are not able to be represented until there is a shared symbolism, language or agreed construct of some kind. The CCC environment allows a shared experience such that representation can be socially constructed with purpose.

Within the data collected for this project, participants strongly believed that CCCs are vital to individual professional development. That this impacts also on the organisation is reinforced by a statement that, without candid feedback and a flow of contribution back and forth within a professional setting, an organisation 'becomes stagnant.'

Similarly, singing or playing an instrument in a group provides opportunities to learn socially. Musicians experience others' interpretations of the music and subconsciously experience the event in a way which influences conscious reflections. Hearing others' musical interpretations broadens the individual's understanding of potentialities within a piece of music. In this way, the individual's learning of styles is impacted over time and the overall connectedness evolves to grow into a unique style for that individual. It is from this connectedness the individual is able to contribute to group efforts in performing. Further, an event which is shared is able to be represented with symbolism, in this case through the median of music.

Reflection is acknowledged within the data as a crucial part of the development of individuals. Further, to be effective in CCCs, the participants need to be experienced, habitual reflective thinkers such that reflection-inaction can occur. Participants within the enquiry felt this included an ability to see issues through different lenses and engage critically from different perspectives. 
These skills do not appear overnight. Repeatedly, respondents referred to the time and purposeful effort required to achieve skills in reflection and criticality. Phrases were used to indicate the degrees to which the skills were achieved which related to identity of a developed self: "modus operandi", "a way of being", "a mode you get into." This developed reflective self provides confidence as to what is known and what needs to be known to make sense of an experience.

This kind of experiential learning cannot be experienced in other ways. Within a CCC, the learning is immediately socially constructed, immediately socially supported, and immediately socially put to the test through challenge or feedback. The trust and reciprocity which exists within a CCC holds individuals accountable through criticality within the moment. This accountability extends to the self-development or 'stretch' as one participant described her learning through CCCs. Reflection could be described as the activity which occurs because of accountability to oneself within the learning opportunity which has been presented.

Likewise, the musician is accountable within the moment. Experience of performing in front of audiences allows the individual musician the opportunity to practise focus and reflection-in-action toward fulfilling expectations of the performance.

Just as musical styles have evolved over time, the nature of CCCs and the requirements for individual development will change over time. Increasingly, this is being identified in the domain of that unique package of connectedness, or entirety, which the individual embodies. Bell, a De Paul University psychology professor was recently quoted by Winsborough regarding the types of people who are sought at NASA for long-term missions:

What really matters over time is that you can do that give-and-take, do that self-monitoring. So, if the situation demands you be extroverted, that you can become extroverted and take charge. Or if the situation demands that you sit back, you can do that too. (Winsborough, 2020)

Professional development cannot occur without some level of engagement with criticality in CCCs. This is demonstrated within the data where one participant stated, "There's no doubts in my mind at all that if you're not in that critical mode then you're going to end up (a) making bad decisions, but (b) there's a whole lot of things that you could have been learning that you're not going to learn."

Personal development of the musician cannot occur without some level of performance. This performance necessitates an audience, feedback, reflection-in-action, and accountability within the context. For example, a concert pianist will be listening and responding differently if performing alongside a jazz group on a Friday evening in New Orleans.

And what of the conductor of the music? Leading the tempo, cueing changes with a nod, smiling encouragement and trusting the skills of the musicians to give a performance worthy of the occasion. In the same way, facilitators are the conductors of CCCs in that they point out opportunities, cue specific moments, and encourage performance of others.

The following is an example of how CCCs are effective and efficient within the workplace, providing sustainability for organisations which are prepared to support CCCs in daily practice.

\section{A LIVED EXAMPLE}

The Kathryn Ryan "Nine to Noon" segment on Radio New Zealand provided a prime example of how the impact of COVID-19 contributed to learning in the workplace in new ways through CCCs. Young engineers were, for the first time, privy to the thinking processes of the more experienced engineers. The senior engineers were in lockdown in New Zealand. The junior engineers lived on islands where the large infrastructure projects were being built. Real-time experience was made possible by directing the physical actions of the younger engineers 
on the structures via audio-visual technology and having a conversation with the younger engineers while they focused on specific aspects of the build (Ryan, 2020). Real-time feedback to both engineers allowed experienced ones to direct actions such as, "Wait, go back over that section again. Something doesn't look right to me." The real-time conversations provided junior engineers chances to understand what they were experiencing through the eyes and reasoning of the experienced engineers. They were in effect being given privy to reflection-inaction by the senior engineers for the first time. The model was so effective, the organisation realised that it could access the knowledge of the experienced older engineers beyond usual retirement timelines through continued constructive critical conversations via technology.

\section{IN SUMMARY}

The ability of organisations to prepare for an unknown future can and must begin in the present through professional development of the individuals within the organisation. The concept of eclectic learning broadens the potential supports toward individuals' self-sufficiency and self-determination in pursuit of lifelong learning practices. Organisations which facilitate eclectic learning opportunities through constructive critical conversations will be better prepared to be flexible and resilient in the face of inevitable future changes because individuals have continued to develop professionally.

The harmony of achieving both individual and organisational goals which is brought about by purposeful engagement in constructive critical conversations will enhance the sustainability of the organisation toward an unknown future.

Marcia Johnson has been involved in tertiary education quality for the past three decades in the New Zealand polytechnic and industry training sectors. Her approach to quality is one of continual improvement through transdisciplinary innovation.

Email: Johnsonpk06@gmail.com

(D) https://orcid.org/0000-0001-9022-3213

\section{REFERENCES}

Bhat, M. A. (2014). Understanding the learning styles and its influence on teaching/learning process. International Journal of Education and Psychological Research, 3(1), 14-21.

Buonomano, D. (2017). Your Brain is a Time Machine. W.W. Norton \& Company, Inc.

Chew, R. (20I5). Transformative Influences: The Long Shadow of John Dewey. Journal of Transformative Learning, 3(2), 9-I4.

Csikszentmihalyi, M. (1997). Finding Flow. Basic Books.

Day, C. (1993). Reflection: a necessary but not sufficient condition for professional development. British Educational Research Journal, 19(I), 83-93.

Drucker, P. F. (1999). Best of HBR 1999: Managing Oneself. Harvard Business Review, I-I2.

Eraut, M. (1995). Schon Shock: a case for reframing reflection-in-action? Teachers and Teaching: theory and practice, I(I), 9-22.

Foucault, M. (2011). The courage of truth. Springer.

Goodwin, C. (2013). The co-operative, transformative organization of human action and knowledge. Journal of Pragmatics, 43, 8-23. doi:10.1145/2388676.2388678

Grzegorczyk, G. (2018). Dialogue and language as factors contributing to transformative learning in academic tutoring. Psychology of Language and Communication, 22(1), 164-186. 
Hatcher, J. A., Shaker, G. G., \& Freeman, T. M. (2016). Faculty Learning Communities: Taking collective action to improve teaching and learning in nonprofit and philanthropic studies. Journal of Nonprofit Education and Leadership, 6(3), $254-272$.

Heidegger, M. (2010). Being and Time. (J. Stambuagh, Trans.). New York: State University of New York. (Original work published 1953)

Kahneman, D. (2012). Thinking Fast and Slow. Penguin Books.

Lave, J. (2019). Learning and Everyday Life. Cambridge University Press.

LMhieu, P. G., Grunow, A., Baker, L., Nordstrum, L. E., \& Gomez, L. M. (2017). Networked improvement communities. Quality Assurance in Education, 25(I), 5-25.

Lyotard, J-F. (2004). Anamnesis: Of the visible. Theory, Culture \& Society, 2I(I), 107-119.

Moon, J. (1999). Reflection in learning and professional development: Theory and practice. RoutledgeFalmer.

Ramachandrin, V. S., \& Blakeslee, S. (2005). Phantoms in the Brain. HarperCollinsPublishers.

Roth, W.-M. (2015). Becoming Aware: Towards a post-constructivist theory of learning. Learning: Research and Practice, I(I), $38-50$.

Ryan, K. (2020, December 17). How the pandemic changed technology use in 2020. Nine to Noon. Radio New Zealand. Retrieved from https://podcast.radionz.co.nz/ntn/ntn-20201217-II20-how_the_pandemic_changed_tech_in_2020-02.ogg

Winsborough, D. (2020, October 15). Martians need to be warm-hearted. The Dominion Post, 17. Wellington, New Zealand.

Zao-Sanders, M. (2021, May 13). Identify and hire lifelong learners. Harvard Business Review. Retrieved from https:// hbr.org/2021/05/identify-and-hire-lifelong-learners?utm_medium=email\&utm_source=newsletter_daily\&utm_ campaign=dailyalert_notactsubs\&deliveryName=DMI32329\# 


\section{HAUMI E, HUI E - A GATHERING OF REFLECTIONS Vicki Rangitautehanga Murray, Ashley Winiata Simpson, Te Poono Te Poono, Charlie Houia, and Patricia Denny}

\section{INTRODUCTION}

In the quest to gain greater understanding, knowledge, and skills to support the most vulnerable in the communities they serve, kaimahi (social and health workers) of the Eastern Bay Iwi Provider Alliance enrolled in a New Zealand Certificate in Public Health and Health Promotion Suicide Intervention and Prevention programme. The four providers in the Alliance are Tūhoe Hauora, Te Pou Oranga o Whakatōhea, Te Tohu o te Ora o Ngāti Awa, and Tüwharetoa ki Kawerau Hauora. The wānanga based course, delivered three days a month over a five-month period, is offered by Te Pu Wānanga o Anamata a Tühoe tertiary provider.

My name is Vicki Murray, the kaiako (tutor) on this programme. When the proposal was put to them, several tauira (students) decided they would tender reflections of their practice toward the Scope: Contemporary Research Topics (Work-Based Learning). Kōrero (contributions) are presented as a Kaupapa Māori bricolage of tones from the spheres of tauira learning in wānanga. Guided by the principles articulated in Tikanga Whakaaro (Barlow, 1994) of kaitiakitanga (stewardship of things pertaining to Māori culture and identity) and manaakitanga (care of mankind), the items are acknowledged as taonga (treasures). They are reproduced with permission from the individuals, who request their names and short statements be presented as whole and entire artifacts. Although they are tauira in wānanga, Ashley, Te Poono, Charlie and Trish are highly regarded practitioners and leaders in their respective fields, and within their communities, hapu and iwi (tribal collectives). These insider narratives (Bishop, 1995) offer a rare opportunity to glimpse into the hearts and minds of the culturally informed practitioner. The expressions in verse are exemplars of indigenous auto-ethnography as 'the practitioner self' in the social, cultural, and spiritual spheres of their lived experiences (Whitinui, 2014).

He maramara kai, na tēnā na tēnā o mātou, (the following are merely chips, bite sized tales recounted from former encounters which continue to inform current thinking). I (Vicki) lead in with a refashioned motif of critical reflection, followed with a kaupapa Māori model of practice by Ashley, a nostalgic rap song by Te Poono, a memo Charlie pens to himself, and a poem on safe practice by Trish. The article concludes with a traditional chaunt by Toroa the captain of the ancestral voyaging canoe, Mataatua thereby acknowledging our collective sacred connection to this region as tangata whenua (tribal peoples) of Te Moana a-Toi mai nga Kuri-a-Whārei ki Tihirau, mai tai ki uta (the Bay of Plenty coastal to mountain territories).

Due to the sensitive nature of the course, tauira are required to participate in supervision to address the reporting and management of mental wellness or unwellness, suicide ideation, attempted suicide, self-harm, and other related issues which may surface. The alliance organisations offer clinical and professional supervision in their suite of work-safe practices but, as non-crisis services, often lack the level of self-awareness and selfcare critical to situations arising from incidents associated with suicide. As a result, tangata whenua supervision sessions (Murray, 2017) in tandem with critical thinking, critical reflection, and influences on tauira beliefs and practice (Dewey, 1933; Schön, 1987) are interwoven into the fabric of the course.

The first feature in this article is an explanation of the model of critical reflection applied in wānanga and its most recent reconfiguration. 
Te Ara Tauwhāiti o Tāwhaki - Vicki Murray

A motif for critical reflection called Te Ara Tauwhaiti o Tāwhaki came to light while writing reflections on practice in the 'Review of Learning', the first of the requirements toward the Doctor of Professional Practice. The model draws on the Ngāti Awa purākau (tribal narrative) of Tāwhaki-nui-a Hema, a demi-god who ascended the heavens to retrieve four kete (baskets) of specialised knowledge. The kete are sequential phases of critical reflection inside a process or pathway defined as Te Ara Tauwhaiti o Tāwhaki (Ngaropo, 2014). In the Tāwhaki traditions, the kete are an analogy to his thoughts in action on the tenuous journey through the heavens (Mead \& Hetet, 1996; Nepe, 1991).

The kete and their functions are Whēkite (the observation of an activity), Whêkaro (learnings from the observation of the activity), Te Werohia (analysis and investigation on the learnings) and Te Whakairihia (application of new activity from analysis and investigation). Te Tuahu Mataaho is the landing place where the critical reflective practitioner has gained new insights. Te Ara Tauwhaiti o Tāwhaki is a multiple perspectives approach and a process of inquiry in the pursuit of matauranga (knowledge). Unveiled the motif as a visual representation of Te Ara Tauwhāiti o Tāwhaki appeared in the Review of Learning (Murray, 2020, p.7) before an assessment panel where questions were asked if the sketch did indeed depict a continuous process of reflection. Upon review, I could see an opportunity to make significant improvements to the design. The refashioned motif (Figure I) not only portrays a process of ongoing reflection but clearly embodies a Kaupapa Māori world view and to the initiated a distinctively Ngāti Awa perspective. The poupou (carved post) representing Tāwhaki and Te Tüahu Mataaho symbol are found at the entrance to Mataatua ki te Mānuka Tütahi in Whakatāne. The kete harakeke (flax baskets) are from the collected artworks of local Ngāti Rangataua weaver Glenda Hape. Exhibited in museums and galleries across the globe to our delight, Glenda's artistry also adorn the whare kai (dining halls) of her Ngāti Pükeko marae.

Over time, I have found tauira make meaning and retain the whole concept of critical reflection better when integrated with a visual of the ancestral whakataukT (metaphor), purākau and real-life artifacts (Lee, 2005; Redden, 2017). In concert with Lee (2005) Te Ara Tauwhāiti o Tāwhaki, a motif for critical reflection, is thus a regenerative formula to preserve and transmit Ngāti Awa ancestral knowledge.

Figure I. A Ngāti Awa motif for critical reflection, Te Ara Tauwhāiti o Tāwhaki '

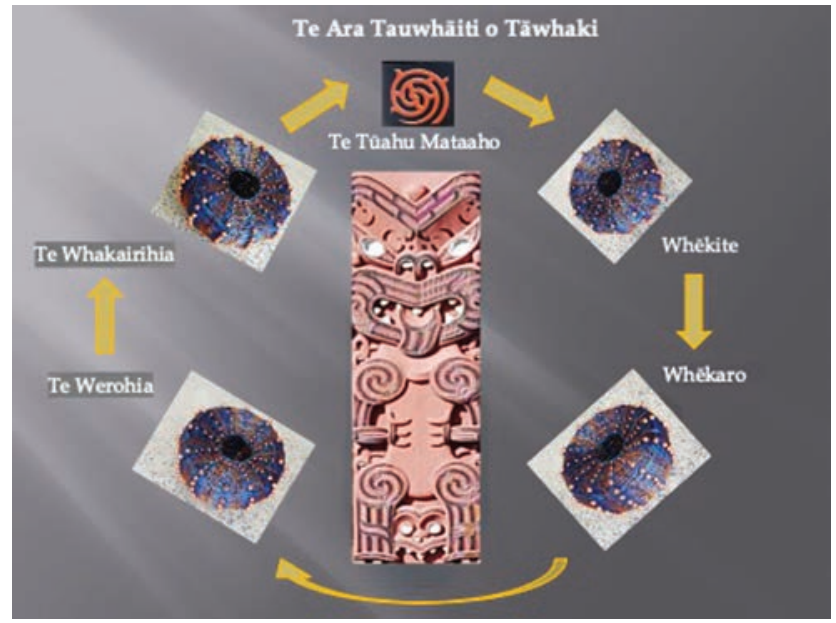

I Figure I. A Ngāti Awa motif for critical reflection, Te Ara Tauwhāiti o Tāwhaki was designed by Vicki Murray (202I) specifically for this article. 
The use of purākau or narrative approaches to explain and explore the meaningfulness of experiences embedded in wānanga is commonplace (Alterio \& McDrury, 2003; Woodhouse, 2019). Te Orokohanga (the Māori creation story) is the backdrop to Ashley's intuitive framework. When discussing how it might be expressed in practice the tauira consensus was that Kia aro ki te hā o te tangata is 'manaaki tangata' (Mead \& Grove, 2000; Shirres, 1997). As a health practitioner, manaakitanga is to show unconditional positive regard to another and as such is a curative process (Durie, 2003; Rogers, 1980). Ashley breathes life into her therapeutic framework, from its genesis through to the edition before us today.

\section{Kia aro ki te hā o te tangata - Ashley Winiata-Simpson}

"Kia aro ki te hā o te tangata." What resonates within me when I speak essence into these kupu? Ae, the existence of he, of she, of they who stand before me. The embodiment of whakapapa (genealogy), of purākau (ancient legends), of ahuatanga (ways of being) past and present that through time has shaped and moulded he, she, they who are presented to me. For what is "kia aro ki te hă" if not the acknowledgement of all that has gone into creating their existence. It is a model of practice created in response to previous rangahau (research) into indigenous theories and frameworks (Hollis-English, 20I3). The core values that underpin my practice centre around acknowledging all aspects of whānau, hapu and iwi. It consists of four other core values; Āhuru Moai (to be in a calm place, a sheltered haven), Âhei ana (within one's power), Aranga ake (to arise, to emerge) and Arataki (to conduct or guide). Aro ki te ha is the first core value of existence and the central theme of this tuhinga (piece of writing).

Aro ki te hā, quite literally can be translated to acknowledge someone's breath and existence. It requires taking in all the ups and downs that has made this person who they are today and recognising that despite everything, this person is here existing. We look beyond the issues they present with and recognise what there is inside them to make positive changes (Pohatu, 20 II). That progressive and empowered state we acknowledge as; kia aro ki te hā o te tangata, kia ora ai.

Like the rock that stands firm in the ocean, I am a 'toka tu moana' strongly positioned within Te Ao Māori. My worldviews, align within its realms of bodies of knowledge that strongly connect Iwi Māori to our tipuna (ancestors), and traditions. It is a fundamental part of our Māori identity and the ways which we as Tangata Māori interpret the world around us. Ko Ashley Winiata Simpson ahau. I am a social work practitioner for Te Tohu o te Ora o Ngāti Awa, with whakapapa links to both Tūhoe and Ngāti Awa within Mataatua. My model emerged from previous experience with rangahau into indigenous theories and models of practice such as Ngā Takepu (Pohatu, 20I0). Kia aro ki te hā is my response to Kaupapa Māori theories and underlining values that are core to my practice. The framework was first presented as Te Tātua Ara Whāngai (The Pathway to Growth) at a research conference in 2018. Since then, after considerable reflection, the model has been reviewed and renamed Ki Aro ki te hā as it resonates more closely with my current practice and philosophies.

From the opening petition to its final rhetoric, his waiata kōingo (a present-day elegy) is a heart-felt reverberation of tragedies unresolved. Composing waiata may become a pou for Te Poono, just as 'he toka tu moana' is the anchor for Ashley in turbulent times. Waiata consequently is a conduit to reflect on professional practice and a medium to search for answers afflicting Māori, more poignantly those within his familial communities of interest. 


\section{Unheard Cries - Te Poono Te Poono}

When will it stop?

Our children killing themselves for what?

Is it a family issue?

So many tragedies and raggedy tissues

And still we fail to remove the veil

I've got a feeling that the malice is too good to dispel

How many youth have died from death by suicide?

The toll is too high, too many unheard cries

The generations fallen and the denigration from then

Dismisses all accountability from the walls within

Kei te ngau i a tătau rangatahi te taniwha nei

Pūhukitia ōnā nihorei today

Don't need to be no academic to see an epidemic is cutting our family trees

Without guidance, they fall victim to the system and the violence

Papa hits, ropes clench, another breath is silenced

What are we doing to prevent, what are we doing to ascend from this immenseness?

The kāwana turns another blind eye

So we got to look towards the whānau and bring it back to our marae

We take the wisdom of our old and instil it in our youth so they realize their being a nobody isn't true

So rangatahi keep your head high

You ain't a kiwi, you are Māori so you can fly.

In 2004, I was privileged to be a part of the hikoi (a march) to Parliament to protest the legislation of the foreshore and seabed. Following the hikoi, a couple of friends and I decided to write a song to express not only the pain and anger stirring within us but also the wairua (spirit) of solidarity felt during the hikoi. This eventuated in several songs being composed and although most were politically driven, we found ourselves writing about various topics affecting Māori at that time. "Unheard Cries" is a verse from a waiata that queried the high suicide rate among Māori, specifically rangatahi Māori (Māori youth). The medium chosen was rap as we believed rangatahi would be more inclined to the message being conveyed in a manner that appealed to them. It is termed a waiata kōingo or yearning song as we long for answers as to why suicides are higher for Māori than any other ethnic group, why our rangatahi are severely affected and what can we do about it? When brought down to the whannau level, those who have been affected are left also asking the same questions, why did he or she do it, why couldn't I see the signs and what could I have done to prevent it?

Te Poono Te Poono

Ki te ui mai koe i poua mai au i hea?

Māku e kTatu,

"I poua mai au i te awe nui o te Toroa

Mai ngā Kuri a Whārei ki Tihirau, mai Te Moana a Toi ki Maungapōhatu." 


\section{Memo to Self - Charlie Houia}

Charlie Houia pens a "Memo to self." Daniel Taylor (1996) advocates strongly in the healing power of stories and insists everyone has a story to tell. As an expression of the truths of his experiences, a "Memo to self" is Charlie's wellness model in praxis. The value of being and becoming through learning, as much as knowing, and doing, is at the heart of his personal and professional journey, the two are intimately entwined.

What is my why? Why do I get up in and repeat the same routine every day knowing I do not know what is in store for me? Sit up, check my phone to see what the time is. Am I late or early have I got time to have a coffee, shower, get changed, turn the TV on to listening to good morning news. Check Facebook to see what others are doing that I'm not.

"Carry on bro, put the kettle on".

Think about what my day looks like? What have I planned for the day? Should I put it on paper or in my head and freestyle it. Plan A, Plan B, Plan C, D all the way to Z. Who will be there? What are the strategies I am going to use today to overcome whatever might happen today? If I did it like this, what would that look like? What happens if it doesn't work? Who is there to support me? What am I going to eat? What waiata are we going to sing at karakia this morning? Put my phone on the charger. Take my phone off the charger. Will I make it through the day? "Carry on bro, you are appreciated".

My why is that I do what I do because of the experiences that I have gained? The mentors that have helped me? The cousin that got me in trouble with the police? The people I have loved? The people I have hurt? Being hurt by other people? DAD.

"Carry on bro, it will pass".

Ah, that's better. So, what is my why? Why I do all this but not in that order. I should say it is because of my family (wife, daughters, and son) but they contribute to who I am. Knowing what I am. Knowing what I am doing is right. Knowing I am doing what I do is with humility.

"Carry on bro, they know".

I am responsible for you. You have come to me. I will do the best I can for you. My skills and abilities are for you. Do you understand what we did? How are you feeling? Are you ok? What happened? What an awesome day. What a draining day. What an uplifting day. Don't forget to eat something.

"Carry on bro, expect the unexpected".

As the sun goes down for my day, the sun rises when I get home. Who are there waiting for me is my why.

"Home time bro".

My name is Charles Houia, I am of Ngāti Porou descent. This piece is a snapshot of my everyday preparation and a reflection and order of what I do every day. I am the alternative teacher at Te Pou Oranga o Whakatohea. The students that I teach are colourful and come from vibrant back grounds. Back, looking back, reflecting, and searching. Grounds are the places where you are, where you have been, and where you go. My goal is to inspire students and ignite the fire that has been extinguished by mainstream systemic racism which I know they can overcome by with me and our team by finding their why.

"Ko te kai hoki i Waiaua."

The food bowl that feeds the world.

This whakatauāk $T$ comes from Whakatōhea and confirms the vision of the iwi of their entrepreneurial spirit, grounded in the history, cultural identity, language, and heritage of being Whakatohea. I relate to this tribal saying because I give everything I have, in skills, knowledge and the attributes I have been gifted to the rangatahi I work with. I go above and beyond what is expected of me, keeping in mind that I have everything that nourishes me, restores my wairua and keeps me well at the end of each day when I go home. 


\section{Safe - Patricia Denny}

FEAR was the first response Trish Denny experienced at the idea of expressing timbres on practice in verse, but her poem "Safe" is a legacy of love, learning and acknowledgement. As the tuakana of the wānanga, Trish has countless wisdoms to impart and is a natural storyteller. It is the hoped this foray into reflections on practice in the genres offered here will encourage Trish and her writing companions to join, gather and compile more of their insights to appear in future publications.

\section{Safe}

Through childhood lenses an abundance of life experiences unfold

Some are kept cherished and close to our hearts

treasured memories

some securely, safely nestled within

perhaps, in our soul

Exploring within

Searching to understand the world

Amidst all this an evolving being

Learning, discovering

Listening attentively

Watching, observing

Imagining, dreaming

Feeling, thinking

Tasting, savoring

Smell

Growing

Developing the senses of body and mind

Uniqueness determined and informed by what is learnt

This emotion a critical survival instinct

Offers

Protection

Safety

Silent existence

Cautiously seeking

Permission, approval

to allow thoughts

dreams ideas to speak

have a voice

to express

feelings, emotions

thoughts

fostering strength to overcome this notion

F- face fear, adversity don't worry

E- embrace concern to address self-doubt and anxiety

A- accept, apprehensiveness, don't panic

$\mathrm{R}$ - restore resilience don't be afraid 
Seasoned eyes

Ignites and stirs

Critiquing

Reflecting

To

Strengthen

Enlightening

Understanding

Values

Beliefs

"Kia tūpato" ("Be carefull)

Carefulness, make no judgements

Be Precautious

Attentiveness in all situations

Beware of hazards

Mindfulness of cultural differences

Watchful through engagement

Constant Awareness

People, places, and spaces

A value to

Guide

Inform

Process

Practice

Safety is Paramount

My name is Patricia Denny, I am a descendant of Te Whānau a Apanui, Ngāti Pōrou, Ngāti Ruanui. My current role is working as an Infant Child Adolescent and Youth clinician (ICAY) with Te Pou Oranga Whakatōhea Social and Health services. Within this role, there are many diverse challenges that our rangatahi face which impact on their health and wellbeing. Anxiety, depression, autistic spectrum disorder and suicidal ideation are some of the tests before them. On reflection the core of this poem has been informed by narratives of our koro, Miki Akuhata who in his wisdom constantly provided his gems of kōrero that were laced with love, compassion, and conviction. Although at the time his intent was not understood or given any clarity, it certainly left an imprint of thought, emotions, and curiosity, seeking answers. Little inquiring minds pondering with inquisitiveness to determine what was truth or fiction. Like our koro Miki with time and age we look back to go forward and endeavor to continue to make sense, appreciate and understand his world of intrinsic knowledge shared so long ago. I feel privileged and humbled to engage with whānau and their rangatahi, whom I have established trusting and secure relationships who trust to share their narratives, I acknowledge them and maintain the care and safety of their stories. In the context of this paper the underpinning message is clearly reflected to provide all encounters with a consciousness of "Safety first." 


\section{CLOSING}

In continuing the theme of safety, we close with the karakia Toroa issued to calm the raging waters at Te Awa o Te Atua (in Matatā) that had trapped the Te Arawa waka. After the chant was performed the waters subsided and tranquillity prevailed, Te Arawa continued their journey to Maketu. In the context of this article, this karakia is proposed to calm the way ahead for the tauira as they continue the journey of serving their communities. The title of the article Haumie e, Hui e, is intoned in the concluding words of the recitation.

Ko wai ra, Ko wai ra, ko wai ra, Te Tangata tutu taua.

Kaore koa, Ko Hau, Ko Nuiho, Ko Nuake, Ko Manu, Ko Weka, Ko Toroa, Ko Ruiahona, Ko Tahingaotera. Tenei te maro te hurua Huruhuru nui no Manu no Weka.

Ka tu tapori atu ka tu tapori mai.

Wero noa, wero noa, nga rakau whakaiaia.

Na nga tupuna i tikina ki rawahi.

Hei homai mo taku waka mo Waimihia.

Te mata o nga rakau a Tu-ka-riri.

Te mata o nga rakau a Tu-ka-niwha.

Te mata o nga rakau a Tu-kai-taua.

Whano! Whano!

Haremai te toki o haumi e! hui e!

Taiki e!

Haumi e! (We have come together!), Hui e! (We have carved our narratives together in this edition of Scope!), Taiki e! (And it is done!)

Ko Vicki Rangitautehanga Murray ahau, he uri nō Ngāti Pūkeko me Ngāti Awa. Vicki holds a certificate to practice, is a member of the Social Work Registration Board, a teacher in wānanga and a learner on the Doctor of Professional Practice with Capable at Otago Polytechnic.

Email: murrayvicki0l@gmail.com

Ashley Winiata Simpson is a social work practitioner for Te Tohu o te ora o Ngāti Awa, with whakapapa links to both Tūhoe and Ngāti Awa within Mataatua.

Charles Houia, I am of Ngāti Porou descent. I am the alternative teacher at Te Pou Oranga o Whakatōhea.

Patricia Denny, I am a descendant of Te Whānau a Apanui, Ngāti Pōrou, Ngāti Ruanui. My current role is working as an Infant Child Adolescent and Youth (ICAY) clinician with Te Pou Oranga Whakatōhea Social and Health services. 


\section{REFERENCES}

Alterio, M., \& McDrury, J. (2003). Learning Through Storytelling in Higher Education: Using Reflection and Experience to Improve Learning (Ist ed.). Routledge.

Barlow, C. (1994). Tikanga Whakaaro: key concepts in Māori culture. Oxford University Press.

Bishop, A. R. (1995). Collaborative research stories: whakawhanaungatanga (Thesis, Doctor of Philosophy). University of Otago. http://hdl.handle.net//0523/53।

Dewey, J. (1933). How we think: a restatement of the relation of reflective thinking to the educative process. Houghton Mifflin.

Durie, M. (2003). Ngā Kāhui Pou. Launching Māori futures. Huia Publishers.

Hollis-English, A. (20I5). Theories in Māori social work: indigenous approaches to working with and for Indigenous people. ANZASW Journal, 5-15.

Lee, J. (2005). Māori cultural regeneration: Pūrākau as pedagogy. The University of Auckland, New Zealand. Paper presented as part of a symposium 'Indigenous (Māori) pedagogies: Towards community and cultural regeneration.' Centre for Research in Lifelong learning International Conference, Stirling, Scotland.

Mead, H. M., \& Grove, N. (2000). Nga Pepeha a Nga Tipuna: the sayings of the ancestors. Victoria University Press.

Mead, H., \& Hetet, T. (1996). Ko Tāwhaki nui-a-Hema: ana mahi whakahirahira. Reed.

Murray, V. R. (2020). A chant to ancestral landscapes. Review of Learning, Doctor of Professional Practice, Otago Polytechnic. In Te Maiharoa, K. \& Woodhouse, A. (Eds.), Indigenous autoethnography: our sacred voices. Te Kura Matatini o Otago (forthcoming).

Murray, V. R. (2017). Hoki ki tōu maunga kia purea ai koe ki ngā hau o Tāwhirimātea - A tangata whenua model of supervision. Unpublished thesis for a Masters in Social \& Welfare. University of Otago, Dunedin, NZ.

Nepe, T. (1991). E hao nei e tenei reanga te toi huarewa tupuna: Kaupapa Maori, an educational intervention system (Unpublished master's thesis) University of Auckland, Auckland, New Zealand.

Ngaropo, P. (20l4, June 16). BOPDHB Whakatane Cultural Wall, Te Ara Tauwhaiti o Tawhaki. https://www.youtube.com/ watch? $=\vee t G G d H X-Q N U$

Pohatu, T. W. (2010). Takepu: principled approaches to healthy relationships. Te Tatau Pounamu Traditional Knowledge Conference, 2008, Auckland (paper).

Pohatu, T. W. (201I). Mauri - rethinking human wellbeing. MAI Review, 3, I-12.

Redden, S. (2017). Metaphor Analysis. In Matthes, J. (Ed.), International encyclopedia of communication research methods (pp. 1-9). John Wiley \& Sons.

Rogers, C. (1980). Way of being. Houghton Mifflin.

Schön, D. A. (1987). Educating the reflective practitioner: Toward a new design for teaching and learning in the professions. Jossey-Bass.

Shirres, M. (1997). Te Tangata: the human person. Accent Publications.

Taylor, D. (1996). The healing power of stories: The life-shaping power of our stories. Doubleday.

Whitinui, P. (2014). Indigenous autoethnography: exploring, engaging, and experiencing "self" as a native method of inquiry. Journal of Contemporary Ethnography, 43(4), 456-487.

Woodhouse, A. (2019). Pūrākau: embracing our indigenous identity and recognising the equality of the implicit other. Scope: Contemporary Research Topics (Kaupapa Kai Tahu 5), 12-17. 


\title{
KA TIRITIRIA - SHARING THE SEEDS OF 'HOPE' (HOLD ON PAIN ENDS)
}

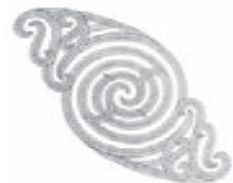

\author{
Kevin Hollingsworth, Vicki Rangitautehanga Murray, \\ Goldie Mihinui, Billy Mihinui, Tuihi Carre, Tiwana Taiatini, \\ Pauline Tai, and Edith Te Papa
}

\section{WHAKAPAPA KŌRERO AND INTRODUCTION}

Ko Kevin Hollingsworth taku ingoa. While my whakapapa is from the North, I was born and raised among Te Arawa. In my own journey of self-discovery, I developed a passion for working with whānau who have mental health and addiction issues. Brought up in a home with strong tikanga principles, my upbringing supports the way I work with whānau. As a registered Māori Clinical Practitioner, I witnessed first-hand there was no support in the community for whānau indirectly and directly affected by methamphetamine. As a result, in 2017, I formed the Mana Enhancing Group, a model care to help awhi (embrace) tangata whaiora and their whānau to feel empowered by the outcome of psychotherapy as a treatment for their addiction and problematic behaviours.

As the roopu grew, those who attended regularly asked us to start up in the community, based in the local Church and Marae based. We did and gave birth to the Mana Enhancing STOP roopu. STOP is an acronym for Stop Taking Our People; that is taking them from us due to methamphetamine. Our processes are reviewed often as we embrace mātauranga Māori (knowledge) and holistic practices to help heal our whānau affected by the rising issue of methamphetamine addiction in Aotearoa.

To gain greater understanding, knowledge and skills to support their communities, the facilitators and whānau tautoko (supporters) of Mana Enhancing STOP enrolled in a New Zealand Certificate in Public Health and Health Promotion Suicide Intervention and Prevention programme. The wānanga based course delivered by Te P $\bar{u}$ Wānanga o Anamata, the Tūhoe PTE (private training establisment), is based in Tāneatua. The roopu orations are reproduced with permission from the individuals, who also desired the use of their names. Each kōrero (contribution) emerges from the Mana Enhancing STOP practice and are covered by Otago Polytechnic Ethics. In addition to this formal process, the words of the roopu are protected by the guardianship of the Mana Enhancing STOP leaders and convenors and held within a space of great reverence.

\section{KA TIRITIRIA: OUR VOICES}

Ka tiritiria speaks to the seeds of hope shared with everyone who enters the Mana Enhancing STOP community. A harmony of expressions of Māori dimensions of resilience echo through personal encounters from within.

Te reo taki, Kevin Hollingsworth (the lead speaker/author) has presented a whakapapa of the emergence of the Mana Enhancing STOP movement. Te reo mirimiri, Vicki Murray, te kaiako (the course tutor) pens this brief introduction to the chorus of voices weaving the article title, te koha körero (gift of words) from her students and selected Shakespearian passages together. In Goldie Mihinui's rendition te reo tuatahi (the first refrain) her 
soul is laid bare as a survivor indirectly affected by meth. Nga reo tuarua (the second compilation of voices) are reflections on aspects of practice by Billy Mihinui and Tuihi Carre. Insights are woven through the application of mana, mauri and tapu followed by an awareness of noa within te porowhita (sacred circle). Tiwana Taiatini goes on to explain the implementation of the rākau, a motif fostering the sense of safety and agency to those sharing in the porowhita. Pauline Tai along with Billy flow on as ngā reo tuatoru (the third accounts) giving a slant on kōhatu as milestones of achievement. He kupu aroha hei kōrero whakakapi (the fourth and fifth unflinching raw recollections) by Edith Te Papa and Billy are inspiring finales to this compilation.

\section{VICKI AND “OTHELLO”}

Once the scripts were gathered together, the moving, normally muted lived experiences portrayed by Goldie, Edith and Billy in concert with the main theme of the course whakamōmori (suicide prevention and intervention) brought parallel iconic theatrical widsoms from the play Othello to mind. In 2016, Regan Taylor saw parallels with Othello and Māori experience in SolOthello, produced in Auckland using Te Mata Kokako o Rehia (masks) (McKee, 2016). The theme of human deterioration is at its heart, and, here, I reapply the mask.

Several citations from William Shakespeare's 1603 tragedy (referenced by act and scene only) resound within these three, real life contexts:

Oh, beware, my lord, of jealousy!

It is the green-eyed monster which doth mock

The meat it feeds on (III.iii.).

Goldie's story: He was overcome with jealousy (line 17).

Men in rage strike those that wish them bes. (II.iii.).

Goldie's story: While in his meth fueled rages I got smashed, punched in the head, my body pummeled, I was dragged about, almost choked to death, a knife held to my chest (lines 18-19.)

[She] loved me for the dangers I had passed (I.iii.).

Edith about Billy: of her love of bad boys (line 5).

I saw 't not, thought it not, it harmed not me (III.iii.).

Edith: at the beginning of their relationship not knowing Billy used, and later not knowing what whānau indirectly affected by meth were going through (lines 10 \& 48).

For I will wear my heart upon my sleeve, for daws to pick at; I am not what I am (I.i).

Billy going clean: Asking for help meant to open up, to be vulnerable; in search of his true self.

Too hideous to be shown, it is deceitful and evil

I am not what I am (III.iii).

lago the deceitful and manipulative antagonist - in this context is the motif for methamphetamine.

Shakespeare's drama ends after the Moor smothers Desdemona, his wife, and then kills himself when he realises she was innocent and he had been duped by his trusted friend, lago.

Then must you speak

Of one that loved not wisely but too well (V.ii.).

Billy sold his soul to meth, and on the pipe he had no consideration of others wreaking havoc upon all and sundry. 


\section{TE REO TUATAHI: GOLDIE'S STORY}

I am Goldie, as a young child I was nurtured by loving parents

I was a happy outgoing girl

One of the youngest of eight

My life was simple, fun and carefree

I lost my pāpā my pou and my rock to cancer when I was 12

Soon after I met my first love, Arthur

He was a quiet fun and caring young man

I moved in with him. Life was beautiful and sweet.

Our first pepe arrived when we were 16.

At 19 he became a patched member and things changed

His staunchness came out, he was ruthless, his behaviour was out the gate

He began using meth

He became controlling not letting me go out

No socialising, no friends, he took away my freedom

I was a prisoner in our home, locked in the room.

Then the beatings started

He was overcome with jealousy

While in his meth fueled rages I got smashed, punched in the head, my body pummeled, I was dragged about, almost choked to death, a knife held to my chest

The bruises were hidden but I was so mamae I couldn't move or sleep

The verbal and physical abuse grew worse as the meth took over him

This was the darkest time for me, and our four tamariki

Who heard, felt, and lived through the violence inflicted on me

They huddled together silenced by terror, their little bodies trembling with fear and anguish

I lost my mana, my mauri was broken and my tapu was shattered!

The demon drug meth, turned my husband into something, someone else

My mind screamed: Who is this person? Why is he doing this?

I never thought I would escape that bleak joyless place

Suicidal thoughts filled my heart, my mind, my whole being

But who would take care of our babies?

What was this pitiful thing I had become?

Exhausted and sick of it all, I knew I had to get away

I had to leave him

I got the strength to seek help and am here today because of the support of my hāhi

I am fully committed to my faith, the love, encouraging words and scriptural advice give me comfort

Finally, one day after trying and failing again and again

He went in search of help and eventually found Mana Enhancing STOP roopu

He asked me to go too, to see that he was indeed working on getting clean

So, I went along to support him

And found that in the sacred circle

I was able to release my mamae to help me heal too

Our journey of recovery together continues today

Arthur and I now have a strong and open relationship

Where we work on everything as a couple, as a whānau. 
My 10 years of debilitating abuse and 18 years of surviving the indirect effects of meth have ended He wahine toa ahau aianei

I am 37 now and am a strong and vibrant woman

I am a wife, a māmā and a nanny

I am Goldie and this is my story.

\section{NGĀ REO TUARUA: MANA, MAURI, TAPU AND NOA}

Billy: At the beginning of each session, we explain mana, mauri and tapu, the three principles applied in our roopu porowhita. From my lived experience of active addiction, our connection to turangawaewae (our whenua, who we are as tangata, our identity) and culture as Māori is lost. This leads to a loss of mana. When people come seeking help, we begin their journey of recovery by seeking to regain their mana. Learning our connection to whenua, to hapu, iwi and each other through whakapapa is one of the first steps we take together. The mauri or life force of the speaker's words is aroused during the rākau kōrero. The rākau gives whānau the opportunity to speak their truth, their pain, their grief, shame, and hope for themselves and loved ones. As this space is tapu they can talk unrestrained to set aside all the guilt and blame they carry knowing it will be acknowledged without judgement.

Tuihi: Tapu is the sacred space we preserve. What we hear in the porowhita, what we say, and who we see is totally confidential. It is a safe place for whānau to be able to share their truth knowing their kōrero stays within the circle. Noa also sits with mana, mauri, and tapu, a holistic practice in our roopu sessions. When whānau arrive, they are offered a hot drink and something to eat, this creates a setting back to normality, or noa.

Almost everyone who attends is struggling to cope with meth addiction or the behaviours of loved ones who are addicted, we acknowledge their own mana, mauri and tapu. These are conveyed within their thoughts and feelings aired in the porowhita. Whānau disclose deep seated feelings, so real and raw that these can trigger others in the circle. Therefore, it is important tikanga in the rākau kōrero is upheld. Once the rākau is handed to the next person, mana and mauri are in a state of hiatus, whereby tapu no longer exists, and noa presides.

Karakia is performed to open and close hui or work within the sacred circle. Post hui, there is time for whānau to mingle and chat informally with others in attendance over a cuppa. The importance this interlude is to ensure whānau are at ease before they leave us.

Vicki: Noa is embraced within the domains of Papatuānuku, the female element. Noa is the constant companion to tapu, or the male element assumed within the realms of Ranginui. The continuum or presence of both tapu and noa is essential in maintaining balance (Durie, 200I; Murray, 2012; Shirres, 1982).

\section{RĀKAU KŌRERO}

Billy: My aunty, Honey Thrupp gifted us this rākau to use in the porowhita. She said to me, "The blue, black, red and yellow colours represent the gangs you will work with. White is the peace you will bring to their lives and green is for growth my boy, which is something you have done. I added the cross for protection."

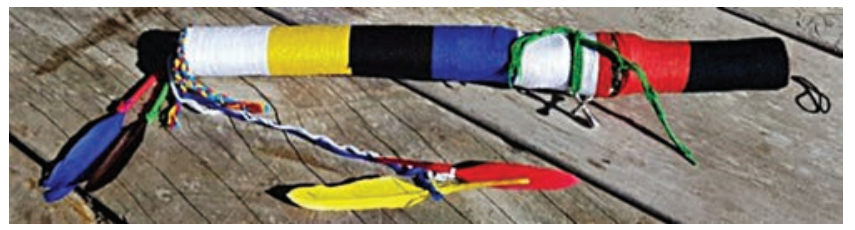

Tiwana: The rākau is introduced to our meetings as the talking stick. The person who holds the rākau is the only one that speaks. When the speaker is finished the rākau is placed on Papatuānuku (on the 
ground) in front of the speaker, as an indication to the facilitator to provide feedback. If the rākau stays on the ground when the facilitator has finished, the speaker is inviting more feed-back from the roopu. Once the speaker picks up the rākau all kōrero stops. The rākau is then passed on to the next person in the circle. The rākau kōrero maintains the mana, the mauri, and tapu within the roopu and specifically with the speaker.

\section{NGĀ REO TUATORU: KŌHATU}

Pauline: We have implemented kōhatu (coloured river rocks) milestones into our programme. Milestones are measurable targets our whānau in recovery can strive toward. The kōhatu are physical and spiritual tohu they receive at different stages of their recovery. Once achieved, whānau have a sense of accomplishment and look forward to achieving the next milestone. We have a 3-month (orange kōhatu), a 6-month (red kōhatu), and a I-year (greenstone/pounamu) milestone. With each kōhatu, whānau also receive a whakataukT. The kōhatu are from Papatūannuku, and if whānau have a slip they give back their kōhatu. We return it to the land, and they are required to start again.

Billy: In our roopu, the kawa (process) is slightly different to our whānau in Te Arawa. When whānau relapse, they become the kaupapa (focus) of the meeting. We do this to give them a sense of community because they are usually whakama (ashamed) and it takes a lot of courage to come back into the roopu when they slip. Our role is to support them by going to the river where we perform cleansing rituals. The kōhatu are then returned to the river. We then reset their plan to overcome their obstacles to recovery.

I choose each kōhatu carefully, looking for certain shapes and sizes. It's more of a feeling, a wairua (intuitive and spiritual knowing). The kōhatu tell me which ones to take. The milestone journey begins when the whannau walk in the door even if they have been clean before they attend. The orange kōhatu is to acknowledge them slowing down, where they ask themselves, "Am I in or am I out?" The orange kōhatu is bigger because the beginning is the hardest part of the recovery journey. This is when they are challenged the most and when whannau are most likely to slip. The red kōhatu means whānau have made the decision to stop.

\section{TE REO TUAWHĀ: EDITH - HOPE}

I was never going to be a stay-at-home wife

I sure was never going to be controlled by any man

Not me!

But that was before Billy

I loved bad boys

And I fell for the biggest gangster bad boy in town

Billy who made me feel like I was the only one on this earth

Billy who would tell me I was so beautiful

Billy who loved that I was wild and couldn't be tamed

I didn't know it at the time but Billy was using

Then he began dealing meth too

Over time it got worse and worse

He left me for other women

His desire to use meth was stronger than his will to live

Billy's addictions were using meth, dealing meth and women

My addiction was Billy

I found myself in gangs to support his use

I became a dealer 
It started with tinnies, synies and then meth

I used Billy as a front

Police with search warrants

Other gangs chasing Billy

And buyers came to our place at all hours of the day

And under the cover of the night cos meth never sleeps

In the 16 years of being indirectly affected by Billy's addictions

I never took any of his money

I never touched the pipe

I would look at Billy's behaviour and say "F..., he's out the gate."

And decided "No way, that's not for me!"

Dealing became my next addiction

Cos I loved getting away with stuff

I was attracted to and then got hooked on the money

I grew a reputation and status

Billy was jealous of my dealing

For years I would send them to Billy

Everyone knew where-ever Billy was, there would be meth

But then people started realising I was the dealer

When that happened

I stopped going out because people I was supplying to would come and find me

I kept on working my other jobs even though I had lots of ready cash

The jobs and Billy were my cover

I was really good at dealing

I never ever thought I had a problem

I was a huge enabler of his addiction

I wanted him off meth but I loved him so much

I would shower him with every-thing

It was a chaotic, intense and poisonous relationship

All we were doing was out chasing meth

I didn't care what it did to others because I didn't see the struggles their whānau were going through

Even though I lost touch with my tamariki, my mokopuna, my whānau and my hapu

Being left for other women nearly broke me

I asked why he couldn't stick with me?

I would do crazy things when I found him with other women

When I started thinking about exposing him and then taking his life, their lives

I knew I was going over the edge

So, I reached out for help

I went on a program for women like me who were in unhealthy relationships

I learned to love myself again, found peace and reconnected with my friends

Joy and laughter returned and I began working to gain back my mana

When Billy saw me change, he started talking about going clean

My whānau told me, to help him I would have to stop dealing

For years I had prayed for Billy to go clean so I stopped and supported his journey of recovery

We are here today because when we were both in addiction

Even though it was such an ugly time especially when he picked up the pipe

I always held a slither of hope, remembering what Billy was like when we first fell in love 
I wanted that Billy back

I am Edith and I got my Billy back

Today my focus is on being a wife, a māmā, a kuia, a sister, a daughter, an aunty, and a cousin again

Living a clean life

I am a co-facilitator in the Mana Enhancing STOP roopu for Tāneatua and Ruātoki

Alongside Billy, we help our community get clean

In the sacred circle, I share my story because the truth needs to be told and it helps me heal

Parts of that life still hurt, our behaviours harmed a lot of people, particularly our tamariki

We know there are many others like us who will need support getting out too

In the beginning it was hard because people were still coming up and saying

"Are you fullas still on?"

I had to say, "I don't do that anymore" and invite them in for a cup of tea

It's not easy because recovery is new to us

We are trying to learn as much as we can to help ourselves help others

The road to recovery is as uncertain as the road through addiction

I still get triggered by those who relapse because I know it means there's more pain ahead for them

Billy was the face of meth during his addiction

Today Billy is the face of recovery

I am in the background, the machine managing and supporting Billy and our roopu

Our recovery is a clear message to the community, to our whānau

that it is possible to overcome addiction

A member of the meth community told us

"Well, if I ever want to go clean, I'll come to see you two."

Me, Billy and our Mana Enhancing STOP roopu are here to give people HOPE

We tell whānau HOPE means Hold on Pain Ends

Ko Edith ahau, tēnei taku kōrero.

\section{(3) TE REO TUARIMA: BILLY - WHY I DECIDED TO GO 'CLEAN'}

My wife stepped away from me

I was broken, my body was shattered, I was so tired of being tired - of not feeling loved

I was in a really dark space, the little fella on my shoulder his voice was so loud

I couldn't see any other way out except death

I was fried when I saw my wife from a distance

I wondered what she was up to her face was glowing

I hadn't seen her big bright beautiful smile in a long time

I was still high at her graduation but could see she was full of life and I envied she could be that happy

without me

Resentful I screamed, "You left me to rot in the gutter."

I broke down, I had P on me, a pipe on me, I said to her I'm done babe I need help!

She said you are not going to like it but you have to go back to rehab

In my darkness I was sick of being sad, lonely

I still wanted to be on this earth for my moko, for my son

The shit I used to put them through was scary

My poor boy must live with the consequences of my behaviours

I know now, if you make the change, they make the change 
I tried buying love, that didn't work, you got to earn the love

I would sit in my car asking the Atua, "Is this all I'm here for? Is this it? But this is dumb."

I was constantly hurting Edith. I had all the money and anything I wanted but I was so lonely

I would rather be poor but have my wife by my side, wake up with her every day

It hurts, it hurts in a good way. I promised my wife, "You don't have to worry anymore."

I have to settle my mind and heart to live a different life. I see better now, am more content

To be a better version of myself, I had to be selfish to get clean, and then came back for my whānau

The Mana Enhancing STOP roopu saved me, I needed the support, I still do

l'd rather be here taking on life's challenges without substance

Sometimes I get angry because this mahi still takes me away from my boy

My wife has invested into this kaupapa fully

It takes so much of our time

The biggest lesson is not taking it home, but we tell people we are a 24-hour service

This space is not made by funding or by people with letters before and after their names

But by whānau loving whānau.

\section{TE REO WHAKAKAPI}

\section{Vicki: Final words}

I kiss'd thee ere I kill'd thee

No way but this

Killing myself, to die upon a kiss. (V.ii.)

Rather than closing with Othello's dying speech because the co-stars of the Mana Enhancing STOP roopu radiate an attitude of gratitude sharing the hopeful kiss of life;

instead the concluding proclamation is:

To mourn a mischief that is past and gone

Is the next way to draw new mischief on. (I.iii.)

Pauline: I've no regrets, what is done is done, we just get on with the mahi.

Ka tiritiria, ka poupoua ki a Papatūānuku, ki te whei ao ki te ao mārama (Murray, 2017; Nepe, 1991), is a closing edict in karakia to declare that the seeds of knowledge have been sown into mother earth to blossom and grow in her loving embrace. This collection of voices is distributed (in Scope Work-Based Learning 2) and planted into the hearts and minds of the reader, to bring light and hope into the lives of those seeking a pathway out of the darkness. 


\section{TE TIRA KŌRERORERO: BIOGRAPHIES}

Ko Kevin Hollingsworth ahau. I am the lead author and currently studying a Master of Professional Practice through Otago Capable NZ, Advance Practitioner Inquiry. My thesis topic is "Mana Enhancing Practices help to inform Therapeutic Communities" from a Te Ao Māori World View, looking at a whānau, hapū, iwi approach to community sobriety and exploring how whānau can heal from methamphetamine addiction.

Email: kevinholly9@gmail.com

Ko Rangipoua me Urukaraka ngā Maunga, Ko Waioira me Ōpurana ngā Awa, Ko Ōmaio me Ngāhina ngā Marae, Ko te Whānau-a-Apanui me Tūhoe ngā Iwi, Ko Josephine Kotiro Mihinui toku ingoa. My whānau and friends know me as Goldie. My role in the roopu is to support whānau.

Ko Maunga Pohatu te Maunga, Ko Mataatua te waka, Ko Tūhoe te iwi, Ko Billy Mihinui ahau. I come from a I6-year addiction with pourakino. I destroyed homes, took whānau away from whānau. I stood over and hurt people. I am now almost 2-years clean and happy in my new skin. I facilitate the Mana Enhancing STOP in Tāneatua.

He uri nō Ngāti Awa, Tūwharetoa, Te Arawa me Tūhoe. Ko Tuihi Carre taku ingoa. I am the secretary for the Mana Enhancing STOP Tāneatua and Ruātoki.

Tarakiha te maunga, Ōpepe te awa, Ōpape te marae, Whakatōhea te iwi. My name is Steven Taiatini, I am 43. I have been in the gang since I was I5. I have been in and out of addiction since I was eight and have also been in and out of jail. Today I am the leader of a gang and a facilitator in Mana Enhancing Stop to support whānau going through addiction mainly with meth. I uphold this stance in my chapter because I have lived through the destruction and have seen what meth does to our whānau.

My name is Pauline Tai, I hail from Te Whakatōhea and Te Whānau $\bar{a}$ Apanui. I am the General Manager and a facilitator of Mana Enhancing STOP Te Arawa and Te Whare Rauora. I survived a 19-year addiction to meth and have been clean for three years. I am a graduate of Te Whare Oranga Ngākau rehabilitation centre. I learned how destructive my addiction behaviours were to everyone I touched. I went from dealer to healer.

Ko ōku pae Mauna: Ko Taiarahia me Tahūhū o Haokitaha. Ko oku Marae: Te Totara me Papakaina. Ko oku Hapu: Te Urewera me Nāti Koura. Ko Ōhinemataroa te Awa. Ko Tūhoe te Iwi. Ko Ruātoki te Kaina noho. Ko Edith Te Rangi Te Papa ahau.

Ko Vicki Rangitautehanga Murray ahau, he uri nō Ngāti Pūkeko me Ngāti Awa. Further to my role as the tutor on the Anamata course, I am a learner on the Doctor of Professional Practice with Te Kura Matatini ki Otago.

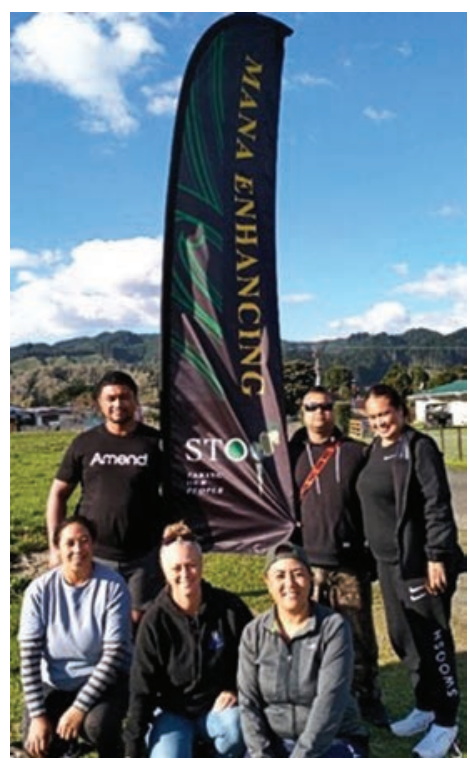

Billy Mihinui, Tiwana Taiatini, Pauline Tai Goldie Mihinui, Tuihi Carre, Edith Te Papa In Tāneatua, May 2021. 


\section{REFERENCES}

Durie, M. (200I). Mauri ora the Dynamics of Māori Health. Oxford University Press.

McKee, H. (2016, June 10). Shakespeare gets a Maori twist in SolOthello. Stuff. https://www.stuff.co.nz/entertainment/stageand-theatre/80922072/shakespeare-gets-a-maori-twist-in-solothello

Murray, V. (20I2). Hoki ki tōu maunga kia purea ai koe ki ngā hau o Tāwhirimātea - A tangata whenua model of supervision. Aotearoa New Zealand Social Work Journal Te Komako, 24(3-4), 3-II. https://doi.org/I0.1 II57/anzswj-vol24iss3-4idI 02

Murray, V. R. (2017). Hoki ki tōu maunga kia purea ai koe ki ngā hau o Tāwhirimātea - A tangata whenua model of supervision. Unpublished Thesis for a Masters in Social \& Welfare at the University of Otago.

Nepe, T. (1991). E Hao E T nei Reanga Te Toi Huarewa Tipuna. Unpublished M.A. Thesis, Auckland University, Auckland. Shakespeare, W. (1603/2004). Othello, The Moor of Venice. Schuster Publishers.

Shirres, M. P. (1982). Tapu. Journal of the Polynesian Society, 91 (I), 29-52. 


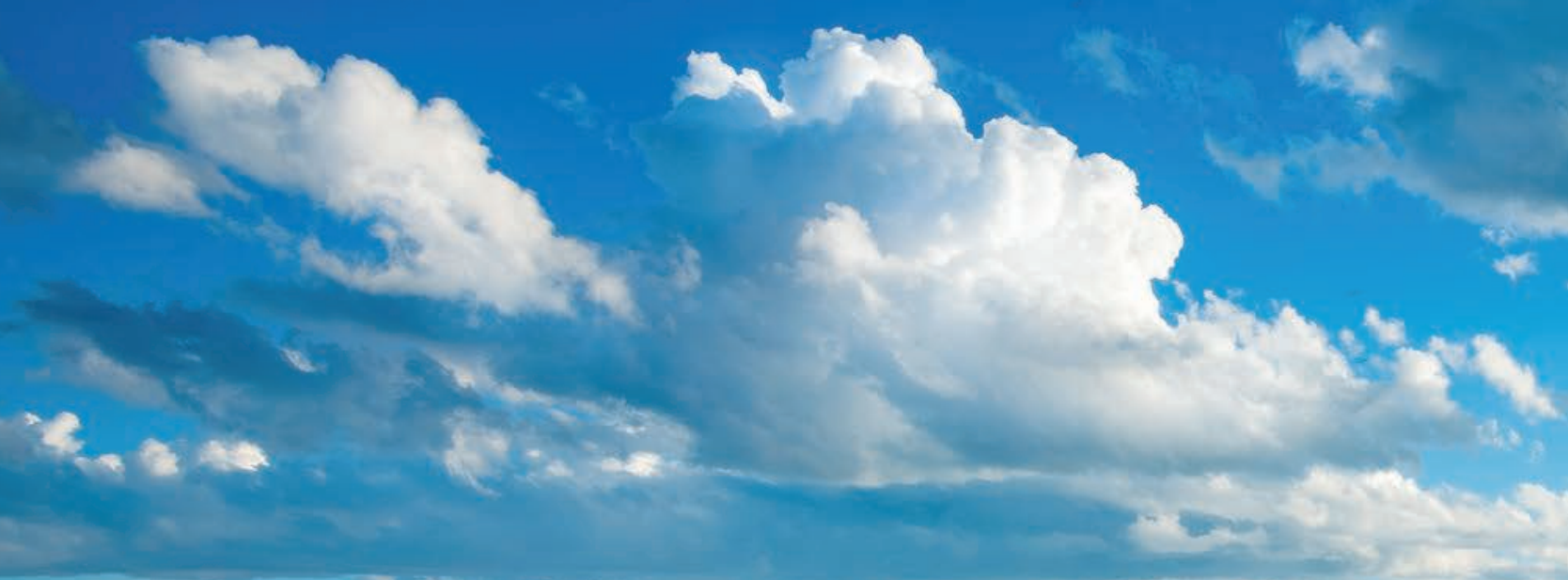

watestis

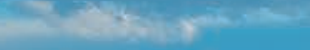

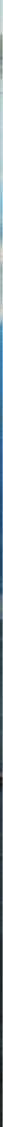

